Universidad de Lima

Escuela de Posgrado

Maestría en Administración y Dirección de Negocios

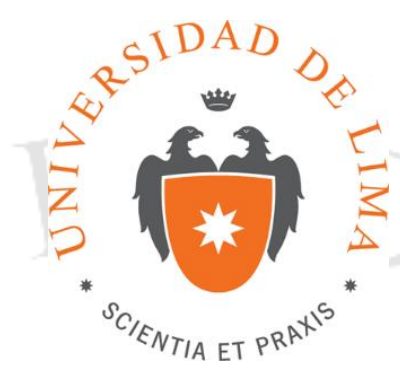

\title{
MODELO DE NEGOCIO DE GUARDERÍA PARA PERROS EN LIMA METROPOLITANA
}

Trabajo de investigación para optar el Grado Académico de Maestro en Administración y Dirección de Negocios

\section{Víctor Joseph Ugarte Mel}

Código 20071923

\section{Asesor}

Carlos Ricardo Chirinos Cuadros

$$
\text { Lima - Perú }
$$

Diciembre 2018 


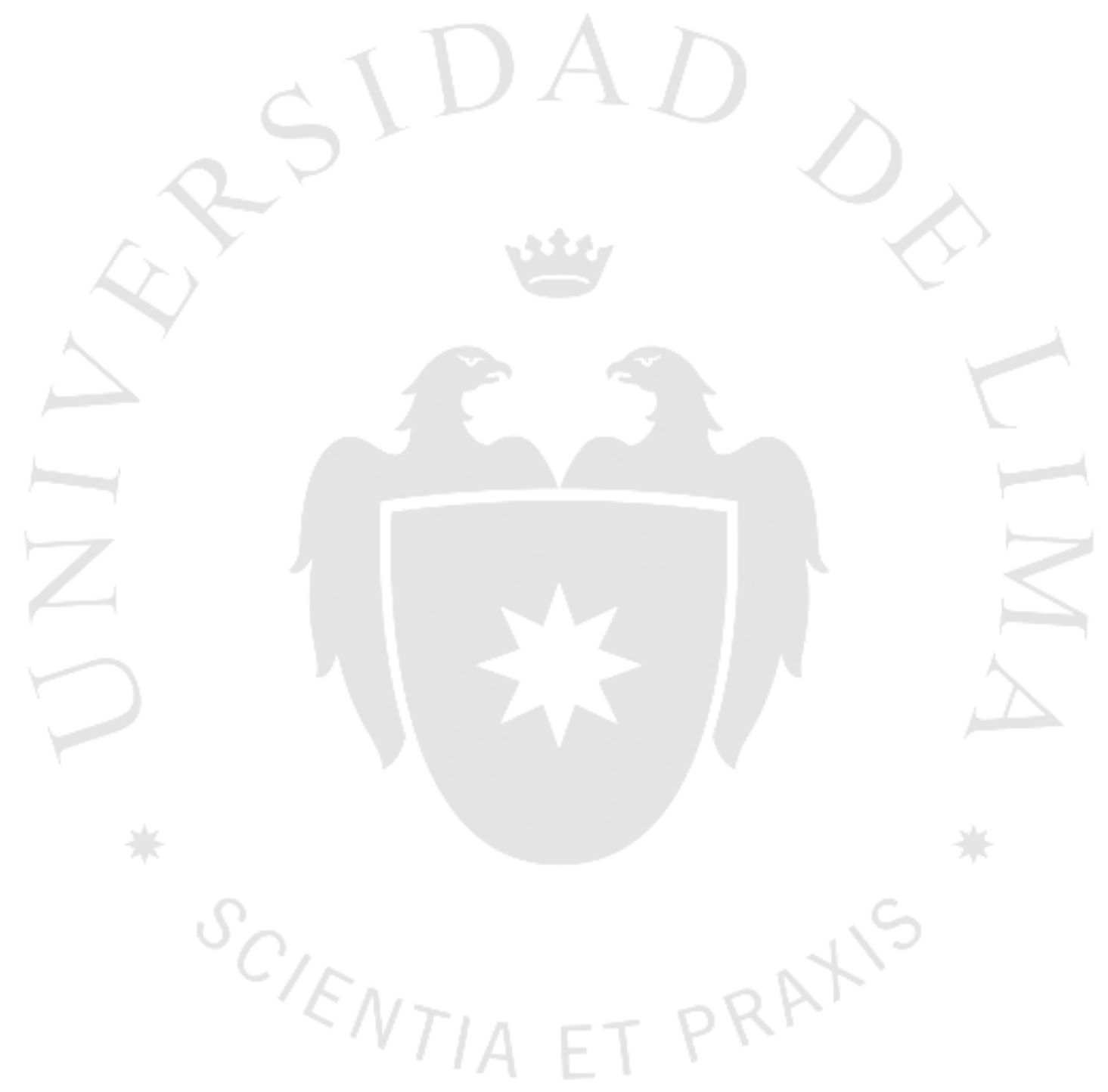




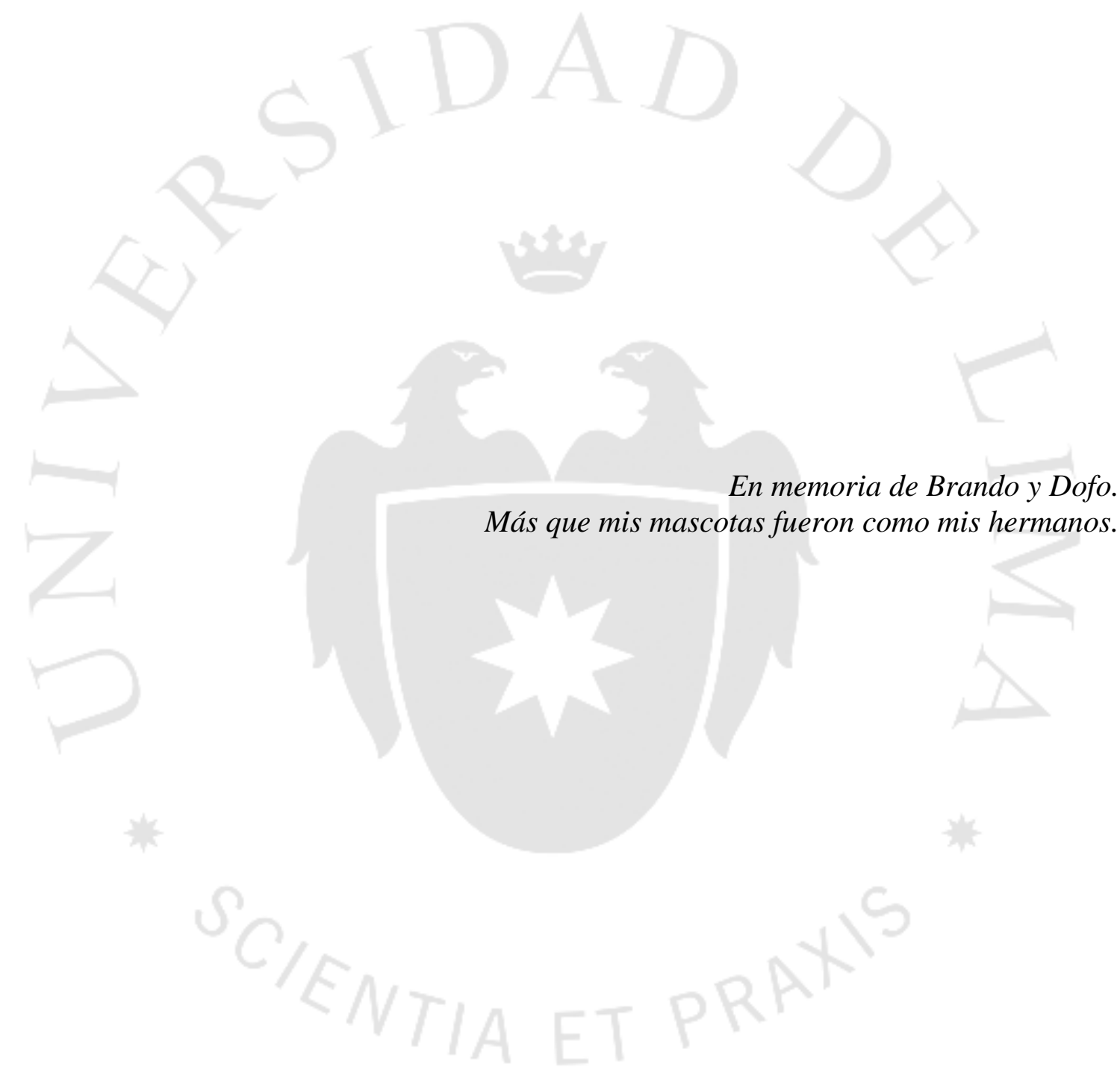




\section{MODELO DE NEGOCIO DE GUARDERÍA}

PARA PERROS EN LIMA METROPOLITANA 


\section{TABLA DE CONTENIDO}

RESUMEN EJECUTIVO................................................................... 13

CAPITULO I: ASPECTOS GENERALES DEL NEGOCIO......................... 15

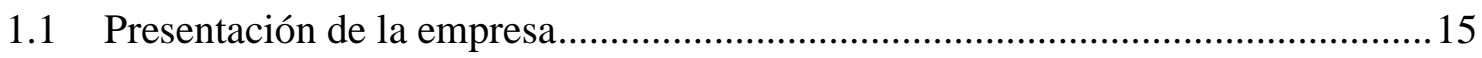

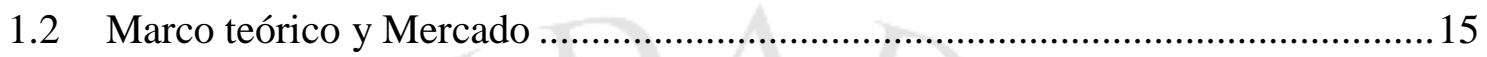

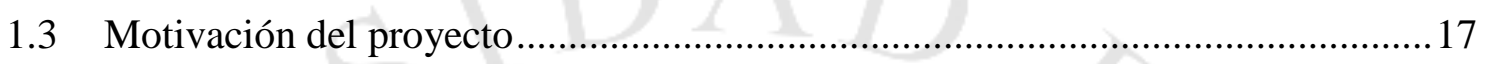

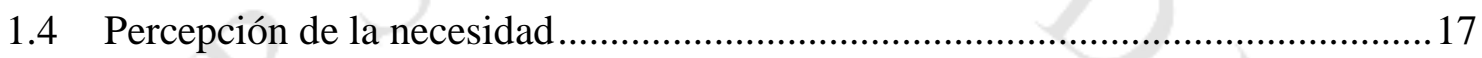

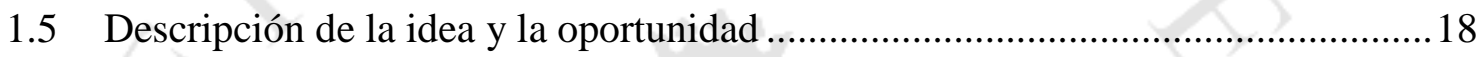

1.6 Justificación del atractivo de la propuesta....................................................... 18

1.7 Estrategia inicial y Objetivos de alcance ......................................................... 19

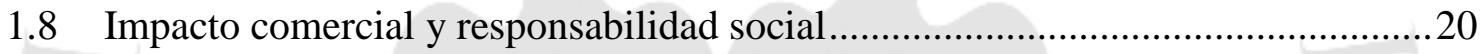

CAPITULO II IDEA, INVESTIGACIÓN Y VALIDACIÓN DE SOLUCIÓN 21

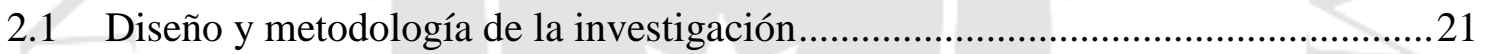

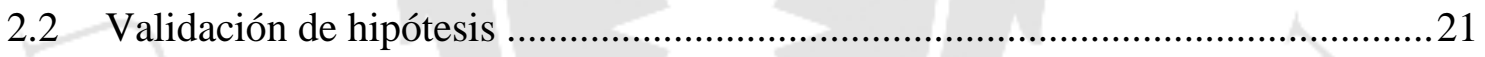

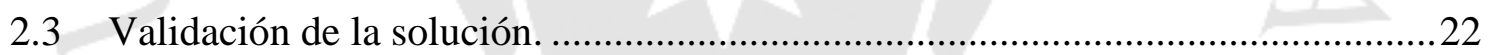

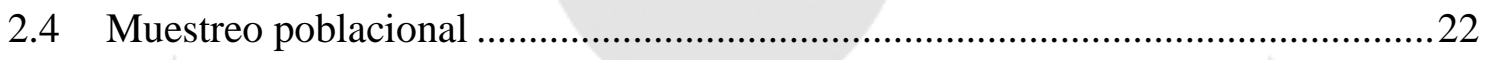

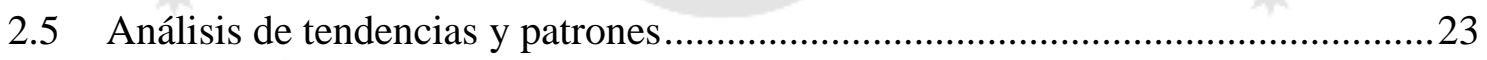

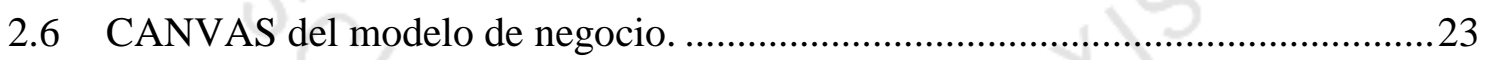

CAPITULO III: PLANEAMIENTO ESTRATÉGICO...............................25

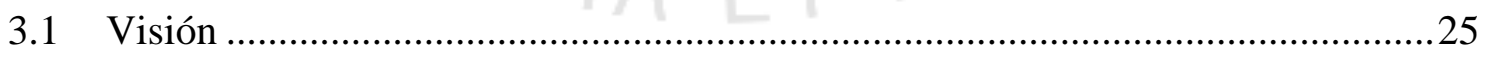

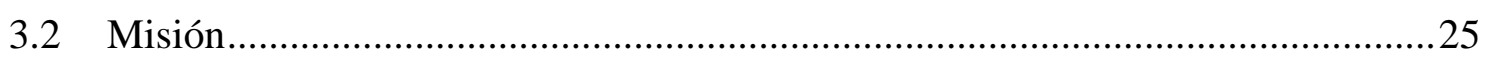

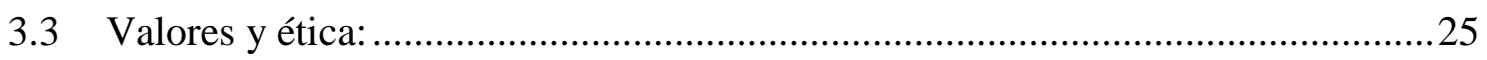

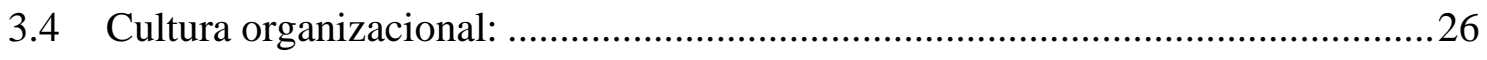

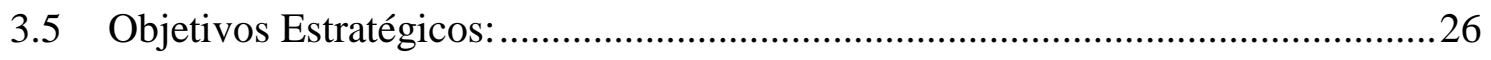




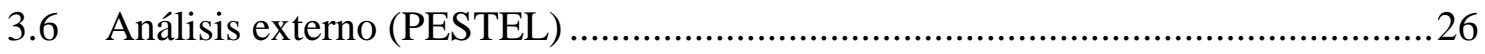

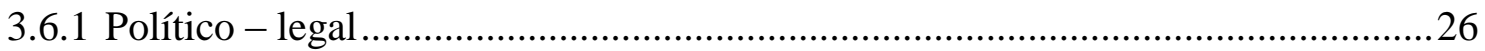

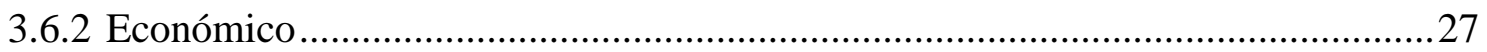

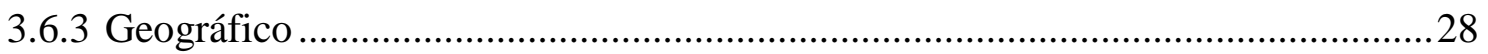

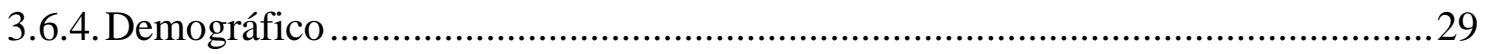

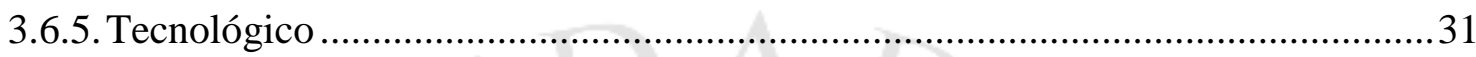

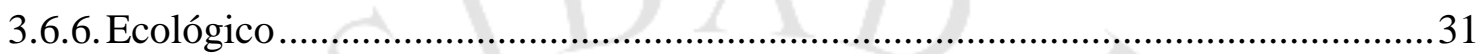

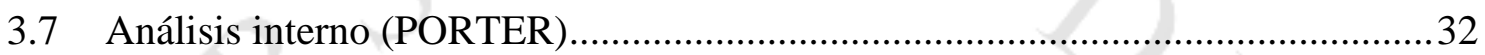

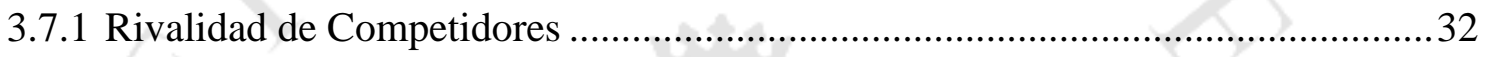

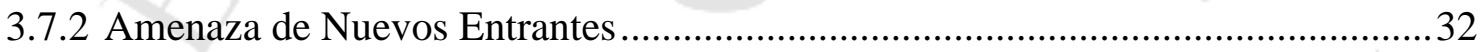

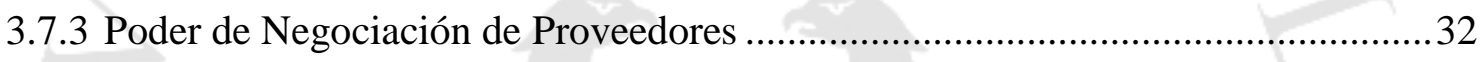

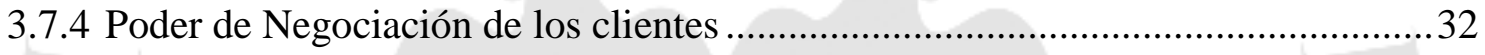

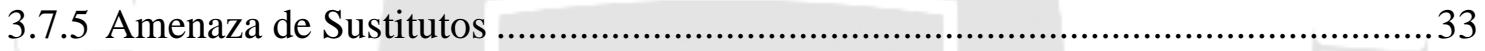

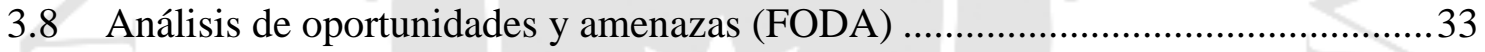

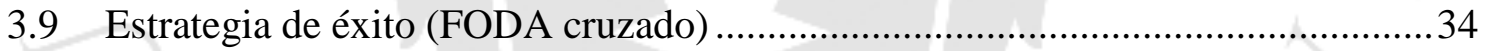

CAPITULO IV: PLAN DE MARKETING ................................................36

4.1 Planteamiento de objetivos generales de marketing...........................................36

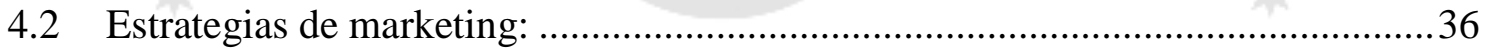

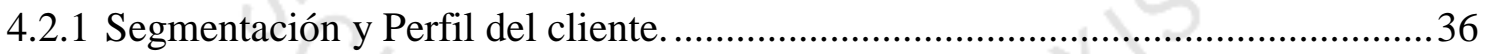

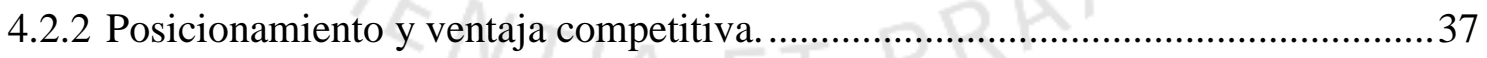

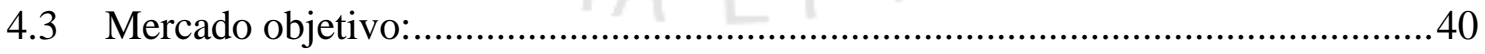

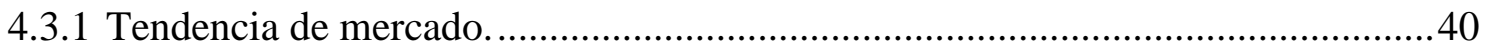

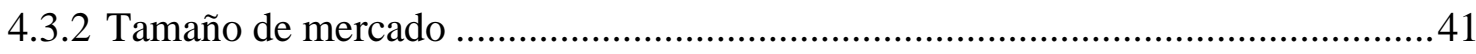

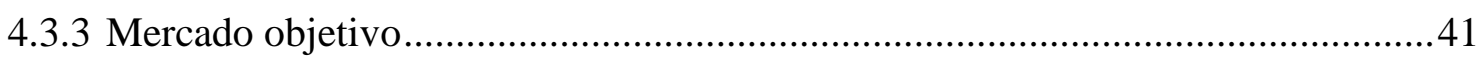

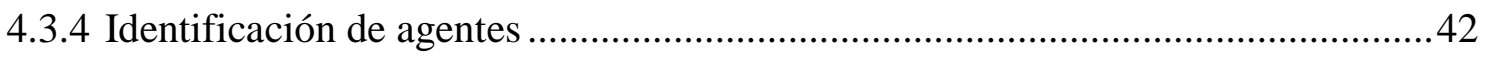


4.3.6 Rivalidad competidora y Potencial de ventas......................................................43

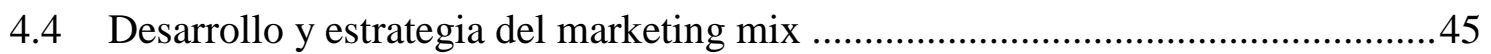

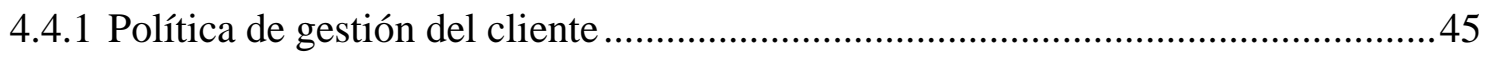

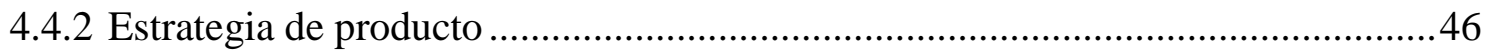

4.4.3 Estrategia de precios: análisis de costos y precios. ........................................ 47

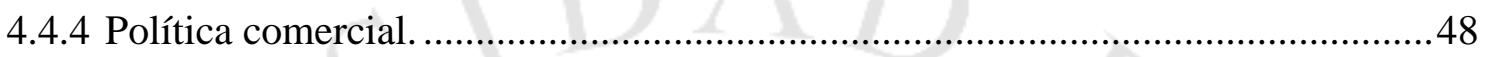

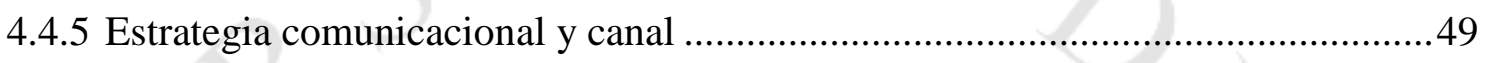

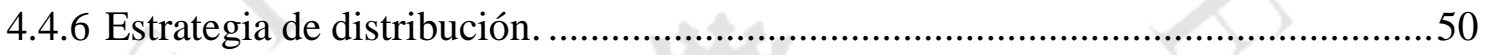

4.5 Plan de Ventas y Proyección de la Demanda ......................................................50

CAPITULO V: PLAN DE OPERACIONES................................................53

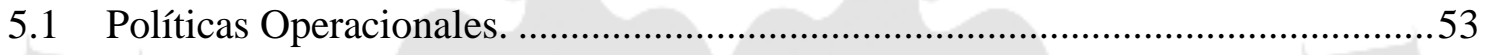

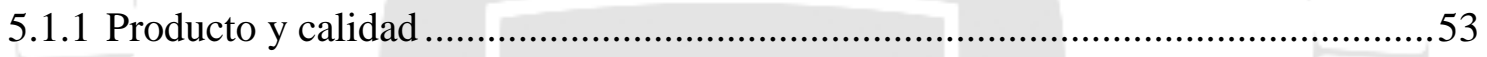

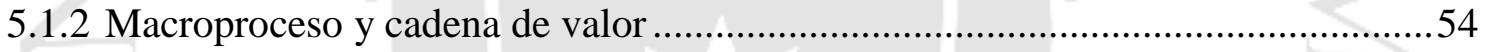

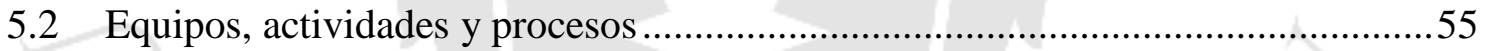

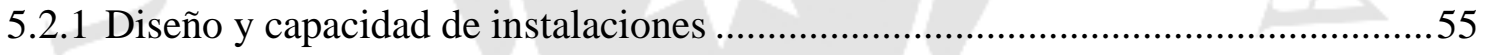

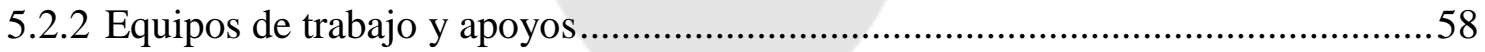

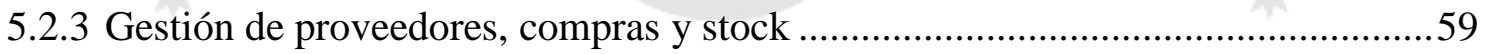

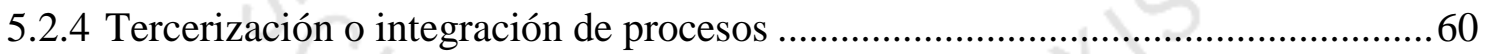

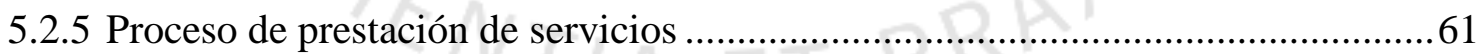

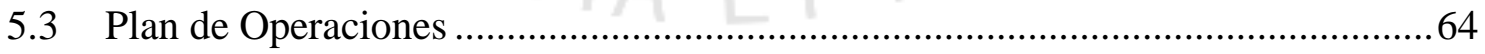

CAPITULO VI: ESTRUCTURA ORGANIZACIONAL Y RECURSOS HUMANOS ...............................................................................................65

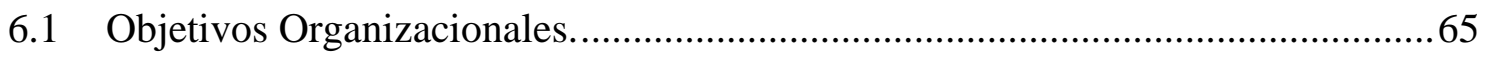

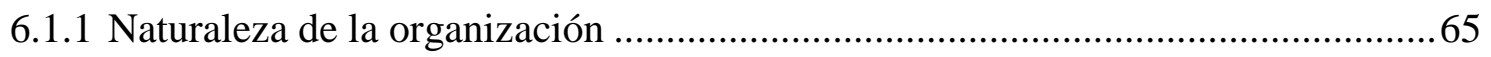

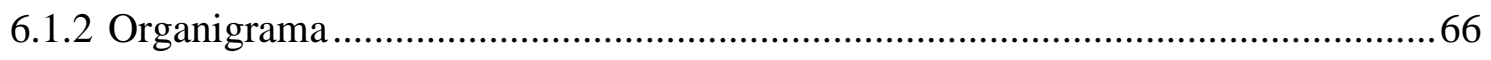


6.1.3 Diseño estructural por proyectos

6.2 Diseño de puestos y responsabilidades. ..................................................... 67

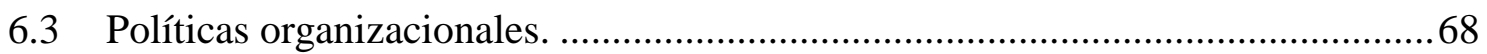

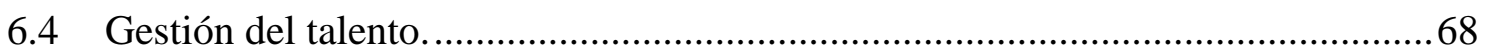

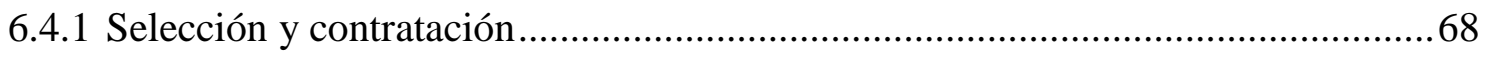

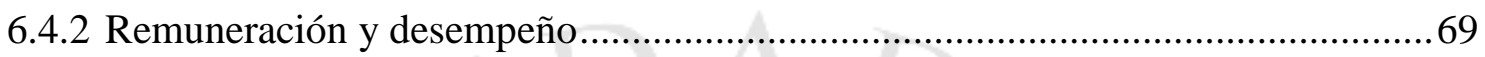

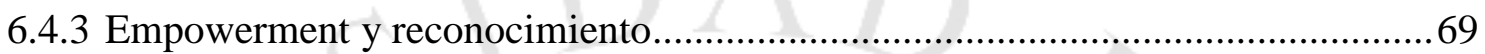

6.4.4 Capacitación, motivación y desarrollo ............................................................. 70

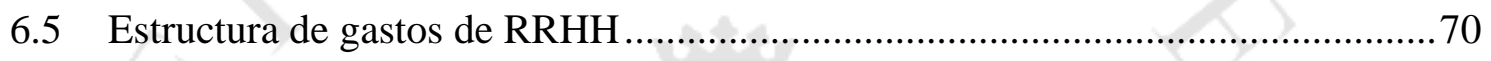

CAPITULO VII: PLAN ECONÓMICO-FINANCIERO ...............................72

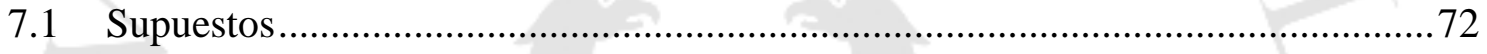

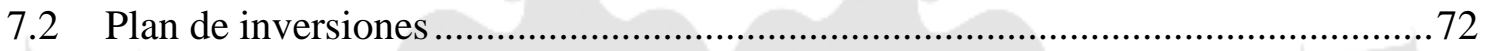

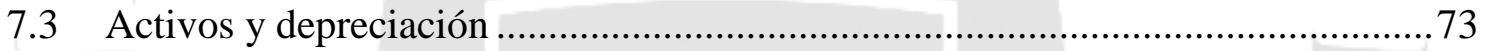

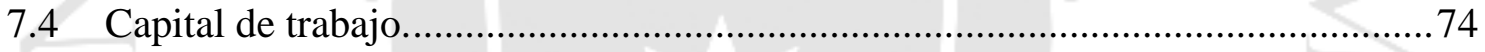

7.5 Fuentes de financiamiento y amortización......................................................... 74

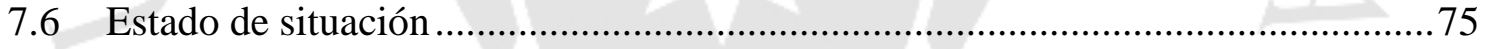

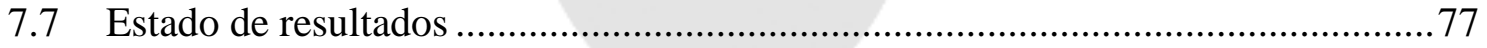

7.8 Proyección de ventas y Flujo de Caja Libre (Free Cash flow).............................77

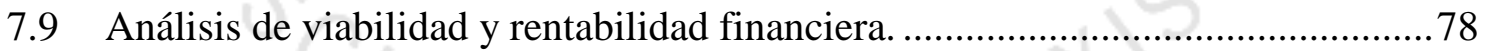

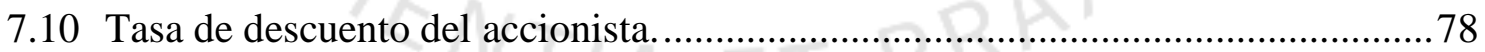

7.11 Indicadores de rentabilidad y otros ratios representativos ................................79

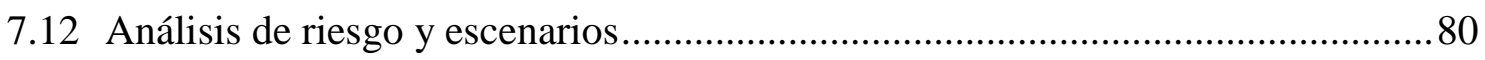

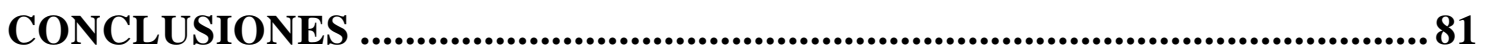

RECOMENDACIONES ............................................................................82

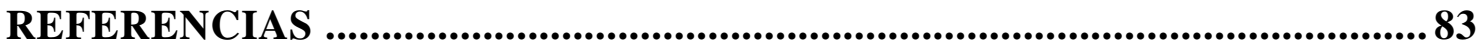

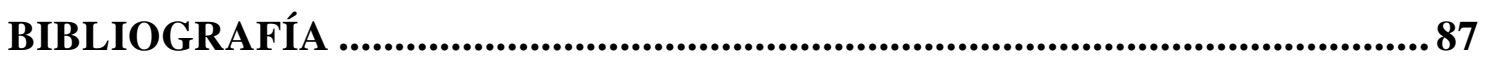


ANEXOS.

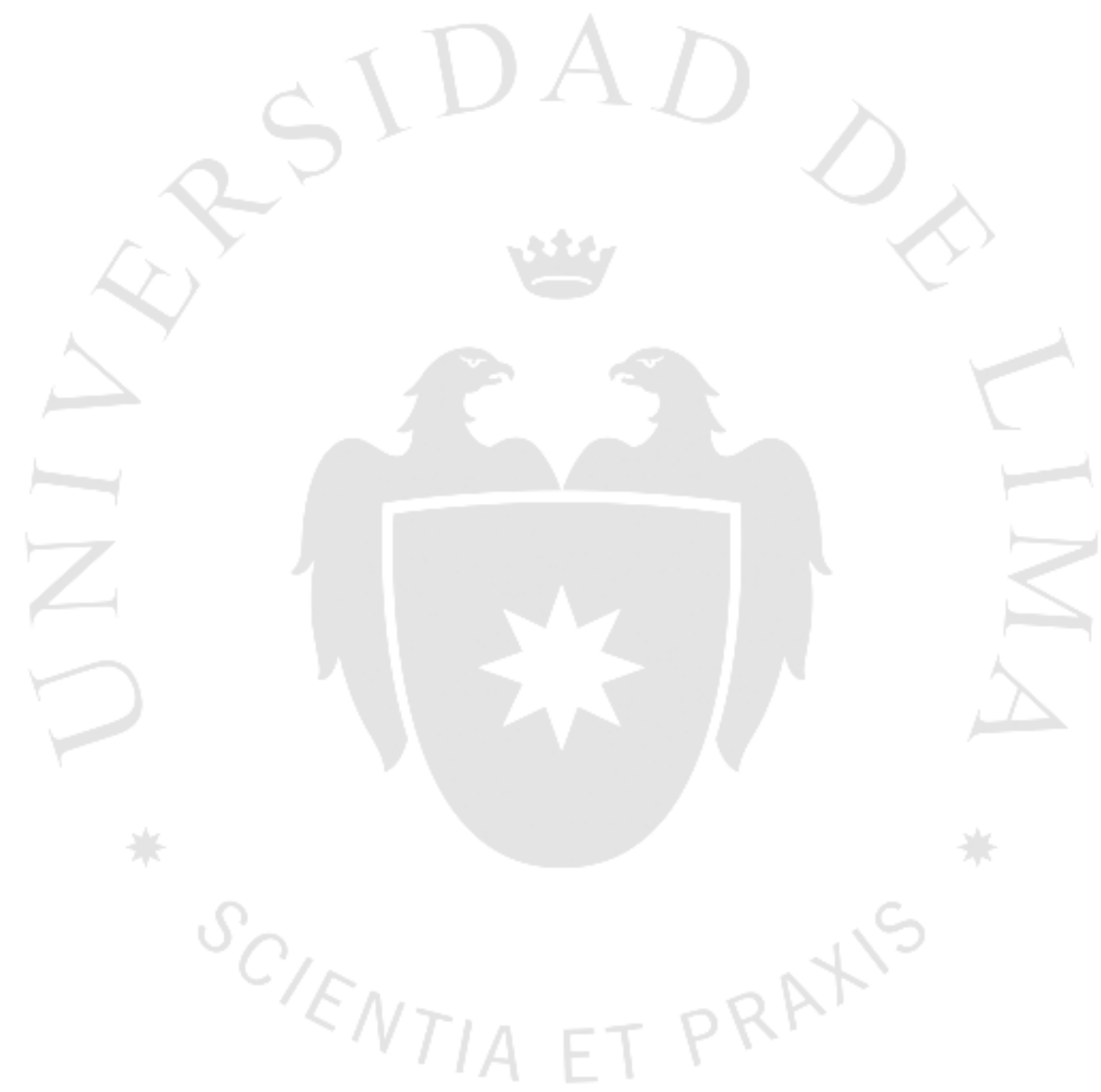




\section{INDICE DE FIGURAS}

Figura 2.1 Modelo de negocio CANVAS de la empresa.............................................24

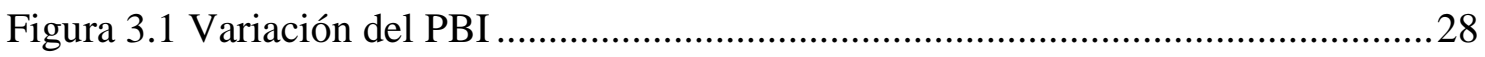

Figura 3.2 Pirámide poblacional en Perú 2014-2021 ................................................29

Figura 3.3 Evolución de la PEA ocupada por edades 2010-2015 ................................30

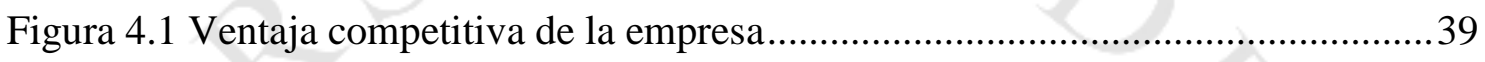

Figura 4.2 Matriz de posicionamiento de la empresa Pet Fun ......................................39

Figura 5.1 Escala de tangibilidad de la empresa......................................................53

Figura 5.2 Macroproceso de la empresa (nivel 0, 1 y 2) ...........................................54

Figura 5.3 Distribución de espacios de la empresa...................................................57

Figura 5.4 Estrategia de planeamiento y operaciones de la empresa............................60

Figura 5.5 Diagrama de flujo del proceso de atención de canes...................................63

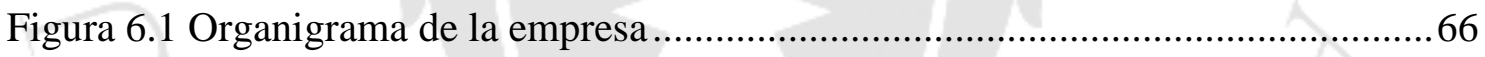

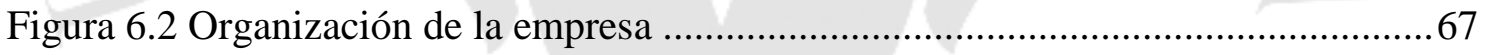




\section{INDICE DE TABLAS}

Tabla 3.1 Distribución por zonas geográficas APEIM 2017 ........................................2 29

Tabla 3.2 Población por sexo y grupo de edad 2017 .................................................. 30

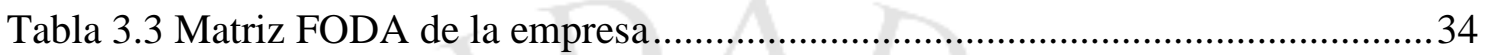

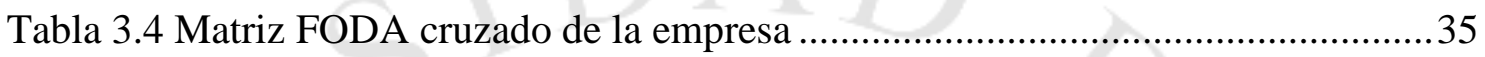

Tabla 4.1 Número de veterinarias en Lima................................................................ 40

Tabla 4.2 Número de tiendas de mascotas en Lima ...................................................40

Tabla 4.3 Evolución de la PEA ocupada por edades 2010-2015 ..................................50

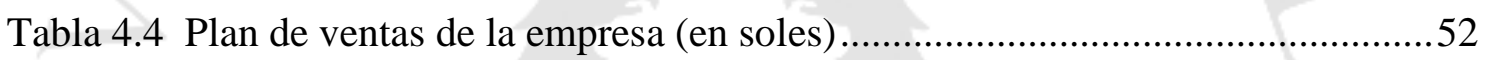

Tabla 5.1 Ranking de factores para determinar localización de la empresa...................56

Tabla 5.2 Plan de operaciones de la empresa (en soles) .......................................... 64

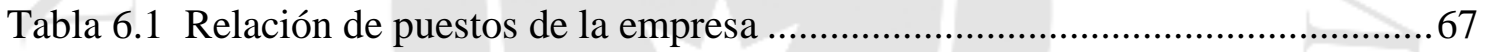

Tabla 6.2 Estructura de gastos de recursos humanos (en soles) ..................................71

Tabla 7.1 Depreciación de activos tangibles (en soles) ............................................ 73

Tabla 7.2 Depreciación de activos intangibles (en soles) ..........................................74

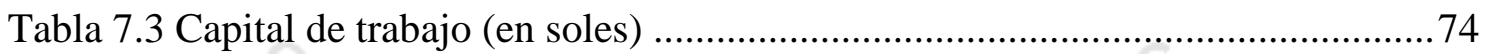

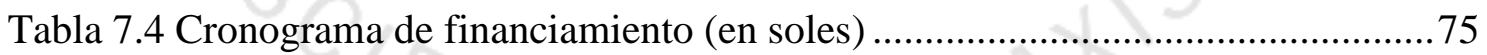

Tabla 7.5 Estado de situación de la empresa (en soles) ...............................................76

Tabla 7.6 Estado de resultados de la empresa (en soles) .......................................... 77

Tabla 7.7 Flujo de caja libre económico y financiero (en soles) ..................................78

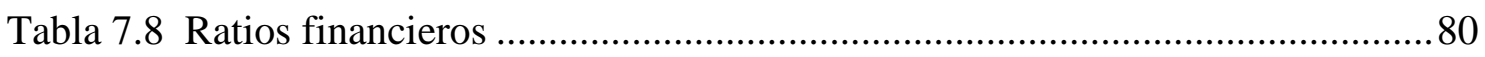




\section{INDICE DE ANEXOS}

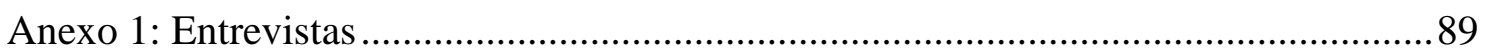

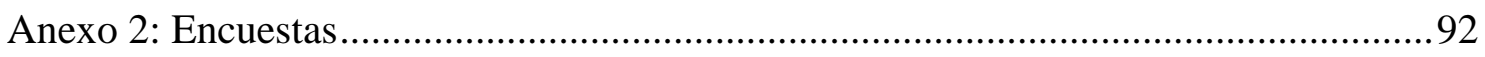

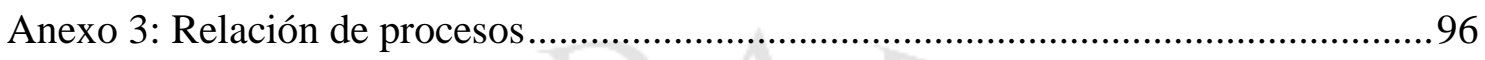

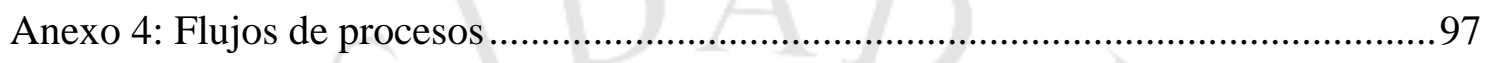

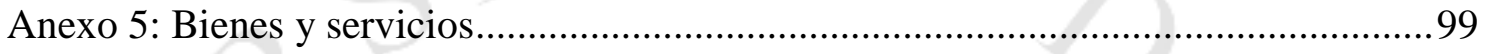

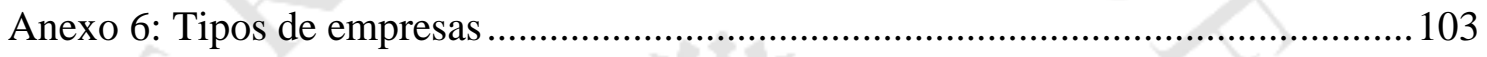

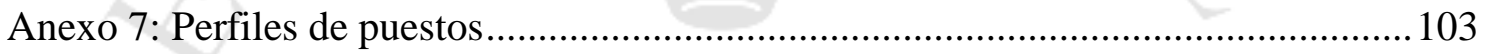

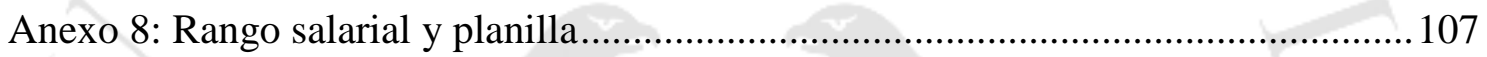

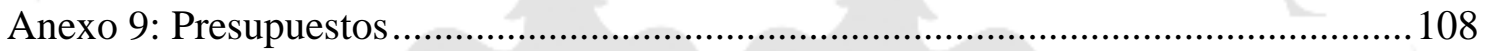

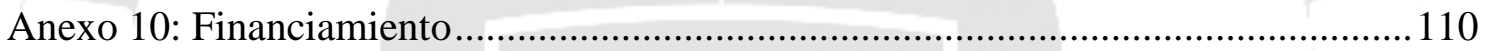

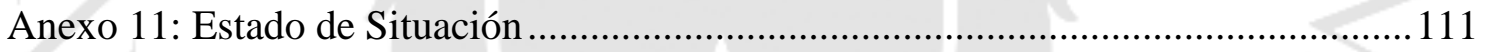

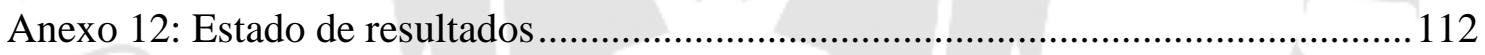

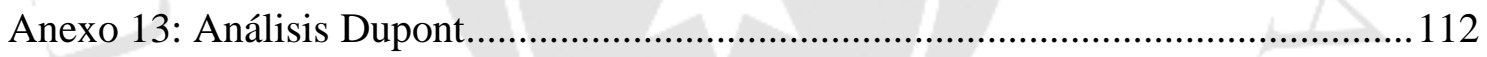

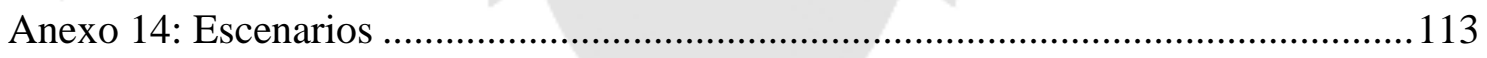

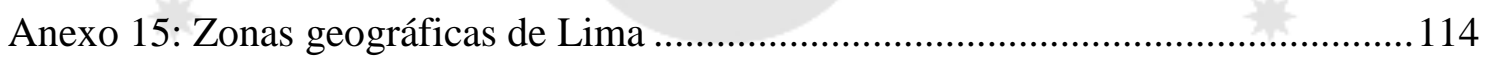

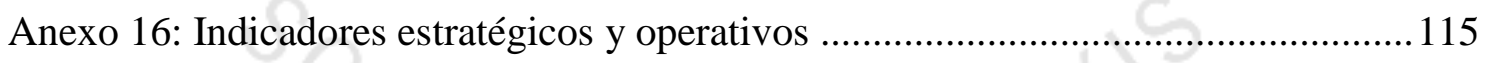




\section{RESUMEN EJECUTIVO}

La presente investigación busca demostrar la factibilidad de la creación de un modelo de negocio de guardería para perros en Lima Metropolitana, al respecto se presentan 7 capítulos en donde se desarrollan distintas herramientas y metodologías para comprobar que esta hipótesis es verdadera.

En los aspectos generales del negocio se presenta el nombre de la empresa y una breve descripción, asimismo se narra la motivación del proyecto y la necesidad que busca solucionar. Se detalla la estrategia y objetivo del proyecto y una justificación breve de porqué el modelo de negocio es innovador, escalable y beneficioso para la sociedad.

En el siguiente capítulo se explica el modelo de investigación que se ha aplicado para el desarrollo de la investigación, el planteamiento de la hipótesis y el resultado de la investigación primaria obtenida a través de encuestas dirigidas al público objetivo del proyecto (a verse con más detalle en el capítulo de marketing), donde se explica la tendencias y patrones del cliente y usuario. Asimismo, se ahonda en el modelo de negocio a través de la herramienta Canvas.

En el planeamiento estratégico de la empresa, se define su visión, misión y objetivos estratégicos, y además se explica la importancia de la cultura organizacional en la empresa. Asimismo, según análisis se determina que algunos factores externos influyentes son el desarrollo de apps para perros, la mejora de ingresos y la edad y perfil de los dueños de perros. Según análisis de Porter el principal sustituto es que el perro se quede en casa, y según el análisis de FODA cruzado se sugiere que la empresa aproveche las tendencias crecientes en el sector mascotas para posicionar la marca y su ventaja competitiva para asegurar la posición de mercado.

Para el plan de marketing se toma como insumos la información revelada por el cliente encuestado y entrevistado previamente. Para ello se define la segmentación y perfil del cliente, así como la ventaja y estrategia competitiva de la empresa. En base a esto se desarrolla el mix de marketing (producto, plaza, precio y promoción) sin perder como 
insumo las preferencias del cliente y tendencias del mercado. Producto de esto, se propone un plan de ventas y proyección de la demanda.

En el plan de operaciones se muestran los procesos nivel 0, 1 y 2 de la empresa, así como los recursos físicos y económicos necesarios para su funcionamiento, por ejemplo entre los procesos misionales se tiene la atención de los canes, preparación logística y monitoreo de operaciones. Este plan es importante porque explica la forma en que va a operar la empresa, para eso establece su diseño y localización según la herramienta de ranking de factores, de donde se obtuvo que la mejor ubicación es en el distrito de Santiago de Surco, y cuantifica conceptos de inversión en personas, local y compras.

La estructura organizacional muestra la naturaleza jurídica de la empresa y su estructura organizacional, elaborada en base a los procesos establecidos, con los perfiles de puestos que la componen. Asimismo, explica las políticas y buenas prácticas organizacionales acogidas y expone la estructura de costos de la planilla, servicios y capacitaciones y bonos.

Finalmente, tomando como insumos los capítulos anteriores que se traducen en presupuestos de ventas, compras, de inversión, gastos administrativos y financieros, se elabora el plan económico y financiero, el cual contiene un análisis de sensibilidad, evaluación de estados financieros, análisis de riesgos y políticas financieras. 


\section{CAPITULO I: ASPECTOS GENERALES DEL NEGOCIO}

\subsection{Presentación de la empresa}

La empresa "Pet fun" es una guardería para perros con un enfoque innovador donde se busca brindar una atención personalizada y de calidad al perro y generar un alto nivel de confianza en sus dueños mientras trabajan, es por eso que está dirigida a personas del nivel socio económico A y B, que tienen perros, trabajan en Lima Moderna y tienen la necesidad de dejar a sus mascotas en un lugar donde sean muy bien cuidadas.

La empresa pertenece al rubro de servicios del sector mascotas y es de régimen jurídico E.I.R.L. Sus operaciones consisten en el cuidado de los perros en un horario de 08:00 a 18:00 horas, según jornada ordinaria de trabajo (Constitución Política del Perú, 1993), tiempo en el que la mayoría de dueños de perros se encuentren trabajando o indispuestos a cuidarlos (Ipsos, 2016), en donde se les alimentará, paseará, hará jugar y adiestrarán. Además, una de las acciones que ofrece esta guardería y que genera mayor confianza en sus clientes es la constante comunicación que tiene con sus clientes.

\subsection{Marco teórico y Mercado}

El origen de la domesticación de animales es inexacto, pero se cree que comenzó cuando el ser humano se dio cuenta que necesitaba establecer lazos entre él y la naturaleza para su supervivencia y desarrollo. El perro fue probablemente el primer animal en ser domesticado y ha acompañado al ser humano durante unos 10.000 años. (National Geographic, 2010).

Narra la historia que en septiembre de 1870 se suscitó el caso "Old Drum” (llamado así por el nombre del perro), que conmovió a los habitantes del Misuri, Estados Unidos, y dio lugar al dicho que el perro es el mejor amigo del hombre. El caso trataba sobre un granjero que acusó a su vecino de haber matado a su perro, y en el juicio, el político y abogado George Graham Vest sustentó que: el mejor amigo que un hombre pueda tener, nuestro propio hijo o aquellos que están más cerca de nuestro corazón pueden convertirse 
en nuestro enemigo y demostrarnos ingratitud, sin embargo, el perro de un hombre está a nuestro lado en la prosperidad y en la pobreza, en la salud y en la enfermedad., siendo así que el perro es el mejor amigo del hombre (Kuhr, 1965).

En la actualidad los animales domésticos no son vistos solamente como compañía, sino que se les considera un ser más similar al humano, con sentimientos y necesidades que deben ser atendidas, incluso son considerados como un miembro más de la familia y comparten actividades que antes solo era exclusiva de las personas, como sentarse a la mesa, celebrar su cumpleaños, ir al salón de belleza, entre otras (Inga, 2016).

Esta tendencia, de la mano con la desaceleración del crecimiento poblacional, supone el reemplazo de personas en muchos casos para tomar su lugar las mascotas, permitiendo así crear productos y servicios capaces de satisfacer estas nuevas necesidades. Actualmente, el mercado ofrece una gran variedad de productos y servicios dirigidos a las mascotas de la casa, que va desde un juguete o plato de comida hasta un catering para fiestas o servicio de hospedaje (Inga, 2016).

Algunos, términos utilizados en el presente trabajo son:

Guardería para perros: Una guardería para perros es un espacio de acogida temporal, algo así como una residencia para perros, no un espacio al que llevar al perro unas horas al día. Los perros son muy sensibles a los cambios bruscos, es por eso que esta debe tener entre sus características personal cualificado para cuidar de los perros, alimentación apta, habitaciones amplias y camas mullidas, gran espacio en el exterior y servicio veterinario (Caro, 2017).

Paseo para perros: A menudo hay personas que les encanta sacar a pasear a su mascota, pero otras afirman que los paseos pueden llegar a ser demasiado estresantes. El principal beneficio del paseo es que el perro puede estimular sus sentidos, comer hierba, socializarse, hacer ejercicio y hacer sus necesidades con total tranquilidad., para ello debe tener la correa floja en todo momento y tener una rutina diaria (Caro, 2017).

Adiestramiento canino: Se pueden clasificar en técnicas de adiestramiento canino basadas en las teorías del aprendizaje y técnicas basadas en etología canina. En el primer 
caso la más conocida y recomendada es el adiestramiento en positivo, en el cual no es necesario usar collares de adiestramiento, y las sesiones de adiestramiento son muy gratificantes tanto para los adiestradores como para los perros. El método principal de enseñanza consiste en el uso de refuerzos positivos, popularmente conocidos como recompensas (Pryor, 2009).

\subsection{Motivación del proyecto}

Un hecho particular y muy visto en estos días que motivó este proyecto es lograr que el tiempo que las mascotas esperan a nuestro regreso a casa después del trabajo, no sea triste sino por el contrario agradable y divertido. Esto sumando al concepto "Pet Friendly" y que las mascotas sean consideradas como parte de la familia y se demanda mucho tiempo, atención y dinero en ellas, este proyecto busca aprovechar esta oportunidad para generar valor en estas personas y a la vez crear un modelo de negocio innovador y rentable.

\subsection{Percepción de la necesidad}

Según información de INEI existen 1.37 millones de hogares que tienen mascotas en Lima Metropolitana y una población económicamente activa de 4.88 millones de personas al 2017, además de la PEA, el 30\% de personas con mascotas tienen como ocupación un trabajo independientes o son estudiantes, lo que significa que no se encuentran en casa (Ipsos, 2016).

Ante la situación de tener que salir del hogar, una alternativa que toman los dueños es dejar a sus mascotas solas en casa, según se señala en la entrevista del anexo 1. Ante esa situación, los perros experimentan varios sentimientos y reacciones como por ejemplo ponerse triste, dormir, se aburren y hacen travesuras, te esperan desde una ventana o intentan salir. Entre estas reacciones, los perros pueden llegar a sufrir de ansiedad por separación, lo cual los motiva a llorar, ladrar, mordisquear objetos e incluso orinar, lo cual en exceso puede afectar su bienestar emocional (García, 2018).

\footnotetext{
${ }^{1}$ La filosofía "Pet Friendly" engloba el concepto genérico de que las mascotas son bienvenidas en un lugar, en donde se trata a la mascota como un cliente más y, con variaciones, se le atiende como tal.
} 
Al respecto, los dueños optan por llevarlos a casa de algún familiar, encargarlos con alguien por unas horas o simplemente dejarlos solos (ver sección 2.5). Actualmente, el mercado ofrece i) escuelas de perros que buscan prevenir, modificar o corregir comportamientos de los canes, ii) hospedajes para perros que ofrece un lugar para dejar a tu perro cuando sales de viaje o no tengas con quien dejarlo, la gran mayoría están ubicados en Lima Provincia, y iii) paseadores de perros por horas.

\subsection{Descripción de la idea y la oportunidad}

Considerando las reacciones emotivas que sufren los perros cuando se separan de sus dueños y teniendo en cuenta los servicios que actualmente ofrece el mercado, se puede inferir que existe una demanda insatisfecha, además de una oportunidad de negocio que justamente atienda estas necesidades, que son i) acercar a las personas y sus mascotas y ii) ofrecer un cuidado profesional y como en casa que haga sentir tanto a la mascota como a su dueño que todo se encuentra bien.

Al respecto, se propone un modelo de negocio de guardería para perros enfocado en las personas que tengan ocupaciones que no le permitan quedarse en casa y que no tengan con quien dejar a sus mascotas, pero que además busquen que sus engreídos reciban un trato profesional y especial como si fuera el de ellos mismos. Para lograr eso, la empresa ofrece canales de comunicación constante entre los dueños y sus perros, además de un servicio donde prima la calidad y está orientado al bienestar de los perros.

\subsection{Justificación del atractivo de la propuesta}

La idea de negocio es innovadora, en el sentido que atiende variables no atendidas actualmente por los servicios de escuelas, hospedajes, paseadores o el hecho de dejarlos en casa. Según los resultados de las encuestas (Ver sección 2.5) las personas consideran como factores relevantes el i) la seguridad y confianza, ii) la distracción y juego y iii) la atención médica inmediata, en ese orden. Al respecto, la empresa incorpora mecanismos para asegurar que se atiendan cada una de estas necesidades. Por lo tanto, la empresa genera un océano azul al atender necesidades insatisfechas de una manera diferente. 
El modelo también presenta un grado alto de complejidad pues requiere para su desarrollo investigar un mercado incipiente como es el de los servicios para mascotas y no hay regulaciones específicas sobre la cultura pet friendly en el Perú. Además, la propuesta es escalable ya que el concepto permite crecer en nuevos productos y categorías de productos como servicios de salud, educación, entretenimiento y otros, tanto para perros como para otros animales domésticos.

Asimismo, la empresa es económicamente responsable al brindar beneficios a la sociedad al generar puestos de trabajo, colaborar con la sociedad de protección de animales y aportar crecimiento a la economía peruana, cuida el equilibrio ambiental al promover el reciclaje de materiales y buen uso de desechos y excreta, y atiende un componente social al promover la adopción de animales abandonados y cuidado responsable de los perros y mascotas en general.

\subsection{Estrategia inicial y Objetivos de alcance}

La estrategia de la empresa es posicionarse como la primera y más grande empresa dirigida al bienestar de la mascota y sus dueños, y planea conseguir ello a través de la diferenciación de sus servicios y creando un océano azul que atenderá variables no atendidas actualmente como la comunicación constante que genere confianza a los clientes y sientan que sus perros se quedan en buenas manos.

El objetivo general de la empresa es el cuidado y entretenimiento exclusivo y personalizado para perros que genere confianza en los clientes.

Los objetivos específicos son:

- Ser la primera empresa en el Perú en posicionarse como líderes en servicios de guardería para perros.

- Invertir como mínimo 100 mil soles acumulados en el primer año.

- Alcanzar como mínimo 300 mil soles de ventas en el año en el que consigue el periodo de recupero.

- Generar como mínimo 5 puestos de trabajo en el año en el que consigue el periodo de recupero. 


\subsection{Impacto comercial y responsabilidad social}

La empresa planea generar un impacto comercial positivo en la industria de las mascotas, pero también en el sector servicios y otros relacionados. Va a generar más competencia e inversión en el PBI servicios. El modelo es replicable a otras provincias del Perú.

Asimismo, la empresa adoptará un modelo responsable que atienda sus demandas actuales sin comprometer las demandas de futuras generaciones, es decir, busca ser sostenible en el tiempo y lograr un equilibrio social, económico y ambiental de la siguiente manera:

- Promoviendo el reciclaje de materiales y buen uso de los desechos y excretas animales.

- Promoviendo la adopción de animales abandonados y cuidado responsable de los perros y mascotas en general.

- Generar educación y cultura social en el cuidado de perros y mascotas en general. 


\section{CAPITULO II IDEA, INVESTIGACIÓN Y VALIDACIÓN DE SOLUCIÓN}

\subsection{Diseño y metodología de la investigación}

Para el presente proyecto se hará una investigación cuantitativa que busque comprobar una hipótesis a través de la generación de una muestra. Asimismo, se usará la metodología de estudio tipo explicativo-descriptivo (Álvarez, 2012), que contiene los siguientes pasos:

a) Selección y definición del caso: en el presente capítulo se propone la hipótesis que se quiere comprobar al finalizar la investigación de tesis.

b) Elaboración de encuesta dirigida al público objetivo: se realizaron encuestas dirigida a los dueños de perros con características definidas en la segmentación y perfil de usuario, así como la muestra de encuesta.

c) Localización de las fuentes de datos: en el desarrollo del presente trabajo se citan las fuentes secundarias así como el resultado de fuentes primarias como encuestas y entrevistas.

d) Análisis e interpretación: en los capítulos de marketing, operaciones, recursos humanos y finanzas se analiza en términos cualitativos y cuantitativos los resultados de investigación.

e) Elaboración de informe: en las conclusiones se determina si se valida o no la hipótesis planteada.

\subsection{Validación de hipótesis}

Como parte de la metodología, se plantean la hipótesis principal e hipótesis secundarias que se quieren demostrar en el desarrollo de la investigación.

- Hipótesis Principal: Implementar una modelo de negocio innovador de guardería para perros en Lima Metropolitana es factible. 
- Hipótesis Secundaria 1: Las personas de NSE A y B dueñas de perros en Lima Moderna están interesadas en el modelo de negocio innovador de guardería para perros.

- Hipótesis Secundaria 2: Existen las técnicas, metodologías, y personal para ofrecer de guardería para perros en Lima Metropolitana.

- Hipótesis Secundaria 3: Implementar una modelo de negocio innovador de guardería para perros en Lima Metropolitana es económicamente o financieramente rentable.

- Hipótesis Nula: Implementar un modelo de negocio innovador de guardería para perros en Lima Metropolitana no es factible.

\subsection{Validación de la solución.}

Para comprobar las hipótesis definidas, se recaba estadística, notas de prensa, estudios, foros e investigaciones referentes a la intención de acudir a servicios de guardería para perros. Al respecto, se recogió como información secundaria, que hay un gran interés de las personas de encargarse de la alimentación, salud y entretenimiento de sus perros. El principal potencial de este mercado son los servicios: veterinarios, educativos y de recreación (El Comercio, 2016), y además, existe otra variedad de fuentes que complementan estas afirmaciones y que se citan en el presente documento.

De otro lado, se busca confirmar y complementar esta información a través de fuentes primarias, como el caso de encuestas dirigidas a los dueños de perros con las características definidas en la segmentación, para validar la intención de contratar los servicios de cuidado para perros de personas que trabajan, y entrevistas a veterinarias como negocios similares, hospedajes para perros, y personas dueños de perros, por ejemplo miembros de clubes de perros.

\subsection{Muestreo poblacional}

Para desarrollar las encuestas antes descritas, se debe determinar la muestra poblacional a quien se aplicará la encuesta, para ello primero se debe definir el mercado total 
disponible y luego ir segmentando de acuerdo con las características del cliente que se quiere atender. En la sección 4.3.2 se detalla la segmentación de mercado.

Tomando en cuenta la población del mercado disponible efectivo de 235,500 hogares de NSE A y B con perros en Lima Moderna (San Borja, Surco, La Molina, Miraflores y San Isidro), y considerando una persona como cabeza del hogar, con 95\% de nivel de confianza y 10\% de margen de error, se obtiene una muestra de 97 personas. Ver anexo 2.

\subsection{Análisis de tendencias y patrones}

Para determinar la tendencia y patrones del mercado objetivo, se encuestaron a 97 personas, hombres y mujeres, mayores de edad de NSE A y B que trabajan en Lima Metropolitana. Tanto el formato como los resultados de las encuestas se pueden ver en el anexo 2. Entre los principales resultados están:

- Se verifica que cerca del 55\% son mujeres mayores de 25 años, trabajan en distintos lugares de Lima Metropolitana pero el 51\% vive en Lima Moderna, en La Molina, San Borja, Surco y Miraflores, y en Barranco y Chorrillos.

- $\quad$ El $70 \%$ tienen un perro y el $23 \%$ tiene dos, que en su mayoría son hembras pequeñas de temperamento tranquilas y poco enfermizas.

- $\quad$ El $40 \%$ deja a su perro solo en casa y el 53\% lo deja con una persona cuando se va a trabajar. Al respecto, lo que más valoran es la confianza de que sus mascotas estén en buenas manos (29\%).

- El $65 \%$ de personas encuestadas tiene interés en contratar un servicio de guardería siempre que le genere confianza, pudiendo pagar entre $\mathrm{S} / 300$ y S/600 mensual en el $43 \%$ de los casos y más de S/750 en un 4\%.

\subsection{CANVAS del modelo de negocio.}

En base a los resultados obtenidos se tiene información del cliente y sus preferencias que sirven para esquematizar el modelo de negocio de la empresa. Al respecto, Osterwalder explica en su libro Generación de modelos de negocio que la mejor manera de describir 
un modelo de negocio es dividirlo en nueve módulos básicos que reflejen la lógica que sigue una empresa para conseguir ingresos, este es llamado "Canvas" y se caracteriza por determinar una propuesta de valor que hace a la empresa especial en el mercado, ubicado en el centro, asociado a la gestión con los clientes, a la derecha, y gestión interna, a la izquierda (Osterwalder, 2011).

Siguiendo este modelo, la empresa ofrece como propuesta de valor "Brindar un servicio de guardería personalizado para perros" y "Generar tranquilidad y confianza en los dueños de perros mientras se encuentren en manos de la empresa".

Figura 2.1

Modelo de negocio CANVAS de la empresa

\begin{tabular}{|c|c|c|c|c|}
\hline Key Partners & Key Activities & Value Propositions & $\begin{array}{c}\text { Customer } \\
\text { Relationships }\end{array}$ & $\begin{array}{l}\text { Customer } \\
\text { Segments }\end{array}$ \\
\hline Clientes & & \multirow{8}{*}{\begin{tabular}{|c|} 
Generar \\
tranquilidad y \\
confianza en los \\
dueños de \\
perros mientras \\
se encuentren en \\
manos de la \\
empresa \\
\end{tabular}} & Afiches & \\
\hline $\begin{array}{c}\text { Comunidades } \\
\text { perrunas }\end{array}$ & Operaciones & & Boca a boca & $\begin{array}{l}\text { Dueños de } \\
\text { mascotas de } \\
\text { NSE A y B }\end{array}$ \\
\hline Municipios & MKT y ventas & & Google & $\begin{array}{c}\text { profesionales } \\
\text { y que }\end{array}$ \\
\hline $\begin{array}{c}\text { Sociedad } \\
\text { protectora de } \\
\text { animales } \\
\end{array}$ & $\begin{array}{c}\text { Gestión del } \\
\text { conocimiento }\end{array}$ & & \begin{tabular}{|l|} 
Redes sociales \\
\end{tabular} & $\begin{array}{l}\text { consideran a } \\
\text { sus perros } \\
\text { parte de la } \\
\text { familia }\end{array}$ \\
\hline Veterinarias & Key Resources & & \multirow{4}{*}{$\begin{array}{l}\text { Channels } \\
\begin{array}{|c|}\text { En efectivo } \\
\begin{array}{c}\text { Transferencia } \\
\text { bancaria }\end{array} \\
\end{array}\end{array}$} & \\
\hline $\begin{array}{c}\text { Empresas de } \\
\text { mascotas }\end{array}$ & Personas & & & \\
\hline \multirow[t]{2}{*}{$\begin{array}{l}\text { Empresas } \\
\text { público y } \\
\text { privadas }\end{array}$} & \begin{tabular}{|c|} 
Servicios \\
Local y vehículo \\
\end{tabular} & & & \\
\hline & Materiales y equipos & & & \\
\hline \multicolumn{2}{|l|}{ Cost Structure } & \multicolumn{3}{|c|}{ Revenue Streams } \\
\hline \multicolumn{2}{|c|}{ Alquiler de local y vehículo } & & \multicolumn{2}{|c|}{ Inscripciones mensuales de guardería } \\
\hline \multicolumn{2}{|c|}{ Bienes y servicios } & & \multicolumn{2}{|c|}{ Servicio de paseo por horas } \\
\hline \multicolumn{2}{|c|}{ Planilla de personal } & & \multicolumn{2}{|c|}{ Venta de accesorios } \\
\hline
\end{tabular}

Elaboración propia. 


\section{CAPITULO III: PLANEAMIENTO ESTRATÉGICO}

\subsection{Visión}

La visión de la empresa es "Ser la empresa líder en el Perú en brindar bienestar a las mascotas".

\subsection{Misión}

La misión de la empresa es "Ofrecemos servicios exclusivos de guardería para tu mascota, diferenciándonos por el excelente nivel de confianza y comunicación que mantenemos con nuestros clientes".

\subsection{Valores y ética:}

Los valores son parte fundamental de la cultura organizacional, son definidos por los colaboradores y se encuentran alineados a la visión de la empresa.

- Amor a nuestras mascotas

- Empatía con nuestros clientes

- Comunicación constante

- Honestidad

- Innovación

- Transparencia

- Responsabilidad social

Asimismo, la empresa establece un código ética y de conducta que define sus valores y dicta como política actuar con integridad dentro y fuera del lugar de trabajo. 


\subsection{Cultura organizacional:}

La cultura en una empresa es tan importante como el espíritu para el cuerpo. Si bien los órganos determinan las acciones del cuerpo, el espíritu es quien encamina a los órganos a cumplir con su visión. La cultura de la empresa será forjada desde sus cimientas a través del cumplimiento y difusión de los valores, los planes estratégicos enfocados en el bienestar del personal y generar sinergias como decanten en mejor eficiencia de procesos y calidad de los productos y servicios ofrecidos al cliente.

$\mathrm{Al}$ respecto, la empresa promoverá las actividades que afiancen la cultura en la empresa y, a su vez, exigirá a sus socios estratégicos que estén alineados a su cultura empresarial.

\subsection{Objetivos Estratégicos:}

Los objetivos estratégicos de la empresa

- Ofrecer un servicio de guardería para perros que genere un alto nivel de confianza en los clientes en al menos el $85 \%$ de los clientes.

- Promover en el $100 \%$ de clientes el cuidado responsable y educación de los perros y mascotas en general.

- Fomentar una cultura organizacional enfocada en las personas.

Los primeros dos objetivos estratégicos serán medidos a través de encuestas periódicas a los clientes, asimismo estos indicadores estratégicos se desagregan en indicadores operativos con el fin de hacer un seguimiento permanente y fino. El detalle de los objetivos e indicadores se encuentra en el anexo 16.

\subsection{Análisis externo (PESTEL)}

\subsubsection{Político - legal}

La tendencia mundial en la concientización por el respeto de las personas por el resto de los seres vivos como las plantas y animales, así como su cuidado y preservación, ha 
repercutido en nuestro país a través de agrupaciones que promueven una cultura de cuidado de los animales y normas que protegen a los mismos. Es así que, el 07 de enero de 2016 se aprueba la Ley No 30407, Ley de Protección y Bienestar Animal, que busca proteger la vida y la salud de los animales vertebrados, domésticos o silvestres mantenidos en cautiverio, impedir el maltrato, la crueldad, causados directa o indirectamente por el ser humano, que les ocasiona sufrimiento innecesario, lesión o muerte; así como fomentar el respeto a la vida y el bienestar de los animales a través de la educación. Además, de velar por su bienestar para prevenir accidentes a sus poblaciones y aquellas enfermedades transmisibles al ser humano.

Por otro lado, a raíz de incidentes causados por estos animales en los que han atacado personas por negligencia mayormente de sus dueños, el Ministerio de Salud aprobó el 13 de diciembre de 2001 la Ley N²7596, Ley que Regula el Régimen Jurídico de Canes, que tiene por finalidad establecer el régimen jurídico que regulará la crianza, adiestramiento, comercialización, tenencia y transferencia de canes, especialmente aquellos considerados potencialmente peligrosos, dentro del territorio nacional, con la finalidad de salvaguardar la integridad, salud y tranquilidad de las personas, así como su Reglamento aprobado mediante Decreto Supremo No 006-2002-SA.

\subsubsection{Económico}

La economía peruana se encuentra actualmente en una fase de recuperación, caracterizada por la disipación de los choques adversos de inicios de año y un contexto internacional favorable. Al respecto, se estima que el PBI crecerá 2,8\% para el 2017 y se acelerará a 4,0\% en el 2018 a través de una mayor simplificación administrativa, mejora calidad regulatoria, fomento del empleo formal y competitivo y mayor inversión en infraestructura. Esta recuperación se dará principalmente por la política fiscal expansiva orientada al proceso de reconstrucción ocasionado por el Fenómeno del Niño y al despliegue de infraestructura para los Juegos Panamericanos, lo cual contribuirá con un 40\% del crecimiento del PBI (Marco Macroeconómico Multianual 2018-2021, 2017).

Estas proyecciones, además de la coyuntura actual, obedecen un crecimiento histórico. Por ejemplo, en el año 2016, el PBI fue de 501,537 millones de soles, del cual 
319,950 millones de soles (63.79\% del PBI) correspondía al componente de Consumo Privado, del mismo modo, el crecimiento del consumo privado fue de 3.1 comparado al 4.0 del PBI. De otro lado, el sector de Servicios también se encuentra muy relacionado, teniendo para el 2016 un $4.3 \%$ de crecimiento.

Figura 3.1

Variación del PBI

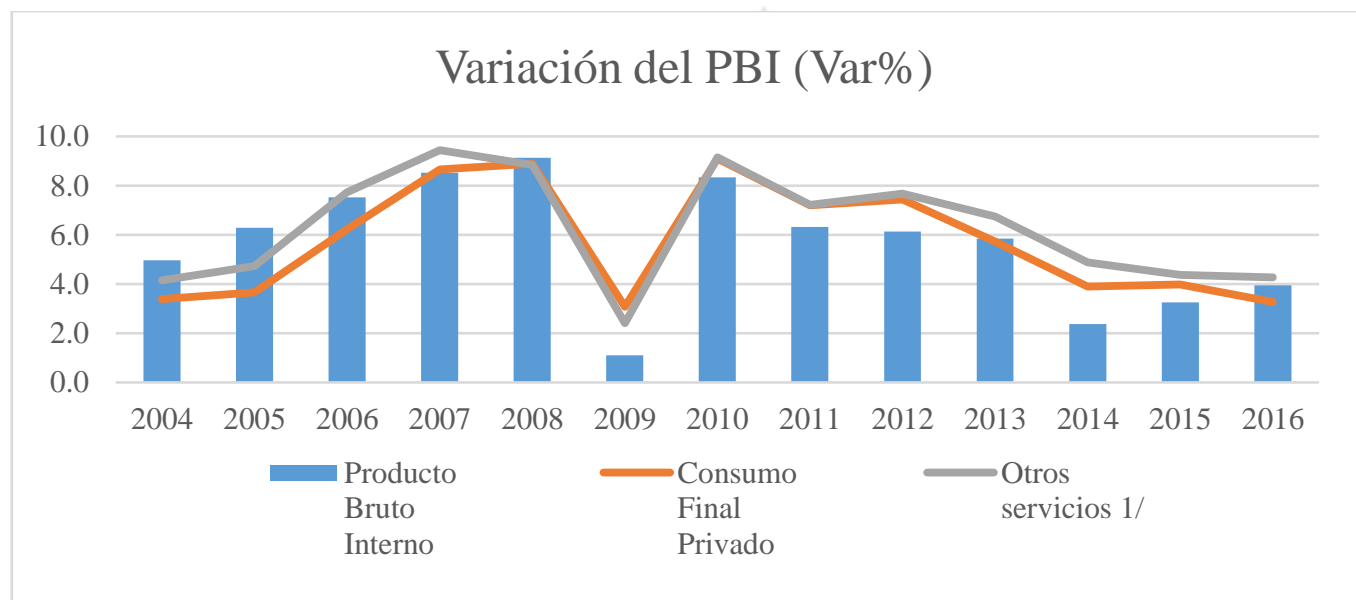

Fuente: BCRP, INEI

Según el gráfico, tanto el consumo privado como el sector de servicios vienen tomando importancia para la economía y consiguiendo un efecto multiplicador, por ejemplo, cuando la situación país y la economía y situación política está bien el consumo incrementa y eso tiene un efecto directo en el PBI.

\subsubsection{Geográfico}

Lima Metropolitana se divide en las zonas Lima Norte, Centro, Este, Sur, Callao, Balearios y Moderna. Asimismo, estas se dividen en zonas geográficas APEIM de acuerdo con la cercanía. Por ejemplo, las zonas 6 y 7 pertenecen a Lima Moderna y son justo en estas zonas donde se concentra la mayor población de NSE A y B. El distrito con mayor población de Lima Moderna es Surco con una población de 357,600 personas (26.98\% de Lima Moderna). Ver anexo 15. 
Tabla 3.1

Distribución por zonas geográficas APEIM 2017

\begin{tabular}{|c|c|c|c|c|c|c|}
\hline \multirow{2}{*}{ Zonas } & \multirow{2}{*}{ Personas } & \multicolumn{5}{|c|}{ NSE (\%) } \\
\hline & & A & B & C & D & $\mathbf{E}$ \\
\hline $\begin{array}{l}\text { Miraflores, San Isidro, San Borja, Surco, La } \\
\text { Molina }\end{array}$ & 795 & 35,9 & 43,3 & 14,9 & 4,5 & 1,4 \\
\hline $\begin{array}{l}\text { Surquillo, Barranco, Chorrillos, San Juan de } \\
\text { Miraflores }\end{array}$ & 877,7 & 3,9 & 26,6 & 44,6 & 20,5 & 4,4 \\
\hline Total Lima Metropolitana & $10.208,60$ & 4,8 & 21,7 & 42,4 & 23,8 & 7,3 \\
\hline
\end{tabular}

Fuente: APEIM, Estructura socioeconómica 2016

\subsubsection{Demográfico}

En el ámbito demográfico uno de los principales indicadores que se debe tomar en cuenta es la evolución de la pirámide poblacional, al respecto se evidencia una reducción de la base y cuerpo poblacional de 0 a 24 años ocasionado por la reducción de la fecundidad. En su defecto se aprecia un leve incremento de los adultos a partir de 40 años.

Figura 3.2

Pirámide poblacional en Perú 2014-2021

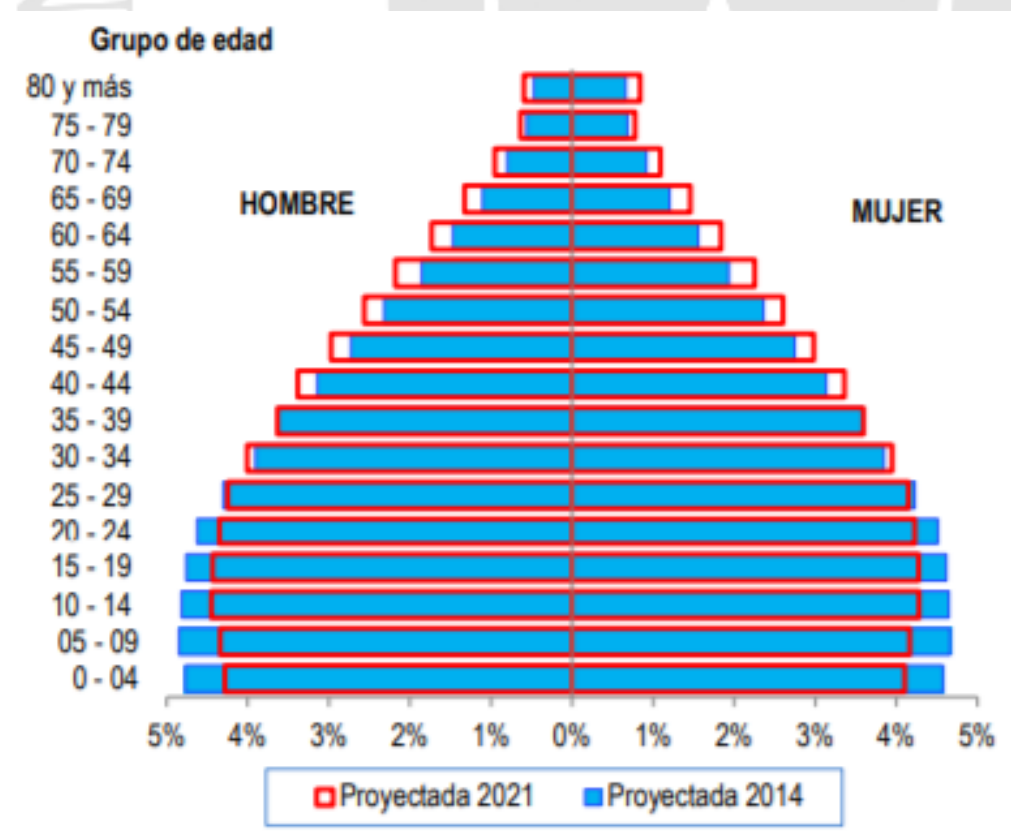

Fuente: INEI, Estado de la población peruana 2014 
Asimismo, tenemos la distribución según grupos etarios, donde podemos observar que la gran masa de la población de Lima Metropolitana está en los hombres y mujeres de 25 a 39 años, seguidos por las personas de 40 a 55 años y de 56 a más.

Tabla 3.2

Población por sexo y grupo de edad 2017

\begin{tabular}{ccccccc}
\hline $\begin{array}{c}\text { Grupo } \\
\text { etario }\end{array}$ & $\begin{array}{c}\text { Total } \\
\text { Miles }\end{array}$ & $\mathbf{\%}$ & Miles & $\mathbf{\%}$ & Miles & \% \\
\hline 00-05 años & 954,5 & 9,3 & 487,7 & 9,8 & 466,8 & 8,9 \\
06-12 años & 1106,5 & 10,8 & 565,5 & 11,4 & 541 & 10,3 \\
13-17 años & 838,4 & 8,2 & 419,7 & 8,5 & 418,7 & 8 \\
18-24 años & 1326,6 & 13 & 654,8 & 13,2 & 671,8 & 12,8 \\
25-39 años & 2492,3 & 24,5 & 1204,4 & 24,4 & 1287,9 & 24,4 \\
40-55 años & 1966,6 & 19,3 & 939,2 & 18,9 & 1027,4 & 19,6 \\
56- + años & 1524,4 & 14,9 & 685,2 & 13,8 & 838,7 & 16 \\
Total & $\mathbf{1 0 . 2 0 9 , 3 0}$ & $\mathbf{1 0 0}$ & $\mathbf{4 . 9 5 6 , 5 0}$ & $\mathbf{1 0 0}$ & $\mathbf{5 . 2 5 2 , 3 0}$ & $\mathbf{1 0 0}$ \\
\hline
\end{tabular}

Fuente: INEI, Estimaciones y proyecciones de población

El entorno demográfico también lo demarca la Población Económicamente Activa (PEA) ocupada, que actualmente son cerca de 16 millones de personas de las cuales el $48.3 \%$ pertenece al rango de 25 a 44 años y el $56.4 \%$ es del sexo masculino.

Figura 3.3

Evolución de la PEA ocupada por edades 2010-2015

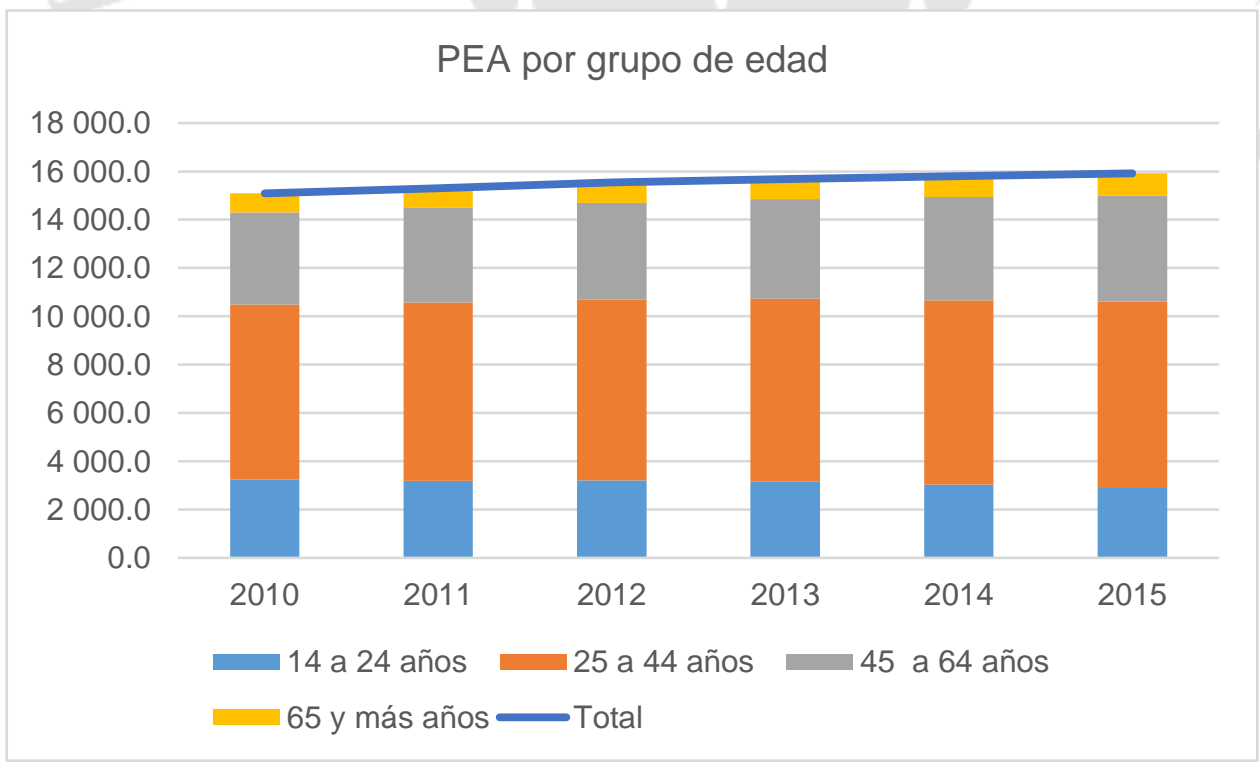

Fuente: INEI 2015 


\subsubsection{Tecnológico}

"Un proyecto de la Universidad Politécnica de Valencia ha creado juguetes robóticos para entretener a los animales cuando se quedan solos en casa, controlados por un humano, pero con la idea de que en el futuro sean automáticos" (Blanco, J., 2018).

Así como este artículo de SrPerro.com (2014) sobre tecnología que permite comunicarse a los canes:

"FIDO (nombre que en inglés se asocia naturalmente con perro) significa en este caso "Facilitating Interactions for Dogs with Occupations", algo así como "Haciendo posible las interacciones para Perros que Trabajan". Se trata de un proyecto realmente interesante en el que diversos científicos trabajan desde hace años con el objetivo de desarrollar artilugios que permitan a los perros comunicarse con los humanos, tanto a distancia (enviando mensajes SMS, alertas, etc.) como sobre la marcha, cuando se produce alguna emergencia."

La tecnología está avanzando a pasos agigantados, y las mascotas no quedan fuera, al respecto se listan algunas innovaciones tecnológicas pensadas para ellos:

- Twindog es una app para encontrar a la pareja ideal de tu perro.

- Petcub son cámaras monitoras para vigilar a tu mascota en casa.

- Borrow my doggy es un servicio donde te prestan una mascota para que la cuides por unos días.

- $\quad$ Pet traker es un dispositivo con GPS que va en el collarín de tu mascota para poder ubicarla cuando se pierda.

\subsubsection{Ecológico}

La Ley Orgánica de Municipalidades establece que La Municipalidad Metropolitana de Lima tiene entre sus funciones especiales en materia de saneamiento ambiental, organizar y controlar la sanidad animal, así como la regulación y control en la tenencia de animales domésticos (Ley No 27972, 2003). 


\subsection{Análisis interno (PORTER)}

\subsubsection{Rivalidad de Competidores}

Según lo indicado por el cliente en las encuestas, el factor más valorado es el nivel de confianza que el perro esté en buenas manos, asimismo identifican otros factores que valoran más o menos, en base a este análisis se propone un modelo de negocio ajustado a las necesidades del cliente. Actualmente otros servicios como hospedajes, escuelas y paseadores de perros no satisfacen plenamente esa necesidad. La creación de este océano azul supone que no hay competencia directa.

\subsubsection{Amenaza de Nuevos Entrantes}

El mercado de las mascotas es un mercado en crecimiento con gran potencial a nivel mundial, al respecto cada vez existen más emprendimientos que atienden los insigths ${ }^{2}$ de los dueños de mascotas. Debido a la baja barrera de entrada, las actuales empresas de hospedaje, escuelas y otros similares se podrían reinventar, y conforme crezca el sector, se podría convertir en un océano rojo.

\subsubsection{Poder de Negociación de Proveedores}

Los principales proveedores de la empresa son las empresas comerciantes de accesorios para perros y los veterinarios. En el primer existe una gran cantidad de proveedores. En el caso de los veterinarios, se puede establecer convenios con clínicas veterinarias de prestigio que en el mercado hay más de una. El poder de negociación es medio.

\subsubsection{Poder de Negociación de los clientes}

Los clientes son las personas que trabajan y tienen perros, con la característica de residir y trabajar en Lima moderna y pertenecer a los NSE A y B. El poder de negociación se va basa en el nivel que ellos establezcan de atención a su perro, es decir, cuán dispuestos

\footnotetext{
${ }^{2}$ Los insights son las motivaciones implícitas no conocidas ni lógicas. Son descubrimientos, no obvio y no conocidos, que permiten entender mejor a las personas y sus problemas.
} 
están en conseguir a sus mascotas un servicio que los atiendan excelentemente y además ofrezcan la tranquilidad y confianza a sus dueños. Este factor no es atendido actualmente, por ende, los clientes no tienen poderosas alternativas de solución.

\subsubsection{Amenaza de Sustitutos}

El mejor sustituto del modelo de negocio es dejar al perro en casa, ya sea solo o bajo el cuidado de alguien. Según la información primaria el factor que más valoran las personas cuando se trata del cuidado de sus perros es la seguridad y confianza de que se queda en buenas manos, valoración que es muy difícil de superar.

Sin embargo, esta alternativa tiene algunas desventajas, como por ejemplo el desorden y los daños físicos que puede causar el can a los bienes del hogar, la dificultad o trabajo que requiere de la persona a su cuidado y, en caso se quede completamente solo, el valor sentimental de tristeza o pena. Poder de negociación alto.

\subsection{Análisis de oportunidades y amenazas (FODA)}

Kotler y Keller (2012) señala: "La evaluación general de las fortalezas, oportunidades, debilidades y amenazas para una empresa se conoce como análisis FODA, y es una manera para analizar el entorno interno y externo de marketing" (p. 48). Al respecto, se muestra el análisis de los factores internos y externos de la empresa. 
Tabla 3.3

Matriz FODA de la empresa

\section{FACTORES INTERNOS}

FACTORES EXTERNOS

OPORTUNIDADES

Servicio especializado en comunicación - Existe una tendencia positiva en el sector de las constante de lo que está haciendo el perro mascotas:

mientras su dueño trabaja. - Los hogares con mascotas en Lima

Plan de marketing adecuado a las demandas del Metropolitana vienen creciendo a una tasa de público objetivo. $1.5 \%$ anual.

Ubicación estratégica en Lima moderna a fin de - Las personas cada vez gastan más dinero en el mantener la cercanía entre perro y dueño. cuidado de sus mascotas, ahora S/250 aprox.

Garantía de la marca y empresa que genere - El componente de consumo privado del PBI confianza y seguridad en las personas que dejan tiene un crecimiento de $3.1 \%$. Esto refleja en a sus perros.

\section{DEBILIDADES} mayor poder adquisitivo.

AMENAZAS

Empresa nueva, no tiene un respaldo financiero - El principal sustituto para no tomar el servicio es fuerte. dejar al perro en casa, pues según los No existe competencia directa, por lo tanto no encuestados ahí estará más seguro.

hay mucha información secundaria que - Las barreras de entradas no son tan altas y el estudiar. modelo podría ser replicado.

\subsection{Estrategia de éxito (FODA cruzado)}

Kotler y Keller (2012) señala:

"Está claro que la empresa no tiene que corregir todas sus debilidades, y tampoco debería regodearse en todas sus fortalezas. La gran incógnita es si debe limitarse a cultivar aquellas oportunidades respecto de las que posee las fortalezas requeridas, o si debe considerar también las que le exigen encontrar o desarrollar nuevas fortalezas.” (p. 48)

Al respecto, el presente modelo de negocio ha buscado en su concepción justamente incrementar los factores que el cliente considera importantes y reducir o eliminar los que no, dicho esto la estrategia es trabajar en potenciar las fortalezas como prioridad. 
Tabla 3.4

Matriz FODA cruzado de la empresa

\begin{tabular}{|c|c|}
\hline ESTRATEGIAS INTERNAS & ESTRATEGIAS EXTERNAS \\
\hline FO & FA \\
\hline $\begin{array}{l}\text { Establecer dentro del plan de MKT estrategias } \\
\text { de precio que considere el crecimiento en el } \\
\text { poder adquisitivo. } \\
\text { Aprovechar las tendencias crecientes en el } \\
\text { sector mascotas para posicionar la marca y su } \\
\text { ventaja competitiva en el mercado para } \\
\text { asegurar market share. } \\
\text { DO }\end{array}$ & $\begin{array}{l}\text { - Aprovechar el know how y especialización para } \\
\text { complejizar el servicio y fijar barreras de } \\
\text { entrada. } \\
\text { - Posicionar la marca como la pionera en servicios } \\
\text { exclusivos a mascotas y su ventaja competitiva } \\
\text { para conquistar otros mercados como sustitutos. } \\
\text { DA }\end{array}$ \\
\hline $\begin{array}{l}\text { Conseguir financiamiento o ruedas de } \\
\text { capitalización para aprovechar la tendencia y } \\
\text { crecimiento económico. } \\
\text { Dado el potencial de la empresa, conseguir - } \\
\text { socios estratégicos para afrontar mejor las } \\
\text { proyecciones. }\end{array}$ & $\begin{array}{l}\text { - Asociarse con un accionista que también sea } \\
\text { cliente, pues conocerá mejor las necesidades y } \\
\text { soluciones. } \\
\text { - Conseguir o generar la mayor información } \\
\text { posible y know how para utilizarlo como activo } \\
\text { y crecer las barreras de entrada }\end{array}$ \\
\hline
\end{tabular}

Elaboración: Propia 


\section{CAPITULO IV: PLAN DE MARKETING}

\subsection{Planteamiento de objetivos generales de marketing.}

Objetivo general de marketing: Establecer los objetivos de marketing de la empresa a fin de definir las mejores estrategias para conquistar el mercado objetivo del proyecto, y en base a eso poder formular correctamente la proyección de la demanda y el plan de ventas que servirá de insumo para un futuro plan de producción y de finanzas de la empresa.

Objetivos específicos:

- Establecer la segmentación y perfil del cliente.

- Establecer la ventaja competitiva de la empresa.

- Determinar el marketing mix de la empresa.

- Encausar el mensaje y motivo de la marca.

- Investigar las tendencias de mercado.

- Servir de insumo para el plan de ventas y proyección de la demanda.

\subsection{Estrategias de marketing:}

\subsubsection{Segmentación y Perfil del cliente.}

En la sección 2.5 se muestran los resultados de las encuestas, los cuales validan los patrones de consumo y preferencias de las personas que tienen perro en Lima Metropolitana. Al respecto, dichos resultados permiten segmentar el mercado de la siguiente manera:

- Demográficamente, son hombres y mujeres mayores de 25 años con poder adquisitivo medio alto.

- Geográficamente, son personas que viven en Lima Moderna. Dado su poder adquisitivo y lugar de domicilio se considera que pertenecen al nivel socioeconómico A y B (ver anexo 15).

- Psicográficamente, son personas que tienen fuertes lazos afectivos con sus mascotas y los consideran parte de su familia, por ejemplo en el caso de las 
parejas jóvenes, su principal motivación es que teniendo perros entrenan sus responsabilidades familiares y la necesidad de una educación y cuidados constantes a los miembros más pequeños de la familia (Jardi, 2013). Asimismo, son personas materialistas, de clase social media-alta y entre profesionales y directivos. Invierten en sus mascotas hasta S/3,000 mensuales (Gestión, 2016).

Considerando la segmentación de mercado y resultados de las encuestas se considera que el cliente de la empresa tiene el siguiente perfil: hombres y mujeres mayores de edad de NSE A y B, materialistas, consideran a sus perros parte de la familia, y son profesionales.

\subsubsection{Posicionamiento y ventaja competitiva.}

Según la encuesta realizada a la muestra poblacional en estudio, el factor que más valoran los dueños de perros es la confianza que su perro esté en buenas manos. Además de este dato cuantitativo, en las entrevistas las personas manifiestan que los perros son parte de su familia y por eso buscan lo mejor para ellos y la tranquilidad que estén seguros.

$\mathrm{Al}$ respecto, la empresa se ha enfocado en atender esa necesidad tan valorada por los dueños de perros, por lo que desarrolla una estrategia de diferenciación plasmada en la generación de confianza como ventaja competitiva. Para lograr esto, se establecen diversos medios que cumplen este objetivo como la 1) trasparencia y participación activa de los clientes, 2) personal especializado y 3) comunicación constante a través de tecnología de punta, siendo este último el principal componente diferenciador. Estos medios son:

- Difundir con total transparencia los procesos internos a través de las redes sociales y canales con los clientes, por ejemplo, las actividades en las que se participa, los lugares donde se pasean a los perros. Asimismo, se puede solicitar la participación de los clientes en estas actividades o incluso en los procesos de selección de empleados (ver sección 6.4).

- Trabajar con personal especializado en el cuidado de los perros, para eso la empresa elabora perfiles de puestos y funciones específicas que deben cumplir los cuidadores al momento de su convocatoria (ver sección 6.4). Asimismo, la empresa brindará periódicamente cursos de capacitación sobre el cuidado de 
los perros, adiestramiento, paseo, alimentación, entre otros, los cuales están presupuestados y se comunicará a los clientes.

- Mantener una comunicación constante con los clientes, principal componente diferenciador de la empresa, desde el momento en que el perro registra su ingreso al local hasta que es retornado a su hogar. Esta comunicación va desde el contacto telefónico y de texto, hasta la implementación de un App que permita el registro del perro, reserva de horarios para recojo, pago mediantes tarjetas de crédito y débito, y monitoreo de la mascota en tiempo real mediante cámara-video y mapa con GPS. Mayor detalle de esto se explica en el plan de operaciones.

A fin de mantener esta ventaja competitiva en el tiempo y generar fuertes barreras de imitación, la empresa promueve una fuerte cultura organizacional que permita gestionar con transparencia los procesos y servicios al usuario, así como la constante capacitación en el cuidado de los perros.

De otro lado, para asegurar que la tecnología no sea fácilmente replicada, y de este modo cuidar su componente diferenciador, la empresa firma un contrato con el proveedor mediante el cual se compromete a no proveer del mismo producto a otra empresa del rubro. Asimismo, según la política de gestión del cliente, la empresa buscará adaptar sus procesos y herramientas a las nuevas necesidades del usuario, por lo que, de ser necesario, la empresa desarrollará mejores herramientas que lo mantengan en la vanguardia.

Es así como, la empresa formula como ventaja competitiva el alto nivel de confianza que genera en sus clientes, y cómo lo consigue. 
Figura 4.1

Ventaja competitiva de la empresa

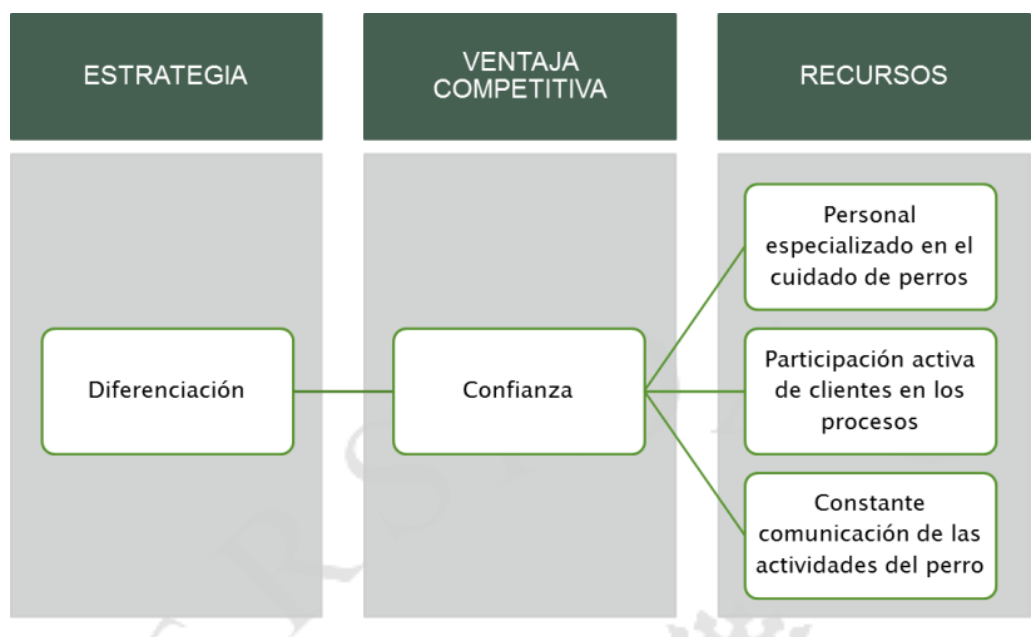

Elaboración propia.

Sin perjuicio de lo anterior, se propone desarrollar progresivamente una estrategia de liderazgo en costos que permitirá a la empresa generar mayores márgenes operacionales.

De otro lado, la empresa probará que esta estrategia de diferenciación creará una ventaja competitiva respecto a los competidores y sustitos, posicionándose de esta manera como referente en el cuidado de los perros. En la siguiente figura se puede observar que la empresa se caracteriza por su alto nivel de confianza y comunicación constante.

\section{Figura 4.2}

Matriz de posicionamiento de la empresa Pet Fun

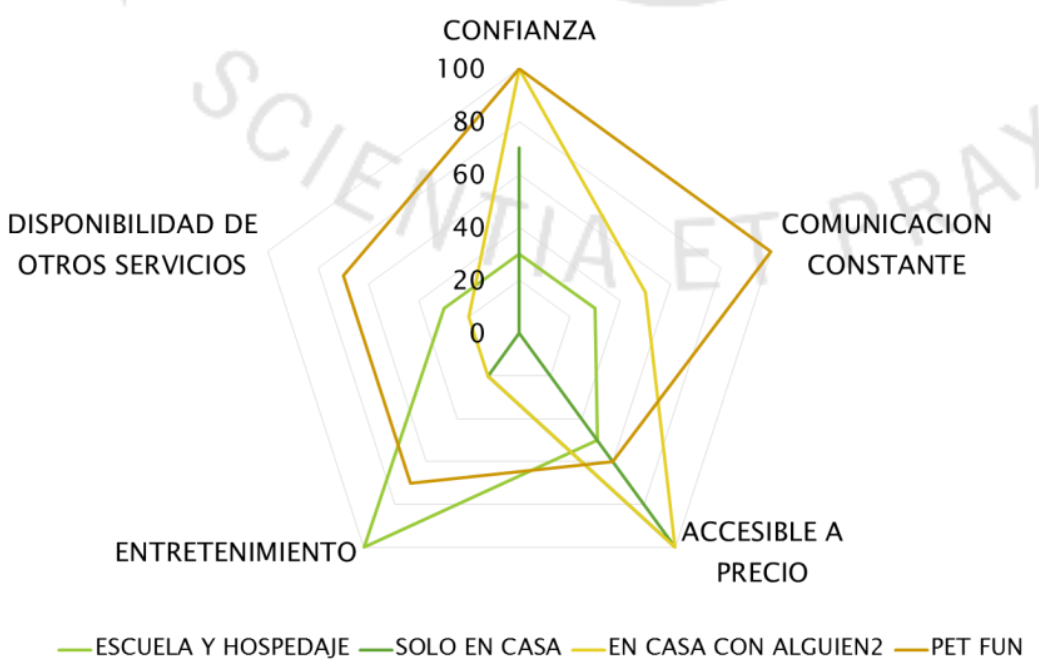

Elaboración propia. 


\subsection{Mercado objetivo:}

\subsubsection{Tendencia de mercado.}

Dado que el modelo de negocio es innovador, es decir tiene componentes nuevos y diferentes a una guardería convencional, no existe información histórica ni precedentes que establezcan el comportamiento del potencial mercado, es por eso que para el análisis de las tendencias y patrones de mercado, lo primero se ha hecho fue elegir otros negocios que atienden la misma necesidad del público objetivo, y siendo más específicos, los negocios el mismo insight del usuario, que de acuerdo a las entrevistas a profundidad, resultó ser que las personas tenían la preocupación de que algo malo les pasara y necesitaban estar pendiente de ellos pues lo consideraban como hijos.

La misma motivación se presenta en los clientes que reciben las veterinarias y pet shops, según entrevista a Veterinaria Family Pet (también vende accesorios y otros productos para perros, funciona como pet shop), donde según indica el dueño, los clientes se preocupan mucho de que su mascota sea bien atendida y reciba más que una consulta, un trato espacial. Ver anexo 1.

Al respecto, las estadísticas indican que se tiene un incremento de veterinarias y pet shop en Lima Metropolitana, llegando a 637 veterinarias y 374 pet shop en para el 2016 (Ipsos, 2016).

Tabla 4.1

Número de veterinarias en Lima

\begin{tabular}{lllllll}
\hline Total & $\begin{array}{l}\text { Lima } \\
\text { norte }\end{array}$ & $\begin{array}{l}\text { Lima } \\
\text { este }\end{array}$ & $\begin{array}{l}\text { Lima } \\
\text { centro }\end{array}$ & $\begin{array}{l}\text { Lima } \\
\text { moderna }\end{array}$ & $\begin{array}{l}\text { Lima } \\
\text { sur }\end{array}$ & Callao \\
\hline 637 & 145 & 123 & 64 & 166 & 107 & 32 \\
\hline
\end{tabular}

Fuente: Ipsos Apoyo 2016

Tabla 4.2

Número de tiendas de mascotas en Lima

\begin{tabular}{lllllll}
\hline Total & $\begin{array}{l}\text { Lima } \\
\text { norte }\end{array}$ & $\begin{array}{l}\text { Lima } \\
\text { este }\end{array}$ & $\begin{array}{l}\text { Lima } \\
\text { centro }\end{array}$ & $\begin{array}{l}\text { Lima } \\
\text { moderna }\end{array}$ & $\begin{array}{l}\text { Lima } \\
\text { sur }\end{array}$ & Callao \\
\hline $\mathbf{3 7 4}$ & 55 & 45 & 92 & 87 & 78 & 17 \\
\hline Fuente: Ipsos Apoyo 2016 & & & &
\end{tabular}


Asimismo, la propuesta pertenece a un sector de mascotas con alto potencial de crecimiento, algunas tendencias son:
a) Alimentos sanos y personalizados
b) Establecimientos comerciales pet friendly
c) Tratamientos naturales y aromaterapia
d) Nuevos reyes de las redes sociales
e) Baño, peluquería y médicos a domicilio

\subsubsection{Tamaño de mercado}

El tamaño de mercado fue revisado en la sección 2.4 a fin de segmentar el mercado hasta llegar al tamaño que se usará de base para las operaciones y planes de venta y financieros. Al respecto, se parte de un mercado total de hogares que tienen mascotas en Lima Metropolitana, segmentando y acotando el mercado hasta llegar al mercado objetivo.

- Mercado Total Disponible (TAM): 1,030,906 hogares con perros en Lima Metropolitana. (Censo 2017, INEI)

- Mercado Disponible Efectivo (SAM): 235,500 hogares de NSE A y B con perros en Lima Metropolitana. (Censo 2017, INEI)

- Mercado Objetivo (TM): 153,075 hogares de NSE A y B con perros en Lima Moderna y con intención de compra. (Fuente: encuestas)

\subsubsection{Mercado objetivo}

El mercado objetivo se obtiene de la aplicación de un porcentaje de personas que tienen intención de compra como resultado de encuestas a una muestra poblacional según lo indicado en la sección 2.4.

Según las encuestas se halló que el $65 \%$ de personas les interesa e interesa mucho la guardería para perros. Por lo tanto, el tamaño de mercado objetivo se acota a 153,075 hogares, lo cual equivale a 214,305 perros considerando que en cada hogar existe 1,4 perros (Ipsos, 2016). 


\subsubsection{Identificación de agentes}

Dentro de los principales agentes o socios estratégicos se encuentran los municipios, quienes son los encargados de brindar los permisos para el funcionamiento de la empresa, así como regular el libre comercio y bienestar de los vecinos. Para este caso, en los próximos capítulos se evalúa el distrito más idóneo para la localización de la empresa, el mismo que debe ofrecer información sobre los procedimientos de trámites y servicios para el otorgamiento de licencia de funcionamiento, entre otros.

Los dueños de los perros, personas de NSE A y B de Lima Moderna, son los principales clientes de la empresa y socios estratégicos a la vez pues una vez que fidelicen con la empresa y marca tomarán un rol de fuerza de ventas indirecta, al conseguir más clientes a través de las recomendaciones y el boca a boca.

De la misma manera, los centros de trabajo ya sean empresas públicas o privadas, son los lugares de trabajo de los clientes, para ello es importante estudiar en qué empresas o zonas empresariales son las más concurridas por los clientes, basado en la encuesta. Asimismo, existe la posibilidad que la empresa se convierta en un cliente, pues puede ofrecer el servicio de guardería de perros como un beneficio para sus trabajadores.

Las sociedades protectoras de animales puede ser un gran socio estratégico para la difusión y promoción de los servicios de la empresa, además de un socio para actividades de responsabilidad social, por ejemplo la Asociación Peruana de Protección de Animales encargada de campañas educativas, vacunación y esterilización y promoción de eventos para recaudar fondos y ayudar a diversos albergues (ASPPA). Para ello es importante establecer contacto y relaciones con los dirigentes o líderes de estas organizaciones, participar de sus eventos e incluso hacer donaciones.

Otras agrupaciones que se pueden sumar a la idea anterior, son las comunidades perrunas o grupos amantes de los perros, por ejemplo el club de labradores, club de bulldog Perú, y otros clubes de razas específicas. Estos se pueden ubicar en redes sociales, normalmente están organizados por un presidente y con frecuencia organizan actividades perrunas. 
Por último, las empresas de alimentos, salud, moda o entretenimiento para mascotas podrían ser un punto de contacto con posibles clientes y hacer de aliados estratégicos, por ejemplo, se puede hacer un trato con una empresa de alimentos para publicitar sus productos en la instalación de la empresa y en viceversa esta empresa hacer publicidad de los servicios de Pet Fun.

\subsubsection{Potencial de crecimiento del mercado}

Según el régimen jurídico de canes, “(...) está prohibido el ingreso de canes a locales públicos, de espectáculos, deportivos, culturales, y otros de asistencia masiva de personas, así como en piscinas, playas públicas y lugares de recreación (...)”(Ley № 27596 artículo $\left.25^{\circ}, 2001\right)$, excepto los parques públicos, en estos casos el régimen jurídico indica que “(...) sólo se permitirá la circulación y permanencia de canes, en áreas de uso público, cuando estén acompañados de la persona responsable de su cuidado." (Ley Nº 27596 artículo $\left.21^{\circ}, 2001\right)$. Estas disposiciones, si bien regulan y piden exigencias para las personas con perros, para la empresa supone una oportunidad de educar y brindar productos o servicios especializados según exige la norma y prefiere el cliente.

Evidentemente, la tendencia de crecimiento de tenencia de mascotas juega a favor de la empresa por ser potencial crecimiento de clientes y por ende ventas.

Por otro lado, la mayor limitante es que las mismas personas se ocupen de hacer todo lo concerniente de su mascota, una tendencia, por ejemplo, es que los servicios sean brindados en la misma casa del cliente. Sin embargo, toda limitante puede convertirse en oportunidad, y en este caso la empresa deberá evaluar adaptar o crear nuevos servicios para atender esta tendencia.

\subsubsection{Rivalidad competidora y Potencial de ventas}

Como se mencionó en la sección de análisis interno, si bien no atienden el mismo objetivo estratégico, lo más cercano a un competidor son las escuelas caninas, hospedajes y paseadores de perros. 
Un ejemplo de escuela canina es VIP Dog Training, cuya misión es ayudar a enriquecer las relaciones que unen a las personas con sus animales de compañía a través de la corrección y educación. El precio de las clases puede llegar a 500 soles en un mes, que consta de clases diarias de hasta tres horas, realizadas en parques públicos, no tienen un local propio ni funciona como guardería (VIP Dog Training).

De otro lado, Wau es un hotel que da alojamiento a mascotas mientras sus dueños están de vacaciones o fuera de casa, y ofrecen un cuidado integral de alimentación, higiene, seguridad y diversión en su local en Pachacamac. Según información brindada por teléfono, sus costos varían de 70 soles por día de alojamiento (no incluye traslado), hasta 800 soles para el caso de una pensión mensual, la cual incluye el alojamiento y traslado semanal de 8:30 a 16:30 horas (Wau).

Según la página web Vet Place, lugar virtual para venta y compra de productos y servicios para perros, se encuentran otros servicios de hospedajes para perros como:

- Vicdogs de San Miguel ofrece hospedaje diario por 60 soles incluido 3 salidas al día de 25 minutos y comunicación por Skype o Whatsapp, Cobra 10 soles adicional para perros de talla grande y se requiere que lleven sus camas.

- Happyfamily ofrece alojamiento en un lugar amplio por 40 soles más 10 soles por traslados.

- Groom Room, ubicado en San Isidro, ofrece hospedaje diario por 60 soles más 10 soles si es perro grande, incluye 3 salidas al día de 25 minutos (Vet Place).

Una variante del hotel para perros es el hospedaje en hogares, según artículo del Comercio, Dog Houser es una empresa que ofrece alojamiento temporal en hogares a aquellos perros que necesitan de espacio libre y de alguien que les dé un cuidado personalizado en su propia vivienda, es decir funciona como un intermediario entre dueños y cuidadores. Los costos pueden variar entre 35 y 40 soles por 12 horas por día, o entre 700 y 800 soles al mes si se habla de días hábiles (Carrión, A., 2018).

De otro lado, para las personas que no tienen la necesidad de dejar a sus perros $8 \mathrm{o}$ 10 horas en una guardería, tienen la opción de contratar a cuidadores de perros encargados de dar a la mascota un paseo diario por horas, como el caso de la empresa de estimulación 
canina Alko, que ofrece este servicio por un tiempo de aproximadamente 2 horas con un costo de 10 a 15 soles la hora dependiendo el distrito (Alko).

Un dato muy importante que ocurre en ambos casos es que estos establecimientos no generan confianza ni seguridad en los clientes pues, según las entrevistas, manifiestan que no siempre el cuidado es bueno, sus perros regresan con bichos o lesionados por pleitos con otros canes. Lo mencionado es una debilidad de estas empresas y supone una oportunidad de diferenciación para la empresa, teniendo en cuenta que además la confianza es el factor que más valoran los dueños de mascotas.

\subsection{Desarrollo y estrategia del marketing mix}

\subsubsection{Política de gestión del cliente}

La empresa, considera que la provisión de servicios adecuado a las necesidades de sus clientes es parte fundamental del negocio y, por ello la gestión del cliente explica cómo se gestionarán las relaciones con los clientes, entre sus acciones están:

- Constante verificación que los servicios estén alineados con las necesidades de los clientes, para ello se cuenta con canales ideados para mantener una estrecha comunicación y retroalimentación, cómo el contacto por redes sociales, a través de chats, comunicación telefónica y encuestas.

- Como parte de la comunicación con el cliente, se establecerá una base de datos de los clientes a través de un aplicativo móvil que registrará en la nube la información cerca del cliente y de su perro, gustos, preferencias y otra información valiosa que ingrese como parte del registro y monitoreo de su mascota (en el capítulo 5 se expone más detalle).

- Disposición de personal competente y debidamente capacitado para llevar a cabo las tareas con las garantías de calidad exigibles. El personal tendrá capacitaciones y reforzamientos constantes en cuidados de los perros, pero además en lo relacionado al trato con el cliente y cómo educar a su perro.

- Establecimiento y difusión de los procedimientos y compromisos establecidos para asegurar la satisfacción global del cliente, para ello se pueden adoptar herramientas de medición de indicadores y comunicación con el cliente. 


\subsubsection{Estrategia de producto}

La empresa ofrece el servicio de guardería para perros, el cual consiste en una suscripción mensual que da derecho al cuidado del perro registrado por el tiempo aproximado de horas que su dueño se encuentra trabajando (no incluye pernocte). El servicio consta de:

- La hidratación y alimentación del can con los alimentos que su dueño proporcione y en la cantidad que indique. Para ello el cuidador tendrá los cuidados necesarios para la agrupación y horarios de cada uno de los canes que se encuentren en la guardería.

- El paseo del can fuera del local en ambientes amplios y exteriores como parques, en un tiempo equivalente a la mitad del tiempo de permanencia en la empresa. Para ello es necesario la autorización del dueño y contar con un collar y correa.

- El adiestramiento básico de los canes que se encuentren bajo los cuidados de la empresa. Esto consiste en enseñarles principalmente a obedecer instrucciones a fin de mantener un orden en el tiempo de permanencia en la empresa. Asimismo, se podrá enseñar trucos o reforzar su comportamiento según lo requiera el dueño.

- Esparcimiento y tiempo de juego, el cual es transversal en todas las actividades pues el objetivo de la empresa es justamente generar el mayor confort y alegría de los perros.

Adicionalmente, para el caso de personas que solo deseen dejar a sus perros por unas horas y prefieren que pasen más tiempo al aire libre, se ofrece el servicio de paseo para perros, que consta de un aproximado de dos horas por día, siendo posible para el cliente tomar el servicio solo algunos días del mes, sin embargo según las encuestas se determina que las personas toman el servicio de paseo semanalmente por todas las semanas del mes salvo excepción. El paseo es el mismo que se brinda en el caso de suscripción, donde un cuidador puede pasear hasta 10 perros y los recoge y deja en su domicilio diariamente.

Por último, la venta de accesorios es un complemento ideal para las actividades de guardería, paseo o para la casa. Un estudio sobre comportamiento de compra de accesorios 
para mascotas (Ipsos, 2016) indica que los principales accesorios que las personas suelen comprar a sus perros son juguetes $(41 \%)$, ropa (35\%), collares y correas $(25 \%)$ y camas $(18 \%)$. Para el caso, por capacidad logística se ofrecen los tres primeros.

Si analizamos los niveles de productos descritos, es importante conocer su enfoque respecto a la oferta en el tiempo, empezando por el enfoque en solo vender y vender (MKT 1.0), luego el enfoque por el cliente y sus necesidades funcionales (MKT 2.0), posteriormente el enfoque en los valores del cliente y como gestionar oportunidades basadas en el funcionamiento de sus impulsos no racionales (MKT 3.0), y finalmente, el futuro se encuentra en el MKT 4.0 que puede estar ligado a inteligencia artificial y busca trascender en algo más allá que el cliente (Fuciu, M. y Dumitrescu, L., 2018).

$\mathrm{Al}$ respecto, se tiene que el beneficio principal de la empresa es el cuidado de los perros, ya sea mediante el servicio de guardería, paseo o venta de accesorios. Es la funcionalidad del servicio, lo mínimo que debe recibir el cliente como contraprestación.

El Producto real es un valor agregado que se ofrece al cliente, por ejemplo, en el caso de la guardería y paseo del perro es la cercanía al hogar del dueño, la transparencia y la comunicación constante de lo que hace su engreído. En el caso de la venta de accesorios es la función complementaria con las actividades que realiza el perro en la guardería.

El Producto aumentado se refiere a un aspecto emocional pues atiende una necesidad implícita del cliente, en este caso es la seguridad y confianza de saber que el perro del cliente se queda en buenas manos, esto se puede conseguir manteniendo al cliente siempre informado de que hace tu perro.

\subsubsection{Estrategia de precios: análisis de costos y precios.}

Como resultado de la encuesta se obtuvo que el $71 \%$ de las personas están dispuestas a pagar entre 300 y 450 soles al mes por el cuidado de sus perros y el $29 \%$ entre 450 y 600 soles al mes. De un promedio ponderado las personas estarían dispuestas a pagar un promedio de 431 soles al mes, siendo 300 soles el mínimo ideal y 600 soles lo máximo aceptable. 
Las BATNAs (Best Alternative to a Negotiated Agreement, por sus siglas en inglés), son críticas para la negociación porque no se pueden tomar decisiones inteligentes acerca de si se debe aceptar un acuerdo negociado, a menos que se conozcan las alternativas (Fisher R. \& Ury W., 1981). Según esta herramienta para la negociación, las partes deben elegir un precio dentro de la ZOPA (Zone of Possible Agreement, por sus siglas en inglés). En este caso se eligió el precio de 493 soles. Este precio incrementará en el largo de la vida útil del proyecto a razón de la inflación.

Al respecto, la empresa sigue la estrategia de fijación de precios basado en el valor, es decir los 493 soles identificados en la encuesta, el cual es fijado como precio meta, y debido que se quiere conseguir al menos una utilidad de $20 \%$ en el año de recupero, según buenas prácticas financieras, eso significaría manejar una estructura de costos no mayor de 410.83 soles por suscripción mensual por perro.

Para el caso del servicio de paseo, se considera un precio promedio del mercado, el cual es 70 soles por semana que equivale a 300 soles mensual para efectos de cálculo, y para la venta de accesorios también se consideran los precios de mercado.

\subsubsection{Política comercial.}

Pet Fun es una empresa especialista en el cuidado de perros, para llegar a sus clientes y generar una relación redituable establece los siguientes lineamientos comerciales:

- Concentración en el segmento de personas que trabajan en Lima Metropolitana y tienen perros. $\mathrm{Al}$ respecto, las estrategias y tácticas deberán estar orientadas a conquistar este público, y siendo más específicos, en las personas de NSE A y B que trabajan en Lima Moderna.

- Realización de convenios de colaboración o contratos con socios estratégicos a fin de aprovechar canales actuales y carteras de clientes existente en el sector mascotas.

- Comunicación multicanal, con especial foco en los medios de mayor uso del público objetivo, por ejemplo, internet y redes sociales en jóvenes y medios tradicionales en adultos. 
- Distribución exclusiva, es decir, la entrega de los servicios será brindada exclusivamente por la empresa en sus locales o puntos de venta que establezca.

- El precio será establecido por la valoración del cliente, considerando que la estrategia competitiva es de diferenciación, la empresa no tiene estipulado entrar a guerras comerciales (océanos rojos) y siempre apostará por la reinversión.

\subsubsection{Estrategia comunicacional y canal}

El mix de comunicación a elegir depende del perfil del cliente, al respecto no se hace diferencias de género ni de edades, sin embargo se considera importante utilizar un lenguaje exclusivo y profesional, pues el público objetivo son personas de cargos profesionales y directivos, de clase social media-alta y materiales, es decir, buscan contactar con una empresa importante y diferente.

Asimismo, las estrategias para comunicar y hacer publicidad de la empresa dependerán del momento en que se encuentra la empresa:

- En la etapa de "interrogante", la estrategia es invertir bastante en publicidad por internet, en google, y sobre todo en redes sociales, ya que tiene un costo bajo y es el canal más usado por el público objetivo. Asimismo, se difundirá afiches en sitios concurridos por mascotas como parques y eventos.

- En la etapa de "crecimiento", automáticamente se iniciará la recomendación de boca a boca. En paralelo, se continuará con marketing digital. El objetivo es posicionar la marca, y para ello es importante planear una estrategia de branding.

- En la etapa de "madurez", además de mantenerse el boca a boca y bajar un poco la intensidad de publicidad, es conveniente establecer convenios y alianzas con otras marcas conocidas de mascotas, así como empresas y establecimientos comerciales. Mientras mejor posicionamiento y participación de mercado tenga la empresa, mayor es el poder de negociación con estos agentes. 
La publicidad estará a cargo del servicio especialista en marketing, el cual elaborará un mix de marketing especificando los canales, horarios y público objetivo de acuerdo a la estrategia planteada por la gerencia. Por ejemplo, trabajará contenido con las experiencias con los clientes y sus perros, asimismo se difundirán los eventos en los que participe la empresa.

\subsubsection{Estrategia de distribución.}

La estrategia de distribución de la empresa es exclusiva ya que tiene un canal directo con el cliente, pocos o ni un vendedor, precio alto, frecuencia de compra media-baja (máximo 10 perros inscritos al año) y los productos son de casi nula variedad (dos servicios estándar y tres tipos de accesorios).

Para las ventas se considera el canal virtual a través de transferencias bancarias, y presencial en tienda con dinero en efectivo. La empresa no da crédito y el pago se realiza antes de brindar el servicio (por adelantado).

\subsection{Plan de Ventas y Proyección de la Demanda}

Para determinar la demanda se ha escogido el número de perros de hogares NSE A y B en Lima Moderna, para eso se ha multiplicado el mercado objetivo que está compuesto por hogares de las mismas características y multiplicado por el número de perros que tienen en promedio ese grupo de hogares, que es 1.4 perros por hogar. Asimismo, para proyectar esta demanda se ha tomado como referencia el porcentaje de crecimiento de hogares con mascota en Lima Metropolitana, el cual es $1.45 \%$ anual según estudio de Ipsos Apoyo (Ipsos Perú, 2016).

Tabla 4.3

Evolución de la PEA ocupada por edades 2010-2015

\begin{tabular}{cccccccc}
\hline Año & $\mathbf{2 0 1 5}$ & $\mathbf{2 0 1 6}$ & $\mathbf{2 0 1 7}$ & $\mathbf{2 0 1 8}$ & $\mathbf{2 0 1 9}$ & $\mathbf{2 0 2 0}$ & $\mathbf{2 0 2 1}$ \\
\hline NSE A & 62.000 & 63.000 & 64.000 & 64.000 & 65.000 & 66.000 & 67.000 \\
NSE B & 242.000 & 246.000 & 250.000 & 253.000 & 256.000 & 260.000 & 264.000 \\
NSE C & 596.000 & 605.000 & 615.000 & 622.000 & 632.000 & 641.000 & 650.000 \\
NSE D & 340.000 & 346.000 & 351.000 & 355.000 & 361.000 & 366.000 & 371.000 \\
NSE E & 92.000 & 93.000 & 95.000 & 96.000 & 98.000 & 99.000 & 100.000 \\
\hline
\end{tabular}

Fuente: INEI Proyección de pobladores por departamento 2025 
Conforme lo calculado en la sección 4.3.3 se tiene un mercado objetivo de 214,305 perros, sin embargo, para elaborar el plan de ventas se considera el tamaño de proyecto, el cual está determinado por la capacidad de atención de la empresa, tanto por la capacidad de personal (cuidadores especializados), de proveedores y socios estratégicos (veterinarias) y de espacio físico del local.

$\mathrm{Al}$ respecto, en Lima Moderna existen 166 veterinarias que atienden al 96.5\% de personas de NSE A y B que llevan a su perro en promedio 1.2 veces al mes (Ipsos, 2016). Del mismo modo, los hospedajes en Lima cuentan con un número fijo de canes inscritos en el mes. Según conversación telefónica con Hospedaje "Wau", hospedan un promedio de 30 perros que conviven y pernoctan en un terreno de $200 \mathrm{~m} 2$ construidos.

Considerando ambas referencias, la capacidad instalada de la empresa es de 40 perros, pero, considerando que la empresa plantea un modelo de atención de turnos de actividades para los perros de $50 \%$ en el local y $50 \%$ fuera del local simultáneamente, la capacidad podría duplicarse hasta 80 perros.

Sin embargo, para las operaciones se considera que el primer año se tiene una curva de aprendizaje donde poco a poco aumenta la demanda de perros (ver crecimiento de ventas mensuales en el anexo 9), y a partir del segundo año se llega a la capacidad máxima de operaciones, siendo esta un $10 \%$ menor a la capacidad instalada, es decir se llega hasta 72 perros.

El objetivo de mantener este $10 \%$ de capacidad sin uso es utilizar dicho margen para situaciones eventuales en las que no todos los perros puedan seguir el modelo de actividades 50-50. Mayor detalle sobre esta forma de atención de los perros se explica en la sección 5.2.1.

Teniendo dicha capacidad y un precio mensual de S/ 525 por perro por 12 meses al año, se estiman unas ventas totales de S/ 314,370 el primer año hasta $S$ / 587,093 el quinto año. En el plan de ventas se refleja la capacidad de operaciones señalada líneas arriba. 
Tabla 4.4

Plan de ventas de la empresa (en soles)

\begin{tabular}{lccccc}
\hline & Año 1 & Año 2 & Año 3 & Año 4 & Año 5 \\
\hline Ventas & $\mathbf{3 1 4 , 3 7 0}$ & $\mathbf{5 3 1 , 0 6 2}$ & $\mathbf{5 4 9 , 1 1 9}$ & $\mathbf{5 6 7 , 7 8 9}$ & $\mathbf{5 8 7 , 0 9 3}$ \\
Ventas por suscripción & 286,650 & 469,022 & 484,969 & 501,458 & 518,508 \\
Ventas por paseo & 9,000 & 29,779 & 30,792 & 31,839 & 32,921 \\
Ventas por accesorios & 18,720 & 32,261 & 33,358 & 34,492 & 35,665 \\
\hline
\end{tabular}

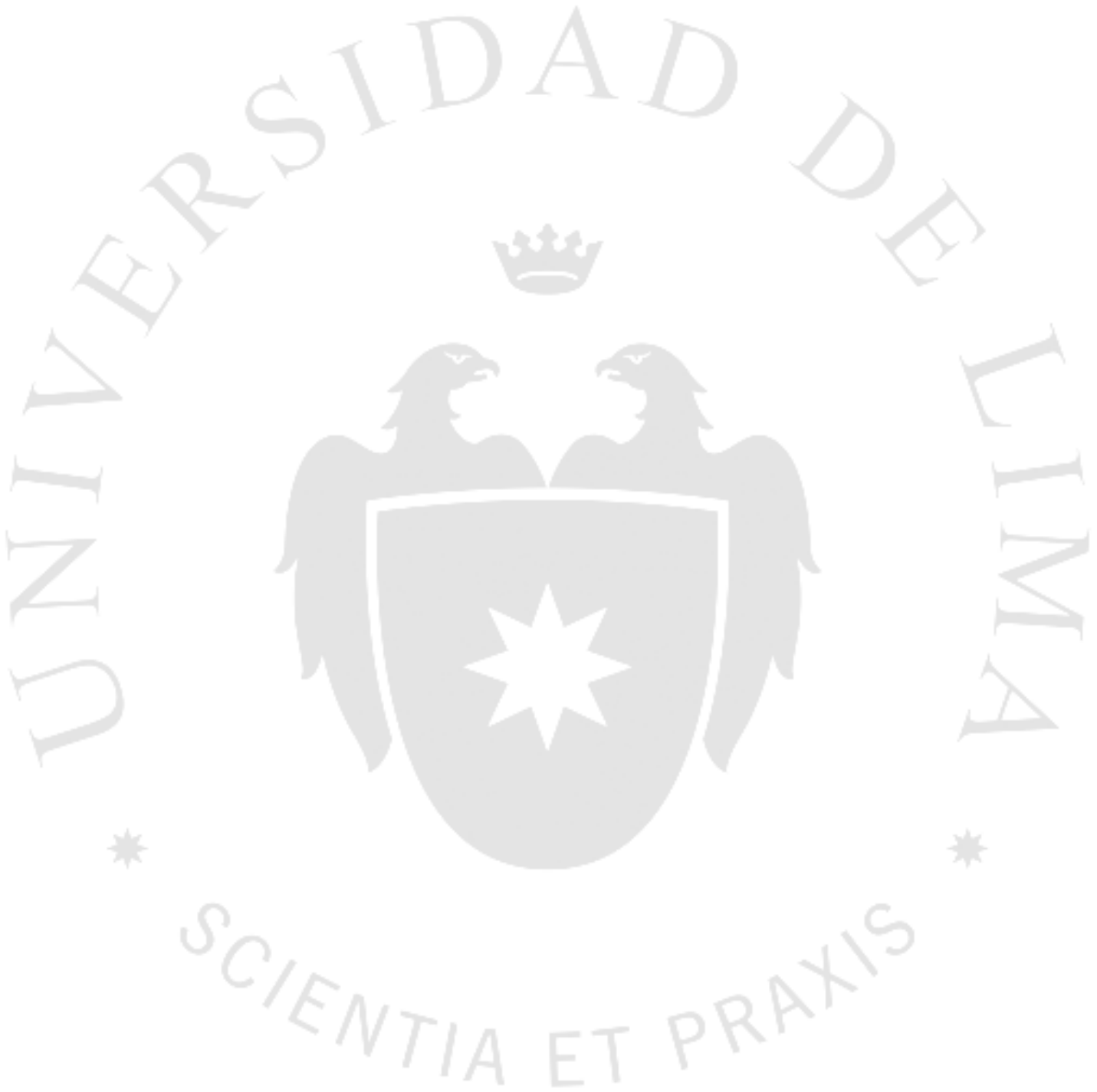




\section{CAPITULO V: PLAN DE OPERACIONES}

\subsection{Políticas Operacionales.}

\subsubsection{Producto y calidad}

La empresa ofrece el servicio de guardería para perros mediante suscripción mensual que consta de hidratación y alimentación, paseo, adiestramiento básico y esparcimiento y tiempo de juego. Adicionalmente, se ofrece el servicio de paseo para perros por horas, y la venta de accesorios como complemento para dichas actividades.

Es importante mencionar que para el registro de los perros que solicitan servicios de guardería o paseo, los dueños deben entregar constancia de vacunación, última desparasitación y anti pulgas y llenen una ficha con las particularidades del perro como antecedentes de agresión o si tiene alguna condición de salud, ello con el fin de cumplir con las normas de sanidad y control de tenencia de animales impartidas por la Municipalidad correspondiente. Asimismo, es requisito que se firme un contrato donde se identifiquen los compromisos y especifiquen las responsabilidades tanto de la empresa como de los dueños de los perros.

En resumen, la empresa ofrece dos servicios intangibles (guardería y paseo) y un producto tangible (venta de accesorios), siendo los servicios la mayor fuente de ingreso, por lo que se considera que la empresa está en un rango desde $20 \%$ tangible hasta $80 \%$ intangible, como a continuación se muestra.

Figura 5.1

Escala de tangibilidad de la empresa

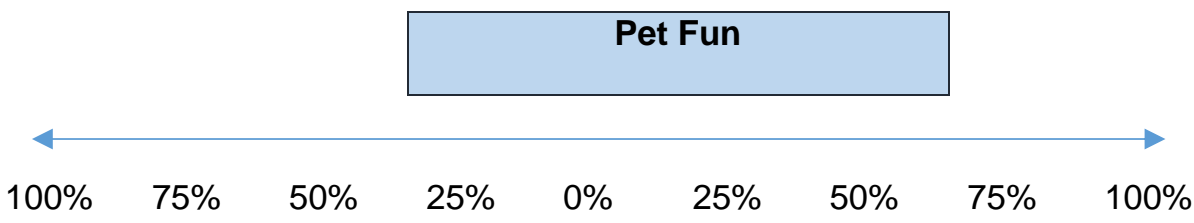

Elaboración propia 
De otro lado, el tipo de servicio que brinda la empresa es "alianza de servicio" debido a que hay una atención personal al usuario, como son el recojo a domicilio y cuidado especializado de los perros, tomando en consideración las características que tenga alergias, temperamento, sexo, entre otras.

Respecto a la calidad del servicio, este debe cumplir las expectativas del cliente, en este aspecto se establecerán indicadores de calidad como la satisfacción del cliente mediante encuestas. Un factor relevante para ofrecer un servicio de calidad y que esté alineado a la estrategia de diferenciación de la empresa es la comunicación constante, para ello se establecen mecanismos y equipos que permitan mantener a los dueños en constante comunicación con sus engreídos, ello sin perjudicar la labor de los cuidadores y considerando la cantidad de perros y actividades en que se encuentren en un momento dado. Más detalle del funcionamiento se explica en la sección 5.2.2.

\subsubsection{Macroproceso y cadena de valor}

La empresa sigue una gestión por procesos, la cual está dividida en procesos estratégicos, procesos misionales y procesos de soporte, según el siguiente gráfico. Asimismo, cada macroproceso (nivel 0) está conformado por procesos de nivel 1 y nivel 2 (procedimientos). La lista de procesos y procedimientos se puede apreciar en el anexo 3.

Figura 5.2

Macroproceso de la empresa (nivel 0, 1 y 2)

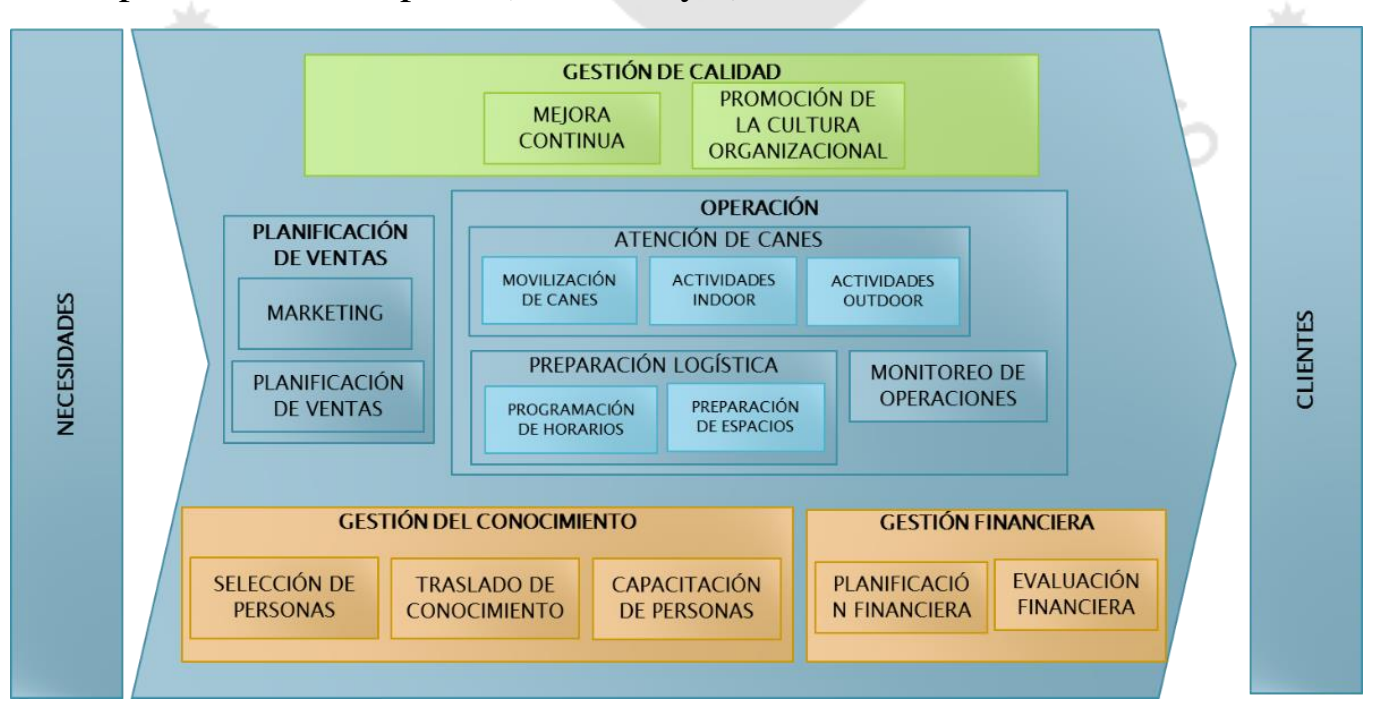

Elaboración propia 
Los procesos de nivel 2 se describirán y esquematizarán mediante flujogramas en la sección 5.2 "Equipos, actividades y procesos". Es importante mencionar que estos procesos guardan relación con el organigrama de la empresa detallado en la sección 6.1.2 "Organigrama".

\subsection{Equipos, actividades y procesos}

\subsubsection{Diseño y capacidad de instalaciones}

La empresa requiere una estrategia de gran capacidad de respuesta y flexibilidad de servicio, alineado a la estrategia competitiva de diferenciación, lo cual permitirá capturar la confianza del cliente y alargar su fidelidad.

Para asegurar la capacidad de respuesta ante los requerimientos del cliente, es necesario contar con una ubicación y tamaño de local acordes con la demanda, considerando un margen ocioso para atender las variaciones que puedan surgir. Es importante considerar que la capacidad de operación también depende de la capacidad de personal y proveedores.

La localización se basa en la decisión de contar con un local para la atención y cuidado de los perros tiene una explicación en la seguridad y protección de las mascotas, asimismo, con el fin de asegurar la calidad de los servicios y constante comunicación con el cliente, se debe considerar en este espacio, exclusivamente el área de operaciones.

Para la ubicación del local se ha considerado dos aspectos relevantes: i) que esté en línea con la propuesta de valor de la empresa y estrategia de competitividad y 2) la cercanía al hogar de los clientes, según lo valorado en la encuesta.

Al respecto, el resultado de la encuesta indica que el $51 \%$ de las personas encuestadas vive en La Molina, Surco y San Borja y el 10\% en San Isidro y Lince y otro 10\% en Barranco y Miraflores. Asimismo, el 23\% trabaja en La Molina, Surco y San Borja, el $21 \%$ en San Isidro y Lince y el $20 \%$ en el Centro Histórico de Lima. Como producto de ello, se ha tomado los distritos de La Molina, Surco, San Borja y San Isidro como alternativas de localización. 
Al respecto, para elegir la mejor alternativa se ha utilizado la herramienta de ranking de factores, donde:

- Costo de m2: el costo promedio de metro cuadrado en San Isidro es de S/ 8,671, Miraflores S/ 7,766, San Borja S/ 7,012, La Molina S/ 6,644 y Santiago de Surco S/ 6,324 (ADI Perú, 2018).

- Permiso municipal: el nivel de permiso está determinado por el costo y requisitos para el otorgamiento de licencias de funcionamiento de un negocio establecidos en el TUPA de municipalidades., En San Borja el costo es de S/ 693.5, La Molina S/ 391, Santiago de Surco S/ 328.4, Miraflores S/ 121.1 y San Isidro es de S/ 76.5 (Diario Gestión, 2016).

- Cercanía al hogar: está determinado por el resultado de las encuestas.

- Cercanía al trabajo: está determinado por el resultado de las encuestas.

La calificación de cada factor es del 1 al 10, siendo 1 la calificación más baja y 10 la calificación más alta.

Tabla 5.1

Ranking de factores para determinar localización de la empresa

\begin{tabular}{cccccc}
\hline Factor & $\begin{array}{c}\text { Precio } \\
\text { de m2 }\end{array}$ & $\begin{array}{c}\text { Permiso } \\
\text { municipal }\end{array}$ & $\begin{array}{c}\text { Cercanía } \\
\text { al hogar }\end{array}$ & $\begin{array}{c}\text { Cercanía } \\
\text { al trabajo }\end{array}$ & Calificación \\
\hline Peso & 0,2 & 0,1 & 0,4 & 0,3 & \\
San Borja & 3 & 2 & 8 & 4 & $\mathbf{5 , 2}$ \\
Surco & 5 & 3 & 8 & 4 & $\mathbf{5 , 7}$ \\
La Molina & 4 & 3 & 8 & 4 & $\mathbf{5 , 5}$ \\
Miraflores & 2 & 5 & 3 & 2 & $\mathbf{2 , 7}$ \\
San Isidro & 1 & 5 & 3 & 3 & $\mathbf{2 , 8}$ \\
\hline Elaboración propia & & &
\end{tabular}

Como resultado se tiene el distrito de Santiago de Surco como mejor alternativa de localización de la empresa. Se propone que la empresa empiece trabajando con un solo local por simplificación de la gestión, y capacidad de inversión. Lo cual significa, además, que la empresa brindará un servicio centralizado y esto le brindará facilidades para el control de las operaciones, por ejemplo, el paseo de los perros. 
La capacidad de la empresa está determinada por la demanda de atenciones, capacidad de personal, de proveedores y de socios, así como el espacio físico del local, por ejemplo, según conversación telefónica con Hospedaje "Wau", hospedan un promedio de 30 perros que conviven y pernoctan en un terreno de $200 \mathrm{~m} 2$ construidos. Por eso, para el diseño de la empresa, se toma en cuenta la capacidad de operaciones que requiere un local de al menos $100 \mathrm{~m} 2$ donde solo funcionaría el proceso de operaciones, la distribución es de la siguiente manera:

- Un espacio para los caniles o espacios de descanso para los perros.

- Un espacio abierto para esparcimiento (juego y adiestramiento).

- Un almacén para los accesorios y otros materiales.

- Una recepción para atender a los clientes.

- Una oficina para el supervisor de operaciones.

Dado que el gerente general tendría un contrato de teletrabajo y los especialistas en marketing y en administración y finanzas serían tercerizados, no utilizarían espacio físico. La distribución de espacios en el local sería la siguiente.

Figura 5.3

Distribución de espacios de la empresa

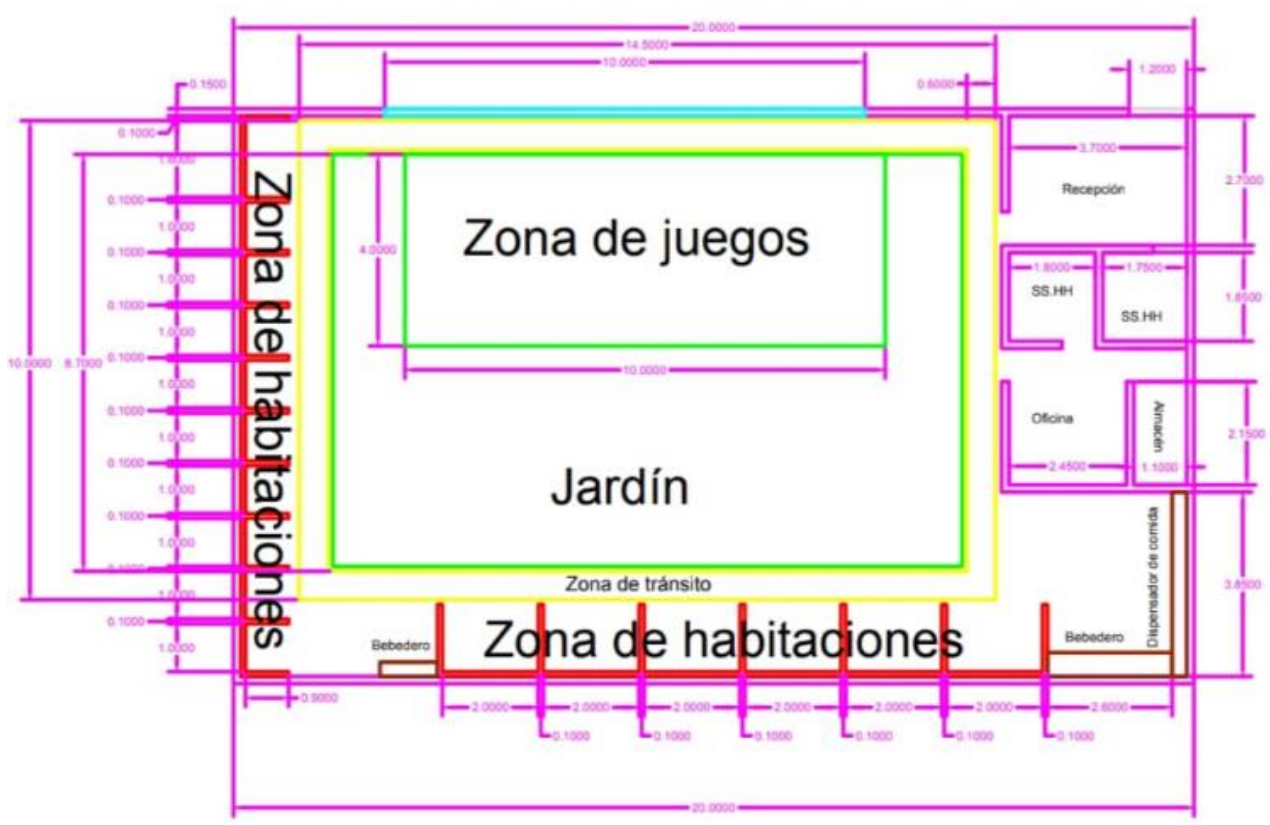

Elaboración propia 


\subsubsection{Equipos de trabajo y apoyos}

Como se menciona en la sección anterior, el Gerente General y los Especialistas en Marketing y en Administración y Finanzas, desarrollan sus labores fuera de oficina, bajo la modalidad de teletrabajo para el primer caso y como servicio de tercero en el caso de los especialistas, lo cual supone que la empresa no invertirá en equipos ni materiales para las labores administrativas.

En cuanto a la operación del negocio, es necesario contar con los siguientes equipos y materiales de apoyo:

- La oficina del supervisor de operaciones debe contar con un servidor (computadora), una silla y un escritorio, además de herramientas, como Office, que le facilite el ejercicio de sus funciones.

- Para el transporte de los canes se requiere un vehículo tipo furgoneta, el cual debe ser espacioso y acondicionado, pues ahí se trasladarán a los canes. Este debe tener una capacidad para 12 canes como máximo entre razas pequeñas, medianas y grandes. Para complementar el transporte se requiere 12 caniles de variados tamaños.

- Para el adiestramiento, paseo y juego de los perros se necesita contar con correas y juguetes para cada perro, materiales que se comprarán mensualmente pues son de uso personal para cada perro.

- El registro, reserva y monitoreo de las actividades de guardería y paseo, debe ser automatizado, además ello contribuye con la estrategia de la empresa de mantener una comunicación constante con los clientes con el fin de generar confianza. Al respecto, se implementará un sistema de monitoreo que consta de 4 cámaras, de las cuales una estará conectada al vehículo que traslada los canes, y las restantes distribuidas en espacios estratégicos en el local a fin de tener una visión completa de las actividades que realizan los perros. Estas cámaras estarán conectadas a un servidor de video y una aplicación para el monitoreo en línea.

- El App mencionado tiene entre sus funciones brindar información a los usuarios, reserva y agenda de citas, y monitoreo de actividades mediante GPS. 
○ Los clientes deberán ingresar al App y registrar sus datos y de sus mascotas, como raza, tamaño, gustos, salud, etc. asimismo podrá elegir y pagar por los servicios que desee para su perro. Para ello el App cuenta con la alternativa de pago vía tarjeta como Culqui, PayU, Visanet, etc.

○ Los clientes podrán una vez registrados, desde la comodidad de sus hogares, trabajo o donde se encuentren, ingresar con su usuario al App y solicitar una cita para el recojo y entrega de su mascota.

○ El App se conectará a las cámaras a través de su IP y podrá ser consultada en tiempo real por la empresa y por los clientes que se hayan registrado, es decir, el cliente puede conectarse desde su teléfono al App de Pet Fun y ver en tiempo real que están haciendo sus perros en el local o si han salido a pasear podrán saber dónde se encuentran, mediante un mapa, su cuidador asignado.

Estos mecanismos de comunicación no están actualmente implementados en ninguna guardería para perros, por lo que hace innovador el proyecto y genera confianza en los clientes. Asimismo, las funcionalidades que tiene el App, como registro de datos, reserva y notificación de horarios, conexión a cámara on-line, visualización de mapa por GPS, pasarela de pagos por tarjeta, son desarrolladas a medida por un ingeniero desarrollador (ver anexo 5).

De otro lado, se considera tener un convenio de alianza estratégica con una empresa veterinaria ubicada cerca del local, con el fin de tener una atención privilegiada y pronta ante alguna situación de emergencia ocasionada por un accidente de algunos de los canes en el momento en que se encuentre bajo el cuidado de la empresa, o por visitas de control preventivo autorizado por el dueño.

\subsubsection{Gestión de proveedores, compras y stock}

El producto principal de la empresa es el servicio de guardería y recreación para, en ese aspecto, la estrategia de planeamiento y operaciones de la empresa es "assemble to order" es decir que el proceso de operación para el cuidado de los canes ya se tiene planificado hasta que se realiza el contrato de servicio con el cliente. Sin embargo, en base a las 
características del perro, pueden hacerse ajustes a la rutina y cuidados de las mascotas, con el fin de atenderlos de manera personalizada, y eso solo se puede saber una vez realizado el contacto con el cliente. En la figura, la flecha marca el momento en que se empieza a utilizar recursos humanos y tiempo para concluir el servicio (delivery lead time).

\section{Figura 5.4}

Estrategia de planeamiento y operaciones de la empresa

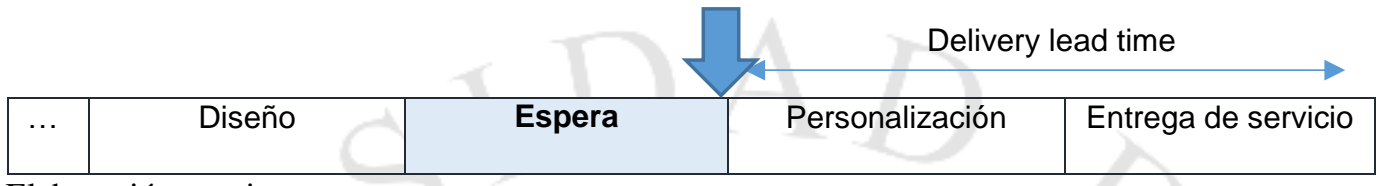

Elaboración propia

De otro lado, la venta de accesorios sigue la estrategia "Make to stock" ya que estos son comprados y almacenados hasta el momento de la compra.

Tanto los accesorios como los materiales para uso exclusivo del servicio (juguetes, platos de comida, otros) son conseguidos del proveedor que existan en el mercado, por ejemplo mesa redonda o supermercados, los cuales se entregarán y serán puesto en el almacén del local con al menos un mes de anticipación.

Es preferente que los proveedores compartan la misma estrategia competitiva de diferenciación, a fin de asegurar que cumpla con los niveles de calidad que ofrece a la empresa.

\subsubsection{Tercerización o integración de procesos}

Para la tercerización de procesos se establecieron como criterios el costo, la integración a los procesos misionales y la alineación a la misión y políticas de la empresa, ver anexo 3 . Según estos criterios, se estableció tercerizar los procesos:

- Marketing y planificación de ventas

- Gestión del conocimiento

- Gestión financiera 


\subsubsection{Proceso de prestación de servicios}

El principal proceso misional de la empresa es la atención a los perros, la cual incluye los siguientes pasos:

- El cliente debe descargar el App de Pet Fun que encontrará a través de la publicidad que haga la empresa o recomendaciones de familiares o amigos, luego debe registrarse para obtener un usuario y contraseña, al respecto debe ingresar sus datos personales y de su tarjeta de corresponder. Asimismo, ingresará información obligatoria sobre su(s) perros(as) como tamaño, raza, temperamento, alimentación, salud, y otros datos no obligatorios como preferencias de juegos, lugares preferidos, fecha de cumpleaños, etc.

- Posterior al registro, el cliente puede elegir el o los servicios que desee entre ellos la inscripción mensual para guardería, paseo por horas y compra de accesorios, y seguidamente elegir la fecha y rango de horas para el recojo de su perro. Luego de elegir el servicio y agenda, el cliente realiza el pago mediante tarjeta de crédito a través de una pasarela de pagos como Culqui, PayU y Visanet, o en efectivo en las instalaciones de la empresa.

- Una vez que el cliente complete la solicitud y pago del servicio, el supervisor de operaciones recibe una notificación y asigna, según disponibilidad, a un cuidador responsable del cuidado del can.

- El cuidador designado establece comunicación con el cliente, presentándose por su nombre de una manera cordial y confirma agenda para recoger al can. Asimismo, puede realizar preguntas adicionales sobre la mascota con el fin de brindar un servicio más personalizado. Con esto, el cuidado prepara el espacio que le asignará al perro y se dirige a recoger al can según horario establecido.

- Una vez que se recoge al can, el cuidador se asegura que el usuario se encuentre cómodo, mientras repite algunas indicaciones a la persona que lo entrega. El can sube a su canil dentro del vehículo y marchan a la empresa donde registra su ingreso y se le asignar un espacio cómodo donde estar. Desde el momento en que se recoge al can y llega al local, el cliente ya tiene acceso a las cámaras y GPS que le indican como se encuentra su engreído y que está haciendo, todo en tiempo real. 
- Las siguientes actividades depende el servicio que haya elegido el cliente, en el servicio de guardería, el cuidador a cargo de un grupo de perros establece turnos según la información de cada usuario y experiencia y criterio propios para que se alimenten, hidraten, jueguen, tomen sus descansos y sean adiestrados según lo requiera el cliente. Siempre se trata de dar la mayor libertad a los perros, pero también se busca educarlos y concientizar a sus dueños de la importancia y herramientas que se utilizan para el cuidado de sus mascotas.

- En el caso de los perros que solo tomen el paseo, al igual que los inscritos en la guardería, se les saca a pasear en grupo de 10 perros por cuidador, teniendo en consideración sus características, a un parque cercano, previa coordinación con los serenos de la zona. El tiempo de paseo no debe ser mayor a 4 horas, y se debe coordinar con los cuidadores dentro del local para que al momento que retorne el grupo del paseo, inmediatamente otro salga y así estén cómodos en el local y no se sature. Durante este tiempo los cuidadores deben permanecer atentos a cualquier comunicación de parte del supervisor de operaciones o del cliente. Terminada la jornada, se coordina el retorno del perro al hogar e informa al supervisor y cliente.

A continuación, se muestra un flujograma general de todo el proceso de atención del can. Asimismo, en el anexo 4 se describen los procesos estratégicos, misionales y de soporte mediante diagramas de flujo. 
Figura 5.5

Diagrama de flujo del proceso de atención de canes

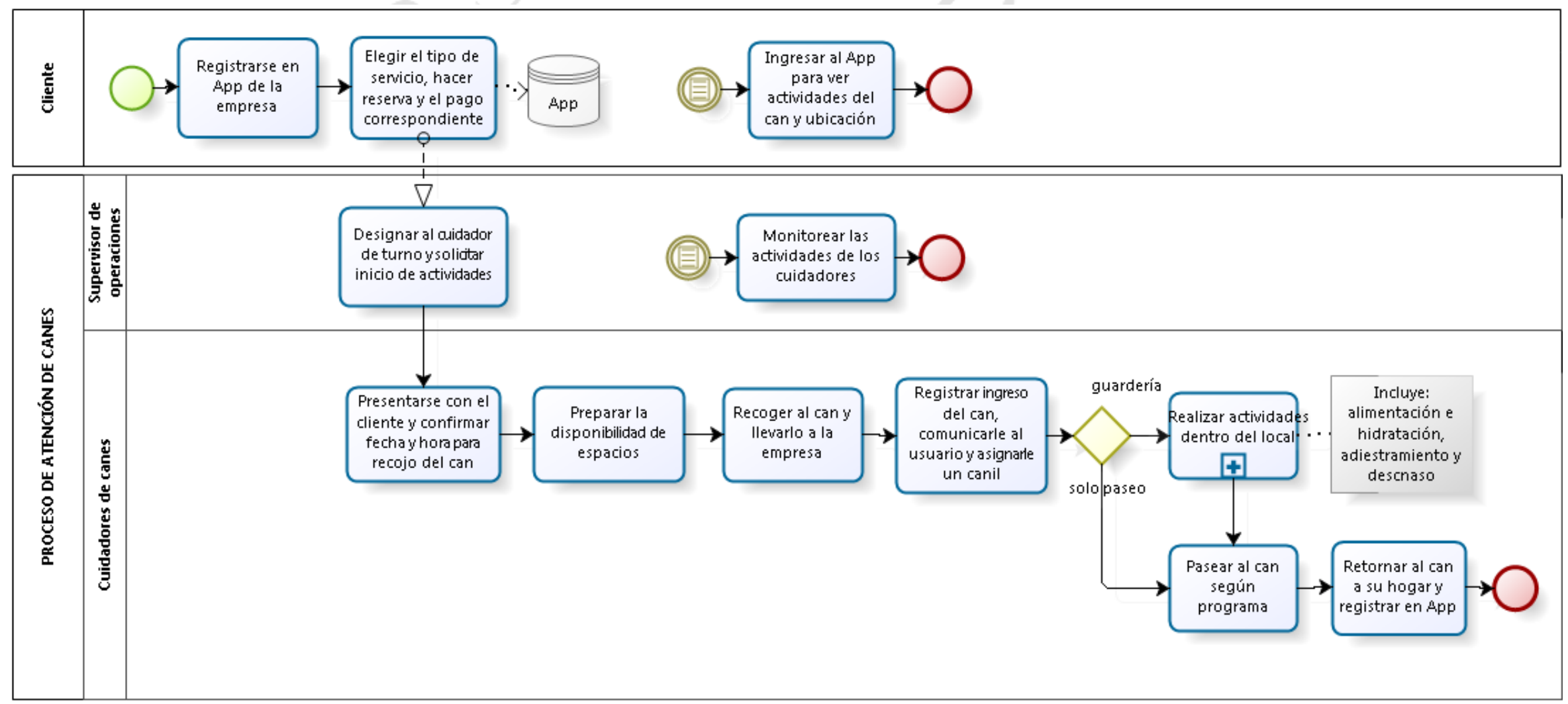

Elaboración propia 


\subsection{Plan de Operaciones}

Para la operación de la empresa se considera la capacidad instalada y plan de ventas, así como los costos fijos de planilla y local, y costos variables en materiales y compras. Adicionalmente el plan de operaciones considera las inversiones en activos tangibles como acondicionamiento de local, cámaras y App e intangibles como permiso municipal y patente. No se considera presupuesto de producción por ser un servicio. Las cotizaciones de local, vehículo y materiales se pueden ver en el anexo 5.

\section{Tabla 5.2}

Plan de operaciones de la empresa (en soles)

\begin{tabular}{lccccc}
\hline & Año 1 & Año 2 & Año 3 & Año 4 & Año 5 \\
\hline Costo de ventas & $\mathbf{1 8 8 , 1 6 8}$ & $\mathbf{2 5 3 , 4 8 7}$ & $\mathbf{2 5 3 , 4 5 8}$ & $\mathbf{2 5 3 , 4 5 8}$ & $\mathbf{2 5 3 , 4 5 8}$ \\
Personal & 89,424 & 153,514 & 153,514 & 153,514 & 153,514 \\
Materiales & 944 & 1,494 & 1,494 & 1,494 & 1,494 \\
Accesorios & 1,083 & 1,762 & 1,733 & 1,733 & 1,733 \\
Servicios & 80,772 & 80,772 & 80,772 & 80,772 & 80,772 \\
Depreciación de Activos & 15,944 & 15,944 & 15,944 & 15,944 & 15,944 \\
Tangibles & & & & \\
\hline
\end{tabular}




\section{CAPITULO VI: ESTRUCTURA ORGANIZACIONAL Y RECURSOS HUMANOS}

\subsection{Objetivos Organizacionales.}

\subsubsection{Naturaleza de la organización}

Según el modelo de organización de Derek F. Abell, todo modelo de negocio debe contemplar tres dimensiones: qué necesidad atiendo, cómo la atiendo y a quién atiendo (D. Abell, 1980). Al respecto, la empresa ha definido la naturaleza de su organización, la cual se redacta de esta forma:

"Buscamos generar seguridad y tranquilidad en nuestros clientes, personas que trabajan en Lima Moderna y nos confían el cuidado de sus perros. Para cumplir esto, ofrecemos un servicio personalizado de acuerdo con el perfil de su mascota, con modelos innovadores de servicios exclusivos de guardería para perros, a cargo de nuestros profesionales"

De otro lado, es importante definir la naturaleza jurídica de la empresa, ello a fin de operar y rendir cuentas a los organismos reguladores. Según la Superintendencia Nacional de Registros Públicos existen cinco grandes tipos de empresa: Sociedad Anónima, Sociedad Anónima Cerrada (con directorio), Sociedad Anónima Cerrada (sin directorio), Sociedad Comercial de Responsabilidad Limitada y Empresa Individual de Responsabilidad Limitada (SUNARP). Ver el resumen de tipos de empresas en el anexo 6.

El régimen jurídico de la empresa es Empresa Individual de Responsabilidad Limitada (E.I.R.L) y el principal motivo para esta decisión es que estas empresas cuentan con su propio capital en cuanto a deudas, quedando libre de responsabilidad del titular y su patrimonio personal. Asimismo, no es necesario contar con un socio para iniciar actividades. 


\subsubsection{Organigrama}

La organización de la empresa consta de un gerente general, el cual es el responsable legal y encargado de velar por la continuidad y éxito de la empresa. Dependen de él un supervisor de operaciones, un especialista en marketing y un especialista en administración y finanzas. Los dos especialistas serán contratados como servicios externos a la empresa, en cambio el supervisor de operaciones es el encargado de la operación de la empresa, y para esta función tiene a su cargo a cinco cuidadores de perros y un asistente de operaciones.

El organigrama de la empresa se ha elaborado en base a tres niveles de jerarquía y por cargos (I. Chiavenato, 1979).

Figura 6.1

Organigrama de la empresa

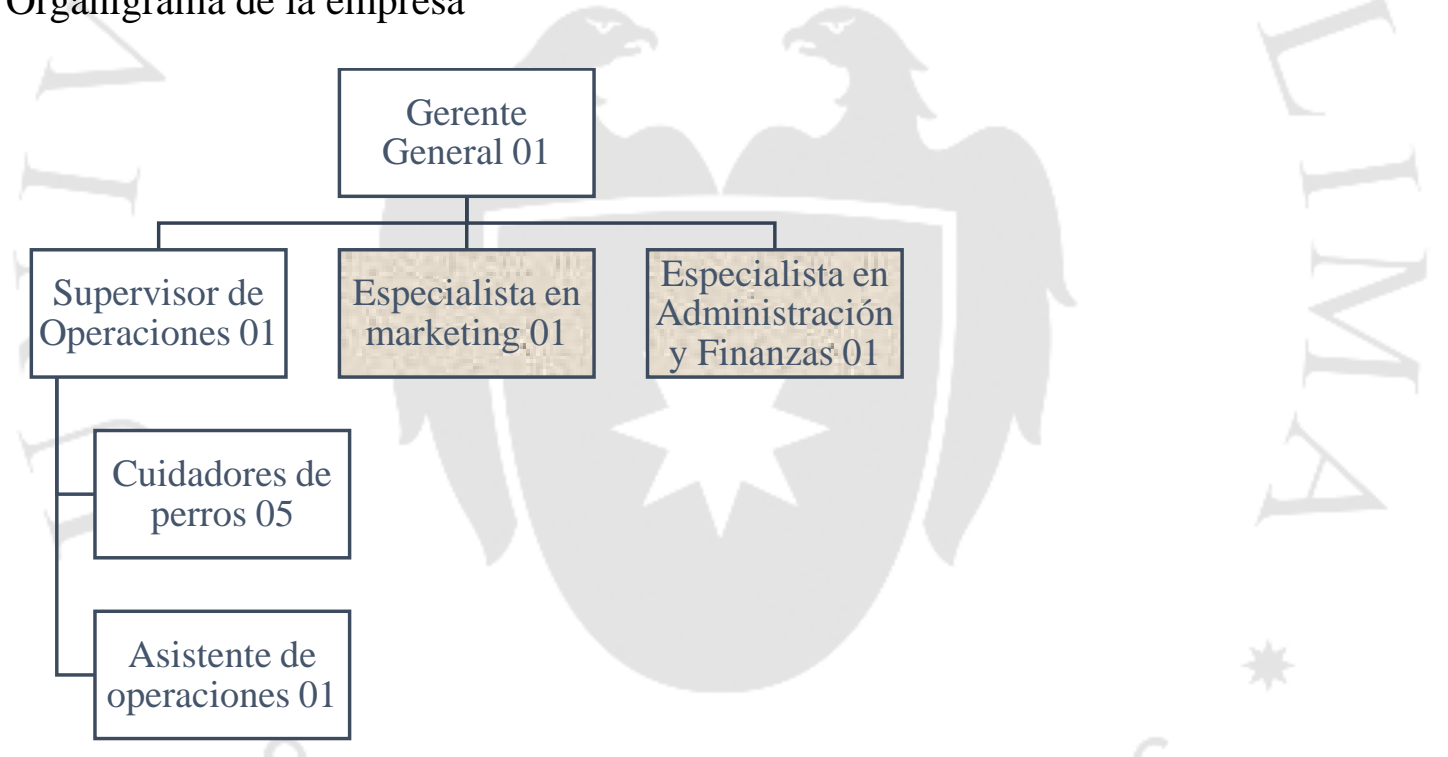

Elaboración propia

\subsubsection{Diseño estructural por proyectos}

En consecuencia con la estructura orgánica de la empresa, los puestos responden una estructura organizacional basada en las condiciones situacionales o del ambiente $(\mathrm{H}$. Mintzberg, 1979). En ese aspecto, la empresa divide la organización en estratégica, de línea media y de operaciones, con asesoramiento técnico y soporte. 
Figura 6.2

Organización de la empresa

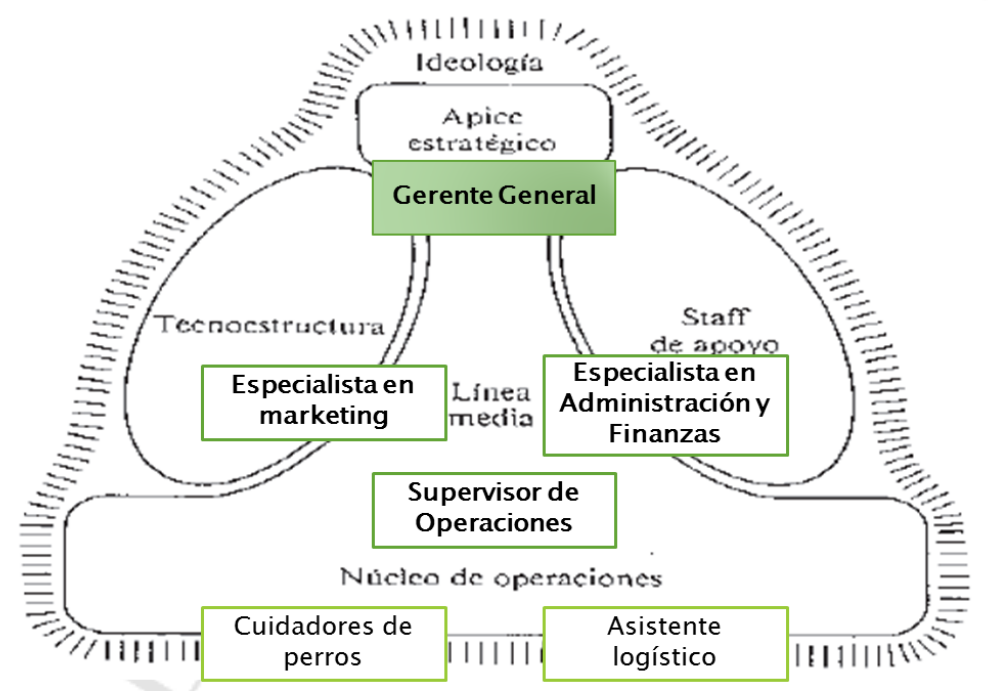

Fuente: H. Mintzberg, 1979

\subsection{Diseño de puestos y responsabilidades.}

El diseño de los perfiles de puestos está determinado en principio por los objetivos estratégicos de la empresa y por los procesos en los que participa el puesto. Al respecto, el puesto considera tres niveles según su jerarquía: Directivos (nivel 1), Servidores de carrera (nivel 2) y servidores de actividades complementarias (nivel 3) (SERVIR, 2016). Asimismo, en el cuadro, se resume el nivel de formación académica y años de experiencia requeridos para cada puesto.

\section{Tabla 6.1}

Relación de puestos de la empresa

\begin{tabular}{lcll}
\hline Puesto & Nivel & Formación & Experiencia \\
\hline Gerente General & 1 & Universitaria & 5 años \\
Supervisor de operaciones & 2 & Universitaria & 2 años \\
Cuidadores de perros & 2 & Secundaria & 1 año \\
Asistente de operaciones & 3 & Primaria & - \\
Especialista en marketing & tercero & Universitaria & 2 años \\
$\begin{array}{l}\text { Especialista en Administración y } \\
\text { Finanzas }\end{array}$ & \multirow{2}{*}{ tercero } & Universitaria & 2 años \\
\hline
\end{tabular}

Fuente: SERVIR 
En el anexo 7 se puede apreciar a más detalle los perfiles de puestos de la empresa, con información como nombre del puesto, nivel de jerarquía, dependencia funcional, misión y funciones, nivel de coordinación, formación académica, conocimientos, experiencia general y específica y competencias (SERVIR).

\subsection{Políticas organizacionales.}

La política organizacional de la empresa se rige por el principio de "si cuidas a tus empleados, ellos cuidaran de tu negocio" (R. Branson). Al respecto, se ha establecido los siguientes principios de organización y gestión de personas.

- La empresa vela por mantener un buen clima laboral y motivación de sus trabajadores, asimismo da oportunidades de crecimiento.

- La empresa reconoce y premia las buenas prácticas y desempeño de sus trabajadores a través de indicadores establecidos para dicho fin.

- La empresa capacitará al ingreso y anualmente a todos los trabajadores en temas innovadores sobre el cuidado de perros, así como en habilidades blandas y cultura organizacional.

\subsection{Gestión del talento.}

\subsubsection{Selección y contratación}

El proceso de selección, evaluación y contratación de nuevo personal que ingresa a la empresa es gestionado por el especialista en administración y finanzas, el cual es un servicio tercero que tiene estas actividades entre sus funciones y términos de referencia.

Al respecto, cabe mencionar que en las actividades de selección, evaluación y contratación participa el gerente general de la empresa, asimismo, en la evaluación también se considera la participación del cliente, según lo establecido en las políticas de servicio de la empresa. El detalle de las actividades se puede observar en los flujogramas en el anexo 4. 


\subsubsection{Remuneración y desempeño}

Para establecer un plan de remuneraciones y compensaciones económicas de la empresa, se ha establecido un rango salarial de acuerdo con información del mercado y en base a las entrevistas a dueños de guarderías y paseadores (ver anexo 1).

Asimismo, se ha tomado como modelo la Ley del Servicio Civil (Ley N 30057, 2013) y la Guía Metodológica para la Elaboración del Manual de Perfiles de Puestos (Directiva $\mathrm{N}^{\circ}$ 001-2016-SERVIR7GDSRH) que establece como criterios para la asignación de un salario, el nivel de proceso, nivel jerárquico del puesto y carrera por desempeño.

$\mathrm{Al}$ respecto, se tiene que el proceso estratégico tiene mayor calificación, seguido del proceso misional y del proceso de soporte. De otro lado, el nivel jerárquico 1 está asociado al gerente general y alta dirección, el nivel 2 está referido a jefes, supervisores o coordinadores y el nivel 3 se refiere a analistas y asistentes.

Finalmente, de la aplicación de los criterios antes descritos, y en base al régimen laboral de la micro y pequeña empresa (SUNAT), se obtiene una planilla anual de puestos de S/ 104594.40 elaborada según la Ley de Promoción y Formalización de la Micro y Pequeña Empresa - MYPE (Ley N ${ }^{\circ}$ 28015, 2003) el Régimen Privado de Trabajo (Decreto Legislativo $\mathrm{N}^{\circ} 728$ ). Los rangos salariales y sus criterios, así como el detalle de la planilla se pueden apreciar en el anexo 8.

\subsubsection{Empowerment y reconocimiento}

El empoderamiento no forma parte de una simple asignación de tareas y funciones, es sino una estructura de trabajo y una organización horizontal, basada en confianza y no en estructuras piramidales (F. Montaña, 2012). Este concepto forma parte de la cultura organizacional y políticas de la empresa, y puede ser empleado por los cuidadores una vez que estén listos y hayan tenido el coaching del supervisor de operaciones. No aplica para los servicios tercerizados.

El reconocimiento de la empresa es parte de la política organizacional y es en base a méritos o desempeño. Este es medido de acuerdo a indicadores cuantitativos, como el 
nivel de satisfacción del cliente o ventas globales de la empresa. La empresa ofrece como reconocimiento un mes de vacaciones remuneradas, además de unas felicitaciones públicas y formalizadas a través de una carta por parte del gerente general de la empresa.

\subsubsection{Capacitación, motivación y desarrollo}

El proceso de capacitación en la empresa se da al inicio de un contrato y anualmente, según lo planificado por el supervisor de operaciones y las necesidades que surjan en el cumplimento de sus funciones. En el anexo 4 se puede apreciar el flujograma con las principales actividades para la capacitación de los colaboradores.

De la misma manera, la empresa ofrece como parte del plan de desarrollo profesional, que los empleados actuales tengan preferencia para postular a un puesto de nivel 2 antes que un postulante externo. En cuanto a la motivación, esta está inmersa en la cultura organizacional de la empresa y se puede apreciar en la sección 3.4.

\subsection{Estructura de gastos de RRHH}

Conforme las políticas organizacionales, perfiles de puestos y rangos salariales, se han establecido un presupuesto de planilla, el cual incluye al personal de operaciones (cuidadores de perros, supervisor y asistente de operaciones), al Gerente General y al personal contratado como servicio tercerizado (marketing y administración finanzas). El primer año se tiene un promedio de 5 cuidadores pero a partir del año 2 se cuentan con 8 cuidadores, dado el incremento en la demanda de perros.

Como reconocimiento se considera medio sueldo mínimo y el presupuesto de capacitación es en base a la cantidad de personal de operaciones, lo cual suma a partir del segundo año un total de S/ 148,629 en personal, según la siguiente tabla. 
Tabla 6.2

Estructura de gastos de recursos humanos (en soles)

\begin{tabular}{lccccc}
\hline \multicolumn{1}{c}{ Gastos } & Año 1 & Año 2 & Año 3 & Año 4 & Año 5 \\
\hline Planilla & 146,064 & 210,154 & 210,154 & 210,154 & 210,154 \\
Reconocimiento & 465 & 465 & 465 & 465 & 465 \\
Capacitación & 2100 & 3000 & 3000 & 3000 & 3000 \\
Total & $\mathbf{1 4 8 , 6 2 9}$ & $\mathbf{2 1 3 , 6 1 9}$ & $\mathbf{2 1 3 , 6 1 9}$ & $\mathbf{2 1 3 , 6 1 9}$ & $\mathbf{2 1 3 , 6 1 9}$ \\
\hline
\end{tabular}

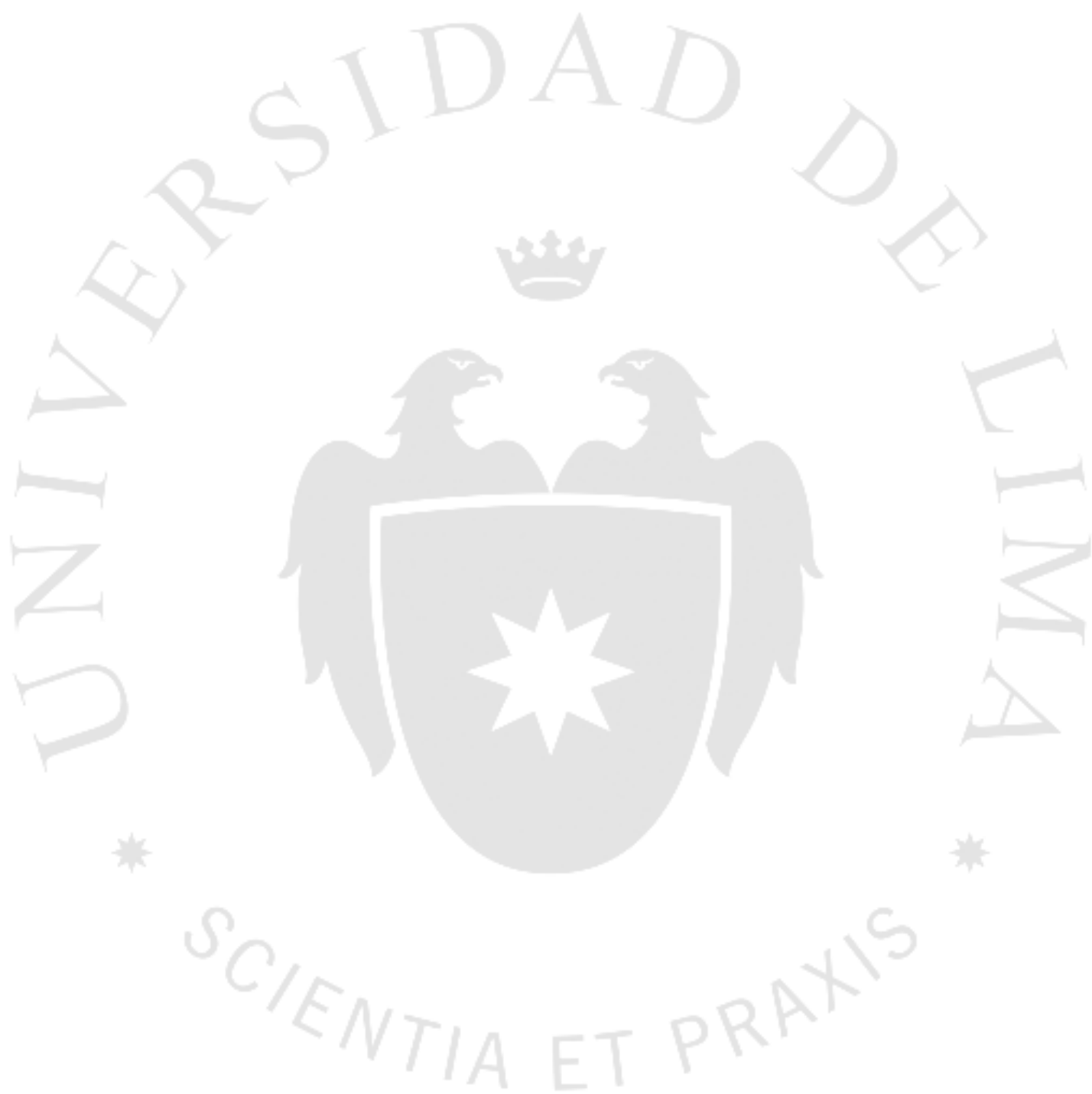




\section{CAPITULO VII: PLAN ECONÓMICO-FINANCIERO}

\subsection{Supuestos}

Para la puesta en marcha de una empresa es importante la confección de presupuestos pues permite cuantificar lo que va a ocurrir en el futuro, según el foro Todostartups (2016) la planificación estratégica tiene un horizonte temporal que suele ser de tres a cinco años.

El presente proyecto supone su desarrollo en un horizonte de 5 años, con una demanda que obedece al crecimiento de hogares con perros y a la posición de la marca, y en un precio inicial de 525 soles determinado por el valor que le asigna el cliente.

Al respecto, el plan económico financiero de la empresa ha sido elaborado en base a los presupuestos de recursos humanos, operativos, de ventas, compras, costos y gastos, así como presupuestos de inversión, financiamiento y capital de trabajo, los cuales se encuentran a detalle en cada capítulo y en el anexo 9.

\subsection{Plan de inversiones}

Todas las inversiones están directamente relacionadas a la operación de la empresa, las inversiones tangibles constan de un servidor (laptop), escritorio y silla para la oficina de operaciones y servirán de apoyo para las funciones del supervisor de operaciones. Los caniles se instalarán en el vehículo que servirá para el traslado de los canes inscritos.

Respecto al local, el arrendador solicita un mes en garantía, asimismo el acondicionamiento de espacios se hará antes de iniciar operaciones e incluyen, según lo acordado con el arrendador, la modificación de espacios, habilitación de tuberías, iluminación, instalación de cámaras de monitoreo, zona de descanso y alimentación de canes, así como espacios separados para algunos canes que lo requieran. El local deberá ser devuelto en óptimas condiciones y en la misma forma que se entregó, lo cual significará un costo adicional de acondicionamiento. En relación a las cámaras de monitoreo, estas se instalarán en espacios estratégicos y estarán conectadas las 24 horas, 
su costo incluye el equipo de vídeo e instalación, las mismas estarán conectadas a un App con GPS que permitirá el seguimiento de las actividades de los canes.

La empresa tramitará su licencia de funcionamiento ante la Municipalidad de Surco y se inscribirá la patente de marca "Pet fun" ante Indecopi. Asimismo, se invertirá en capital de trabajo que asegure la operación de la empresa, el cual incluye pago de planilla y servicios por al menos 15 días.

La empresa hará una inversión total de S/ 113,196 para iniciar sus operaciones.

Tabla 17

Presupuesto de inversión (en soles)

\begin{tabular}{|c|c|c|c|c|c|c|}
\hline & Año 0 & Año 1 & Año 2 & Año 3 & Año 4 & Año 5 \\
\hline Inversión Fija tangible & 102,832 & & & & & \\
\hline Inversión Fija Intangible & 828 & & & & & \\
\hline Inversión en KW & 9,536 & 2,722 & -1 & 0 & 0 & \\
\hline Inversión total & 113,196 & 2,722 & -1 & $\mathbf{0}$ & $\mathbf{0}$ & \\
\hline
\end{tabular}

\subsection{Activos y depreciación}

Los activos tangibles como equipos de oficina, cámaras, App y acondicionamiento tienen una vida útil de 5 años, al final del cual su valor residual contable será de 0 soles. La depreciación para los activos tangibles es de S/ 15,944 por año.

Tabla 7.1

Depreciación de activos tangibles (en soles)

\begin{tabular}{lccccc}
\hline & Año 1 & Año 2 & Año 3 & Año 4 & Año 5 \\
\hline Servidor & 169 & 169 & 169 & 169 & 169 \\
Escritorio y silla & 47 & 47 & 47 & 47 & 47 \\
Sistema de monitoreo & 169 & 169 & 169 & 169 & 169 \\
App de reservas y & 1,007 & 1,007 & 1,007 & 1,007 & 1,007 \\
seguimiento & 568 & 568 & 568 & 568 & 568 \\
Caniles & 13,983 & 13,983 & 13,983 & 13,983 & 13,983 \\
Acondicionamiento & $\mathbf{1 5 , 9 4 4}$ & $\mathbf{1 5 , 9 4 4}$ & $\mathbf{1 5 , 9 4 4}$ & $\mathbf{1 5 , 9 4 4}$ & $\mathbf{1 5 , 9 4 4}$ \\
Total & & & & & \\
\hline
\end{tabular}

En el mismo periodo se deprecian los activos intangibles a razón de S/ 166 anual, como se observa en la tabla. 
Tabla 7.2

Depreciación de activos intangibles (en soles)

\begin{tabular}{lccccc}
\hline & Año 1 & Año 2 & Año 3 & Año 4 & Año 5 \\
\hline Permiso municipal & 59 & 59 & 59 & 59 & 59 \\
Patentes & 107 & 107 & 107 & 107 & 107 \\
Total Dep Act Intang & $\mathbf{1 6 6}$ & $\mathbf{1 6 6}$ & $\mathbf{1 6 6}$ & $\mathbf{1 6 6}$ & $\mathbf{1 6 6}$ \\
\hline
\end{tabular}

\subsection{Capital de trabajo.}

El capital de trabajo se puede apreciar en la siguiente tabla, como instrumento de inversión, este tiene el fin de asegurar una caja mínima requerida para operar, la cual se vuelve constante a partir del segundo año, por tanto no habría inversión adicional más que la del año 0 y 1.

\section{Tabla 7.3}

Capital de trabajo (en soles)

\begin{tabular}{lcccccc}
\hline & Año 0 & Año 1 & Año 2 & Año 3 & Año 4 & Año 5 \\
\hline Caja Minima Operaciones & $7,176.0$ & $9,897.6$ & $9,896.4$ & $9,896.4$ & $9,896.4$ & 0.0 \\
Caja Minima Administrac & $2,360.0$ & $2,360.0$ & $2,360.0$ & $2,360.0$ & $2,360.0$ & 0.0 \\
Requerim en KW & $9,536.0$ & $12,257.6$ & $12,256.4$ & $12,256.4$ & $12,256.4$ & 0.0 \\
Inversión en KW & $\mathbf{1 1 3 , 1 9 6}$ & $\mathbf{2 , 7 2 2}$ & $\mathbf{- 1}$ & $\mathbf{-}$ & - & - \\
\hline
\end{tabular}

\subsection{Fuentes de financiamiento y amortización.}

Para financiar el monto de la inversión mencionada en la sección 7.2, fue necesario recurrir a la entidad financiera Interbank, la cual emitió una simulación de préstamo por el monto de S/ 88,550 (78.23\% del monto total de inversión, de acuerdo con la línea crediticia personal del accionista) con una tasa efectiva anual de $12.99 \%$ para ser pagado en 36 cuotas constantes (método francés) con 26 días de período de gracia. El cronograma detallado por meses se puede ver en el anexo 10. 
Tabla 7.4

Cronograma de financiamiento (en soles)

\begin{tabular}{lccrr}
\hline & Año 0 & Año 1 & Año 2 & Año 3 \\
\hline Saldo & 88,550 & 63,447 & 33,839 & - \\
Amortización & - & 25,103 & 29,608 & 33,839 \\
Intereses & - & 10,464 & 6,267 & 2,325 \\
Seguro desgr. & - & 767 & 459 & 170 \\
Cuota & - & 36,334 & 36,334 & 36,334 \\
Escudo tributario & - & 3,139 & 1,880 & 698 \\
\hline
\end{tabular}

\subsection{Estado de situación}

El estado de situación de la empresa, o balance general, es la fotografía de la empresa al 31 de diciembre de cada año. La empresa muestra un total de S/ 356,731 en activos al primer año, asimismo se tiene que los ingresos por efectivo representa un promedio el $88 \%$ del total de activos, información que puede apreciarse en el análisis horizontal y vertical en el anexo 11. 
Tabla 7.5

Estado de situación de la empresa (en soles)

\begin{tabular}{|c|c|c|c|c|c|c|}
\hline & Año 0 & Año 1 & Año 2 & Año 3 & Año 4 & Año 5 \\
\hline Efectivo (incluido IGV) & 9,536 & 266,415 & 450,053 & 465,355 & 481,177 & 497,537 \\
\hline Inventarios & & 43 & 72 & 72 & 72 & 72 \\
\hline Activo corriente & 9,536 & 266,459 & 450,125 & 465,427 & 481,249 & 497,609 \\
\hline Activo fijo neto tangible & 102,832 & 86,888 & 70,944 & 55,000 & 39,056 & 23,112 \\
\hline Cambio de KW & & 2,722 & - & 1 & - & - \\
\hline Activo fijo neto intangible & 828 & 662 & 497 & 331 & 166 & - \\
\hline Activo no corriente & 103,660 & 90,272 & 71,439 & 55,331 & 39,221 & 23,112 \\
\hline TOTAL ACTIVOS & 113,196 & 356,731 & 521,565 & 520,758 & 520,470 & 520,721 \\
\hline Pasivo financiero & 88,550 & 62,556 & 33,186 & - & - & - \\
\hline Impuestos por Pagar & - & 769 & 38,290 & 45,179 & 51,274 & 56,182 \\
\hline Otras cuentas por pagar & & 260,358 & 323,453 & 241,953 & 115,931 & 19,818 \\
\hline Pasivo & $\mathbf{8 8 , 5 5 0}$ & 323,683 & 394,929 & 287,131 & 167,205 & 36,364 \\
\hline Capital social & 24,646 & 24,646 & 24,646 & 24,646 & 24,646 & 24,646 \\
\hline Utilidades acumuladas & & 8,402 & 101,990 & 208,980 & 328,620 & 459,711 \\
\hline Patrimonio & 24,646 & 33,048 & 126,636 & 233,626 & 353,266 & 484,357 \\
\hline $\begin{array}{l}\text { TOTAL PASIVO + } \\
\text { PATRIMONIO }\end{array}$ & 113,196 & 356,731 & 521,565 & 520,758 & 520,470 & 520,721 \\
\hline
\end{tabular}




\section{7 $\quad$ Estado de resultados}

El estado de resultados o de ganancias y pérdidas, muestra las ventas, costo de ventas, gastos operativos y financieros e impuestos que determinan finalmente la utilidad neta de la empresa, la cual es a S/ 8,402 el primer año y llega hasta S/ 131,091 al final del proyecto en el año 5. Asimismo, la utilidad antes de impuestos (EBIT) se incrementa en un promedio de $12 \%$ desde el año 2 que se consigue operar al total de capacidad instalada, detalle que se puede verificar en el análisis horizontal y vertical en el anexo 12.

Tabla 7.6

Estado de resultados de la empresa (en soles)

\begin{tabular}{lrrrrr}
\hline & \multicolumn{1}{c}{ Año 1 } & \multicolumn{1}{c}{ Año 2 } & \multicolumn{1}{c}{ Año 3 } & \multicolumn{1}{c}{ Año 4 } & \multicolumn{1}{c}{ Año 5 } \\
\hline Ventas & $266,415.3$ & $450,052.9$ & $465,354.7$ & $481,176.7$ & $497,536.7$ \\
Costo de ventas & $172,223.9$ & $237,542.6$ & $237,513.7$ & $237,513.7$ & $237,513.7$ \\
Utilidad Bruta & $\mathbf{9 4 , 1 9 1 . 4}$ & $\mathbf{2 1 2 , 5 1 0 . 3}$ & $\mathbf{2 2 7 , 8 4 0 . 9}$ & $\mathbf{2 4 3 , 6 6 3 . 0}$ & $\mathbf{2 6 0 , 0 2 3 . 0}$ \\
Gastos Operativos & $56,640.0$ & $56,640.0$ & $56,640.0$ & $56,640.0$ & $56,640.0$ \\
Utilidad Operativa & $\mathbf{3 7 , 5 5 1 . 4}$ & $\mathbf{1 5 5 , 8 7 0 . 3}$ & $\mathbf{1 7 1 , 2 0 0 . 9}$ & $\mathbf{1 8 7 , 0 2 3 . 0}$ & $\mathbf{2 0 3 , 3 8 3 . 0}$ \\
Depreciación & $15,944.1$ & $15,944.1$ & $15,944.1$ & $15,944.1$ & $15,944.1$ \\
Amortización & 165.6 & 165.6 & 165.6 & 165.6 & 165.6 \\
UAII & $\mathbf{2 1 , 4 4 1 . 7}$ & $\mathbf{1 3 9 , 7 6 0 . 6}$ & $\mathbf{1 5 5 , 0 9 1 . 3}$ & $\mathbf{1 7 0 , 9 1 3 . 3}$ & $\mathbf{1 8 7 , 2 7 3 . 3}$ \\
Intereses & $9,439.5$ & $6,062.9$ & $2,247.7$ & & \\
UAI (EBIT) & $\mathbf{1 2 , 0 0 2 . 2}$ & $\mathbf{1 3 3 , 6 9 7 . 7}$ & $\mathbf{1 5 2 , 8 4 3 . 6}$ & $\mathbf{1 7 0 , 9 1 3 . 3}$ & $\mathbf{1 8 7 , 2 7 3 . 3}$ \\
Impuestos & $3,600.7$ & $40,109.3$ & $45,853.1$ & $51,274.0$ & $56,182.0$ \\
Utilidad Neta & $\mathbf{8 , 4 0 2}$ & $\mathbf{9 3 , 5 8 8}$ & $\mathbf{1 0 6 , 9 9 0}$ & $\mathbf{1 1 9 , 6 3 9}$ & $\mathbf{1 3 1 , 0 9 1}$ \\
\hline
\end{tabular}

De otro lado, la política de aplicación de resultados de la empresa es que todas las utilidades se reinviertan en la empresa.

\subsection{Proyección de ventas y Flujo de Caja Libre (Free Cash flow).}

La empresa genera flujos de ingresos por suscripción mensual, servicio de paseo y venta de accesorios. A estos ingresos se le descuentas los egresos operativos y depreciación para hallar el flujo económico de la empresa. Adicionalmente, si se le agrega el flujo financiero originado por el préstamo, se obtiene el flujo de caja financiero, conforme se aprecia en el cuadro. 
Tabla 7.7

Flujo de caja libre económico y financiero (en soles)

\begin{tabular}{|c|c|c|c|c|c|c|}
\hline & Año 0 & Año 1 & Año 2 & Año 3 & Año 4 & Año 5 \\
\hline Ingresos & 0 & 266,415 & 450,053 & 465,355 & 481,177 & 497,537 \\
\hline Inversión & 113,196 & 0 & 0 & 0 & 0 & 0 \\
\hline Cambio en KL & 0 & 2,722 & -1 & 0 & 0 & 0 \\
\hline Costo de ventas & 0 & 172,224 & 237,543 & 237,514 & 237,514 & 237,514 \\
\hline Gastos operativos & 0 & 56,640 & 56,640 & 56,640 & 56,640 & 56,640 \\
\hline IGV por pagar & 0 & 32,145 & 65,528 & 68,869 & 72,059 & 75,004 \\
\hline IR por pagar & 0 & 769 & 38,290 & 45,179 & 51,274 & 56,182 \\
\hline Liquidación & 0 & 0 & 0 & 0 & 0 & 21,018 \\
\hline FLUJO ECONOMICO & - 113,196 & 1,916 & 52,053 & 57,154 & 63,690 & 93,215 \\
\hline FINANCIAMIENTO & $-88,550$ & 32,602 & 33,615 & 34,759 & & \\
\hline FLUJO FINANCIERO & 24,646 & 30,686 & 18,439 & 22,395 & 63,690 & 93,215 \\
\hline
\end{tabular}

\subsection{Análisis de viabilidad y rentabilidad financiera.}

Para analizar si el proyecto de factible, se debe evaluar su viabilidad comercial, técnica y económica. Para evaluar la viabilidad económica-financiera se pueden utilizar herramientas como el Valor Actual Neto (VAN) y la Tasa Interna de Retorno (TIR), las cuales se relacionan directamente con el flujo de caja para calcular cuánto un negocio tarda en recuperar su inversión (Besley \& Brigham, 2008).

Al respecto, el VAN económico de la empresa es S/ 57,861.46 y su TIR económico es $27 \%$, cifras que varían cuando se agrega el componente de financiamiento, obteniendo un VAN financiero de S/ 81,039.71 y TIR financiero de 44\%. Al respecto, se deduce que el proyecto de empresa es rentable toda vez que su valor presente neto es positivo, su tasa de retorno de la inversión es mayor al costo de oportunidad (COOK), el tiempo de recupero de la inversión es de 3.23 años y el beneficio generado por la empresa es 6.78 veces mayor al costo.

\subsection{Tasa de descuento del accionista.}

La tasa de descuento o rendimiento que exige un accionista a un proyecto está en función directa a su riesgo, para ello es necesario hallar las tasas COK y el WACC para descontar a los flujos de caja libre económico y financiero y determinar la rentabilidad del proyecto (P. Briceño, 2012). 
El costo de oportunidad del inversionista $(\mathrm{COK})$ es de $13 \%$, para obtener esta cifra se utiliza la fórmula " $\mathrm{COK}=\mathrm{Lr}+\beta(\mathrm{Rm}-\mathrm{Lr})$ " donde $\mathrm{Lr}$ es la tasa libre de riesgo que a setiembre 2018 fue de $4.28 \%$ según lo comunicado por el Banco Central de Reserva del Perú (BCRP, 2018), (Rm-Lr) es la prima de riesgo donde es importante conocer el rendimiento de mercado, en este caso del rubro comercio que es $11.65 \%$ según el Índice General de la Bolsa de Valores de Lima (IGBVL), y finalmente beta $(\beta)$ es indicador de sensibilidad de la empresa frente al mercado el cual es 1.20.

Es preciso señalar que para hallar beta se tomó como referencia el promedio de betas ( $\sin$ deuda) de otras empresas de mascotas similares que cotizan en la Bolsa de Valores de Nueva York (NYSE), como PetMed Express Inc. empresa dedicada a la venta on-line de medicinas para mascotas, Trupanion Inc. Dedicado al negocio de seguros médicos y otros para mascotas, e Idexx Laboratories Inc. que vende variedad de productos y servicios exclusivos para mascotas.

De otro lado, el costo promedio ponderado de capital (WACC) tiene en cuenta tanto el nivel de fondos propios de la empresa (E\%) y su coste $(\mathrm{COK})$, como el nivel de endeudamiento $(\mathrm{D} \%)$ y su coste financiero $(\mathrm{Kd})$, así como la tasa impositiva que debe afrontar la empresa (T) que es de 30\%. Al respecto, de la aplicación de la fórmula "WACC $=\operatorname{Kd}(1-\mathrm{T})(\mathrm{D} \%)+\mathrm{COK}(\mathrm{E} \%)$ " se obtiene una tasa de $10 \%$.

\subsection{Indicadores de rentabilidad y otros ratios representativos}

La rentabilidad de la empresa sobre las ventas es $3 \%$ y llega a $26 \%$ el quinto año, la rentabilidad sobre los activos (ROA) llega a $25 \%$ y la rentabilidad sobre el patrimonio (ROE) llega a $37 \%$.

Asimismo, se puede mencionar que la empresa es líquida a razón de 4.26, y que tiene una solvencia deuda/activo de 0.78 , lo cual quiere decir que la inversión es significativa. En la siguiente tabla se pueden apreciar otros ratios por año, y en el anexo 13 se realiza el análisis Dupont de la empresa. 
Tabla 7.8

Ratios financieros

\begin{tabular}{lccccc}
\hline & Año 1 & Año 2 & Año 3 & Año 4 & Año 5 \\
\hline $\begin{array}{l}\text { Ratios de Liquidez } \\
\text { Liquidez corriente }\end{array}$ & 4.26 & & & & \\
Ratios de Solvencia & & & & & \\
Endeudamiento patrimonial & 3.59 & 9.81 & 3.03 & 1.06 & 0.28 \\
Razón deuda/activo & 0.78 & 0.91 & 0.74 & 0.48 & 0.19 \\
Cobertura de intereses & 2.98 & 24.71 & & & \\
Ratios de Rentabilidad & & & & & \\
Rentabilidad sobre ventas & 0.03 & 0.21 & 0.23 & 0.25 & 0.26 \\
Rentabilidad sobre patrimonio & 0.34 & 2.83 & 0.84 & 0.51 & 0.37 \\
Rentabilidad sobre activos & 0.07 & 0.26 & 0.21 & 0.23 & 0.25 \\
\hline
\end{tabular}

\subsection{Análisis de riesgo y escenarios}

En la evaluación de un proyecto de inversión, el riesgo es un factor común y está atribuido a la probabilidad de ocurrencia de situaciones que afecten el desarrollo normal de las actividades de una empresa e impidan el logro de su misión y visión. Esta variabilidad de los beneficios esperados por los inversionistas es planteada a través de escenarios normales, pesimistas y optimistas (N. Sapag, 2007).

Para plantear los escenarios se ha tomado como variables la distorsión en la demanda de los servicios para perros y la remuneración mínima en el Perú. En el escenario pesimista se ha considerado que la remuneración mínima en el Perú aumente de $\mathrm{S} / 930$ a S/1,000. Al respecto, eso conllevaría a que los costos variables en planilla aumenten $7.5 \%$ consiguiendo un nuevo VANe de S/ 37,121.64 y un nuevo TIRe de $22 \%$. En este escenario el proyecto aún es económicamente viable (TIR>COK).

De otro lado, en el escenario optimista se ha considerado que la entrada de grandes competidores extranjeros, tenga un efecto en los ingresos del sector incrementándose el precio de los servicios relacionados hasta en 5\% anual, como el caso del sector mascotas en un país referente como es España (Gómez F., 2018), consiguiendo un nuevo VANe de S/ $145,867.32$ y un nuevo TIRe de $46 \%$.

Los escenarios y sus resultados se muestran en el anexo 14. 


\section{CONCLUSIONES}

- La empresa "Pet fun" es una guardería para perros con un enfoque innovador donde se busca brindar una atención personalizada y de calidad al perro y generar un alto nivel de confianza en sus dueños mientras trabajan, está dirigida a personas del nivel socio económico A y B, que tienen perros, trabajan en Lima Moderna y tienen la necesidad de dejar a sus mascotas en un lugar donde sean muy bien cuidadas.

- Según las encuestas realizadas al público objetivo, al menos el 65\% de las personas encuestadas, cuyo perfil es de NSE A y B dueñas de perros en Lima Moderna, están interesadas en el modelo de negocio innovador de guardería para perros", lo cual hace comercialmente viable el proyecto de empresa.

- Según la investigación de mercado realizada, existen las técnicas y metodologías de cuidado y adiestramiento de perros, así como el personal idóneo y veterinarias, que hacen técnicamente viable el proyecto de empresa.

- El proyecto de empresa es económica y financieramente viable, siendo el VANe S/ 106,333.78 y el TIRe de $37 \%$ mayor al COK de 13\%, asimismo, su VANf es de S/ $134,506.29$ y el TIRf de $64 \%$ mayor al WACC de $10 \%$.

- De acuerdo a las conclusiones previas, es factible implementar un modelo de negocio innovador de guardería para perros en Lima Metropolitana. 


\section{RECOMENDACIONES}

- Se recomienda explorar la alternativa de contratación de una póliza de seguros de responsabilidad civil que cubra eventos que causen daños a las mascotas y a terceros en el local donde se les atenderá y en exteriores, dentro del tiempo que estén bajo el cuidado del establecimiento. Asimismo, se sugiere al propietario que tenga una cobertura de este tipo a fin de trasladar el riesgo parcialmente.

- Cuando el servicio de guardería alcance su madurez, o incluso antes, se recomienda evaluar la extensión de marca a otros productos que demuestran viabilidad comercial y financiera, como por ejemplo alimento para perros y servicio relacionados a viajes o paseos para personas con mascotas, a fin de posicionar más la marca "Pet fun". 


\section{REFERENCIAS}

Abell, D. (1980). Defining the Business: Starting Point of Strategic Planning. México D.F.: Prentice Hall.

Alko - Estimulación canina. Sitio web. Recuperado de https://www.facebook.com/SomosAlko/

Asociación Peruana de Protección a los Animales. Sitio web. Recuperado de http://www.asppa-peru.org/acerca-de-nosotros/

Barciela, F. (19 de enero de 2018). Cuidadores de mascotas en cadena. El País. Recuperado de https://elpais.com/economia/2018/01/19/actualidad/1516374368_170287.html

Besley, S. y Brigham, E. (2008) Fundamentos de Administración Financiera (14a ed.). México D.F.: Cengage Learning.

Blanco, J. (24 de abril de 2018). Tecnología bestial: del mando a distancia para perros a la Kinect para orangutanes. Eldiario.es. Recuperado de https://www.eldiario.es/hojaderouter/tecnologia/Tecnologia-bestial-distanciaKinect-orangutanes_0_764323675.html

Briceño, P. (09 de enero de 2012). Determinando la tasa de descuento de un proyecto (parte 1). Gestión. Recuperado de https://gestion.pe/blog/deregresoalobasico/2012/01/determinando-la-tasa-dedescue.html

Caro, S. (29 de mayo de 2017). Claves para un buen paseo con tu perro [Mensaje en un blog]. Recuperado de https://toppercan.es/guarderia-perros/\#comment-2477

Caro, S. (29 de mayo de 2017). Guardería para perros [Mensaje en un blog]. Recuperado de https://toppercan.es/guarderia-perros/\#comment-2477

Chiavenato, I. (1979). Administración de recursos humanos: El capital humano de las organizaciones (8a ed.). México D.F.: McGraw-Hill Interamericana.

¿Cómo constituir una Empresa Individual de Responsabilidad Limitada? (19 de noviembre de 2017). Gestión. Recuperado de https://gestion.pe/economia/constituir-empresa-individual-responsabilidadlimitada-150711 
Conoce cuánto cuesta el metro cuadrado en cada distrito de Lima. (05 de agosto de 2018). Publimetro. Recuperado de https://publimetro.pe/actualidad/noticia-conocecuanto-cuesta-metro-cuadrado-cada-distrito-lima-71309

Constitución Política del Perú. (30 de diciembre de 1993). Recuperado del sitio de internet del Portal Digital Único del Estado - Gob.pe https://www.gob.pe/institucion/presidencia/informes-publicaciones/196158constitucion-politica-del-peru.

Cruz Trejo E. A. (2008). Análisis de riesgo en proyectos de inversión. Universidad Tecnológica de Pereira. Recuperado de file:///C:/Users/Joseph/Downloads/DialnetAnalisisDeRiesgoEnProyectosDeInversionUnCasoDeEstu-4749607.pdf

Decreto Supremo N. ${ }^{\circ}$ 006-2002-SA, Aprueban Reglamento de la Ley que regula el Régimen Jurídico de Canes. (22 de junio de 2002). Diario El Peruano.

Decreto Supremo N. ${ }^{\circ}$ 002-97-TR, Texto Único Ordenado del Decreto Legislativo No 728 , Ley de Formación y Promoción Laboral. (21 de marzo de 1997). Diario El Peruano.

Escuela Canina Vip Dog Training. Sitio web. Recuperado de http://www.adiestramientocaninolima.com/index.html

FIDO: la tecnología que hace hablar a los perros y ayuda a los humanos (19 de noviembre de 2014). Sr.perro.com. Recuperado de https://www.srperro.com/blog_perro/fido-la-tecnologia-que-hace-hablar-a-losperros-y-ayuda-a-los-humanos

Fisher, R. y Ury, W. (1981) Getting to Yes: Negotiating Agreement Without Giving In. Nueva York: Penguin Books.

Fuciu, M. y Dumitrescu, L. (2018). From Marketing 1.0 To Marketing 4.0 - The Evolution of the Marketing Concept in the Context of the 21ST Century. International conference KNOWLEDGE-BASED ORGANIZATION. doi:10.1016/j.procs.2014.08.053

García, M. (14 de mayo de 2018). ¿Qué sienten los perros cuando les dejas solos en casa? [Mensaje en un blog]. Recuperado de https://www.expertoanimal.com/quesienten-los-perros-cuando-les-dejas-solos-en-casa-21921.html

Gómez, F. (14 de junio de 2018). El sector de las mascotas no frena su crecimiento desde 2007. Forbes. Recuperado de http://forbes.es/emprendedores/43847/el-sector-delas-mascotas-no-frena-su-crecimiento-desde-2007/

Inga, C. (07 de noviembre de 2016). Cuánto gastan los peruanos en sus mascotas y en qué. El Comercio. Recuperado de https://elcomercio.pe/economia/dia-1/gastanperuanos-mascotas-146999 
Ipsos Perú. (2016). Mascotas 2016. Lima: Ipsos Perú.

Jarque, J. (22 de noviembre de 2013). El vínculo afectivo con los animales. La Vanguardia. Recuperado de https://www.lavanguardia.com/estilos-devida/20131122/54393704768/el-vinculo-afectivo-con-los-animales.html

Ley N. ${ }^{\circ}$ 30057, Ley del Servicio Civil. (03 de julio de 2013). Diario El Peruano.

Ley N. ${ }^{\circ}$ 28015, Ley de Promoción y Formalización de la Micro y Pequeña Empresa. (03 de julio de 2003). Diario El Peruano.

Ley N. ${ }^{\circ}$ 27972, Ley Orgánica de Municipalidades. (17 de marzo de 1981). Diario El Peruano.

Osterwalder, A. y Pigneur, Y. (2011) Generación de modelos de negocio (19a ed.). Coruña: Deusto S.A. Ediciones.

Pryor, K. (2009) ¡No lo mates... enséñale!: el arte de enseñar y adiestrar: moldeado, reforzamiento positivo y técnicas de modificación de la conducta (4a ed.). Coruña: Kns ediciones.

Kuhr, M. (1965) Senator George Graham Vest and the 'Menace' of Mormonism, 18821887. Missouri Historical Review 65.

Licencias de funcionamiento: ¿Dónde es más caro y más barato para poner un negocio? (01 de setiembre de 2016). Gestión. Recuperado de https://gestion.pe/tudinero/licencias-funcionamiento-caro-barato-poner-negocio-147510

Mintzberg H. (1979). Estructure in 5's: A Synthesis of the Research on Organization Design. The Institute of Management Sciencies. Recuperado de https://www.ics.uci.edu/ corps/phaseii/Mintzberg-StructureIn5s-MgmtSci.pdf

Montaña, R. F. (2012) El empoderamiento como herramienta de desarrollo del talento humano en las organizaciones. (Tesis de Especialización). Universidad EAN, Bogotá.

https://repository.ean.edu.co/bitstream/handle/10882/1986/MontanaFreddy2012. pdf? sequence $=1 \&$ is Allowed $=\mathrm{y}$

Perro doméstico (05 de septiembre de 2010). National Geographic. Recuperado de https://www.nationalgeographic.es/animales/perro-domestico

Peruanos ya gastan hasta $\mathrm{S} / 3,000$ al mes en ropa y accesorios para mascotas (28 de diciembre de 2016). Gestión. Recuperado de https://gestion.pe/economia/empresas/peruanos-gastan-s-3-000-mes-ropaaccesorios-mascotas-149685

Resolución de Presidencia Ejecutiva N. ${ }^{\circ}$ 052-2016-SERVIR-PE, Aprueban la Directiva N 001-2016-SERVIR/GDSRH "Normas para la Gestión del Proceso de Diseño 
de Puestos y Formulación del Manual de Perfiles de Puestos - MPP”. (21 de marzo de 2016). Diario El Peruano.

Sapag, N. (2007) Proyectos de Inversión. Formulación y evaluación. México D.F.: Prentice Hall.

Vet Place. Hospedaje. Recuperado de http://www.hospedajeparaperros.com/

Wau - Hospedaje para perros. Sitio web. Recuperado de http://www.hospedajeparaperros.com/ 


\section{BIBLIOGRAFÍA}

Carrión, A. (08 de marzo de 2018). Alojamiento en hogares y libre de rejas suma adeptos. El Comercio. Recuperado de https://elcomercio.pe/wuf/noticias/alojamientohogares-libre-rejas-suma-adeptos-noticia-502730

Cotillo Yafac, L., Gálvez Romero, L., y Mamani Ramírez, G. (2017). Plan de negocios para la implementación de una empresa "club integral para canes" dedicada a prestar servicios de cuidado, educación y recreación para perros (Tesis de maestría).

2_09_T.pdf?sequence $=1 \&$ isAllowed $=\mathrm{y}$

Gutiérrez, P. (27 de mayo de 2013). Una guardería para perros. Publimetro. Recuperado de https://publimetro.pe/actualidad/noticia-guarderia-perros-13993 


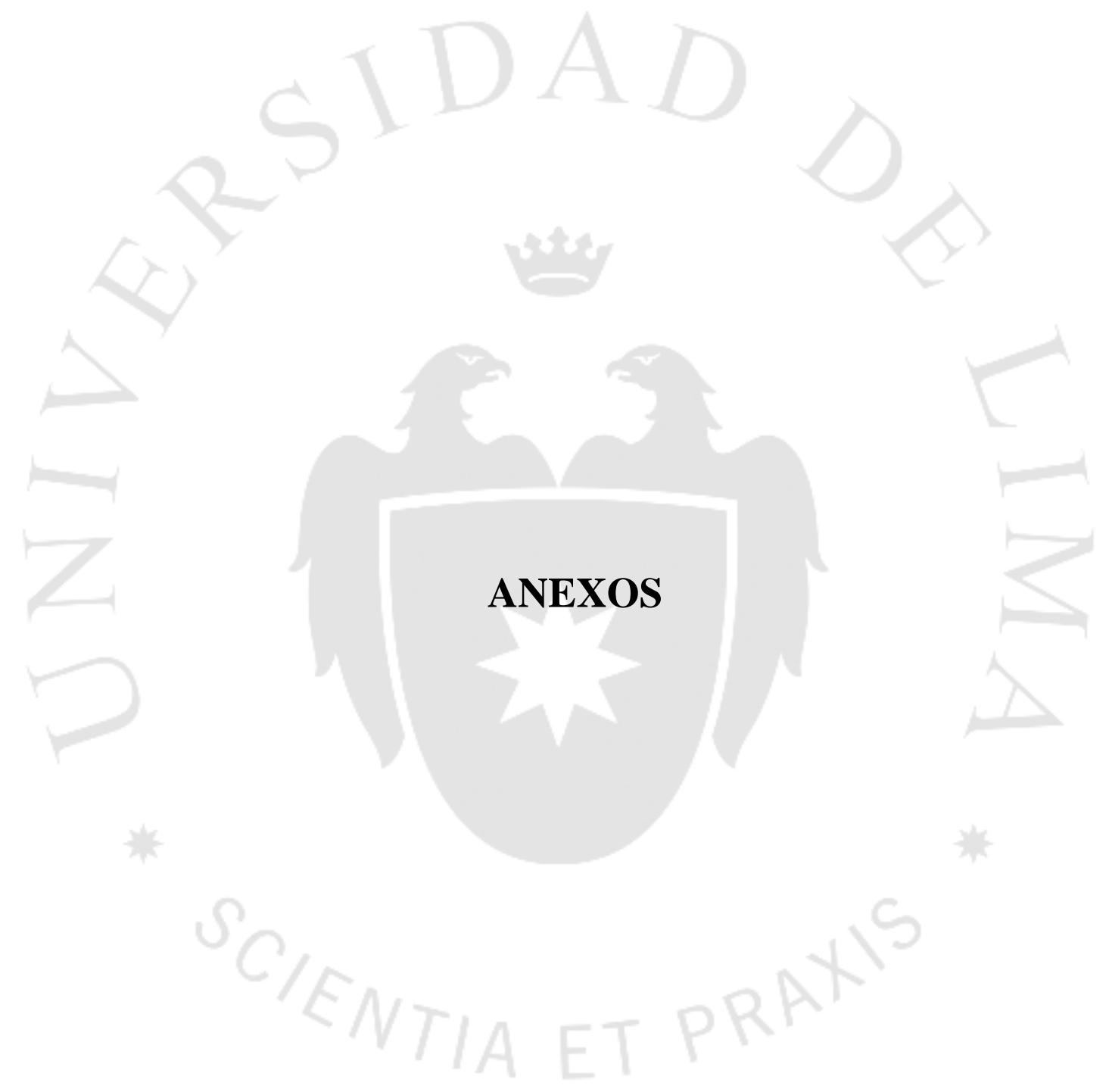




\section{Anexo 1: Entrevistas}

\section{Formato de entrevista}

\section{Entrevista a stakeholders sobre la implementación de guardería para mascotas}

Este formulario tiene el objetivo de recoger la opinión de expertos en animales y su comportamiento respecto a la factibilidad de implementar una guardería exclusiva para las mascotas con dueños que trabajan en Lima Metropolitana.

Nombre y rol de entrevistador: Joseph Ugarte Mel (Alumno de ULIMA)

Nombre y rol de entrevistado*:

* El entrevistado da su conformidad para que la presente entrevista sea utilizada para fines académicos.

1. ¿Qué opinas de los negocios sobre las mascotas? ¿Qué negocios actuales consideras importantes conocer?

2. ¿Cuál consideras es la principal problemática o necesidades que existen para las personas que tienen mascotas?

3. ¿Para la implementación de un negocio sobre cuidado y entretenimiento de mascotas en Lima moderna, qué aspectos considera importantes tomar en cuenta? (Ejemplo: ubicación, espacio, servicio, etc)

4. ¿Qué más puede comentar o aconsejar sobre el cuidado de las mascotas y negocios sobre eso? 


\section{Entrevista $\mathbf{N}^{\circ} 01$}

Nombre y rol de entrevistador: Joseph Ugarte Mel (Alumno de ULIMA)

Nombre y rol de entrevistado: Gerente de Veterinaria Family Pet

El entrevistado da su conformidad para que la presente entrevista sea utilizada para fines académicos.

1. ¿Qué opinas de los negocios sobre las mascotas? ¿Qué negocios actuales consideras importantes conocer?

Yo inicié mi negocio por conocimientos en la materia, mas no tenía mucho conocimiento de administración y eso lo fui mejorando en el tiempo. Hoy por hoy, soy consciente que los negocios sobre mascotes está teniendo mucho éxito, las veterinarias somos las más comunes, sin embargo cada vez hay más pet shops y alojamientos. Yo le hecharía un vistazo a los negocios relacionados a especializaciones, por ejemplo en traumatología.

2. ¿Cuál consideras es la principal problemática o necesidades que existen para las personas que tienen mascotas?

La mayoría de mis clientes me visitan por incidentes o accidentes antes que por prevención, lo cual me da el indicio que aún no hay mucha cultura en el cuidado de las mascotas.

De otro lado, mis clientes han aumentado y eso quiere decir que hay más preocupación por atender a las mascotas y brindarles más cuidados, por ejemplo, muchos de mis clientes, principalmente las mujeres, me llaman seguido al teléfono para saber cómo se encuentran sus perros, ellas dicen que los consideran como sus hijos.

Considerando ambas premisas, yo creería que la oportunidad está en ofrecer servicios que ayuden a las personas a cuidar y engreír a sus mascotas, dejándolas en manos de especialistas.

3. ¿Para la implementación de un negocio sobre cuidado y entretenimiento de mascotas en Lima moderna, qué aspectos considera importantes tomar en cuenta? (Ejemplo: ubicación, espacio, servicio, etc)

Sin dudar alguna, es importante, sino indispensable, que ese negocio tengo conocimientos en primeros auxilios o medicina básica, a fin de prevenir accidentes y el perro pueda ser atendido a tiempo. Asimismo, más que la ubicación o el espacio, lo más importante es el servicio que brindes, si es un servicio de calidad los clientes siempre regresarán.

4. ¿Qué más puede comentar o aconsejar sobre el cuidado de las mascotas y negocios sobre eso?

Lo más importante es brindar un buen servicio, y si estás pensando en un negocio perdurable, es mejor adquirir el local antes que alquilar, porque el costo de alquiler cada vez es más alto y "te saca la mugre". 


\section{Entrevista $\mathbf{N}^{\circ} 02$}

Nombre y rol de entrevistador: Joseph Ugarte Mel (Alumno de ULIMA)

Nombre y rol de entrevistado: Jessica Granda, dueña de "Fedor" y miembro de Club de Pastores Alemanes

El entrevistado da su conformidad para que la presente entrevista sea utilizada para fines académicos.

5. ¿Qué opinas de los negocios sobre las mascotas? ¿Qué negocios actuales consideras importantes conocer?

El negocio de alimentos para perros me parece un negocio súper rentable, sobre todo ahora que se ha vuelto más especializado, ya que hay alimentos por tipo de mascota, tamaño, raza, etc, incluso si tu perrito es alérgico debes comprarle comida especial. Sin embargo, además de estos negocios y las veterinarias, ahora hay nuevos productos y servicios dirigidos para perros como hospedaje, catering para fiestas, escuelas, etc.

6. ¿Cuál consideras es la principal problemática o necesidades que existen para las personas que tienen mascotas?

Bueno, yo creo todos los que tenemos mascotas, sobre todo perros, nos encanta pasar tiempo con ellos y darles lo mejor, son como nuestros hijos. Yo creo que cada vez hay más empresas que entienden esta necesidad y les dedican mayores cuidados y especialización a sus servicios, sin embargo, aún hay empresas que no cumplen este estándar. Por ejemplo, la última vez que viajé por cuatro días, dejé a Fedor en un hospedaje canino, pero grande fue mi sorpresa y enfado cuando regresé a recogerlo y lo encontré con pulgas, garrapatas y con una herida producto de una gresca con otro perro. ¡Ni más vuelvo a ese sitio! Y los mismos comentarios tengo de varias amigas.

7. ¿Para la implementación de un negocio sobre cuidado y entretenimiento de mascotas en Lima moderna, qué aspectos considera importantes tomar en cuenta? (Ejemplo: ubicación, espacio, servicio, etc)

¡Indispensable un servicio de calidad, así cueste más yo estoy dispuesta a pagarlo! Segundo, debe ser un sitio que me quede cerca, para que ante cualquier evento pueda ir o me lo traigan rápidamente. Además, también es muy importante la comunicación de la empresa con los clientes, sería genial que exista alguna forma de poder saber que está haciendo tu perro en cualquier momento del día sin necesidad de esperar que te manden una foto por el WhatsApp.

8. ¿Qué más puede comentar o aconsejar sobre el cuidado de las mascotas y negocios sobre eso?

Es importante conocer las características de cada perro, no todos los animales son iguales y sería bueno considerar eso en un negocio dedicado para perros: la personalización. 


\section{Anexo 2: Encuestas}

\section{Cálculo de muestra}

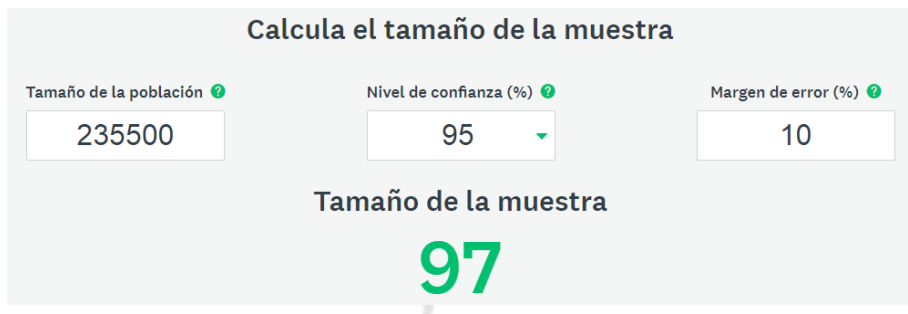

\section{Formato de encuestas}

\section{Una solución para perros con dueños que trabajan}

Esta encuesta está dirigida a personas que trabajan y que tienen perros, a fin de recoger sus intereses y preferencias.

*Obligatorio

¿Qué edad tienes? *

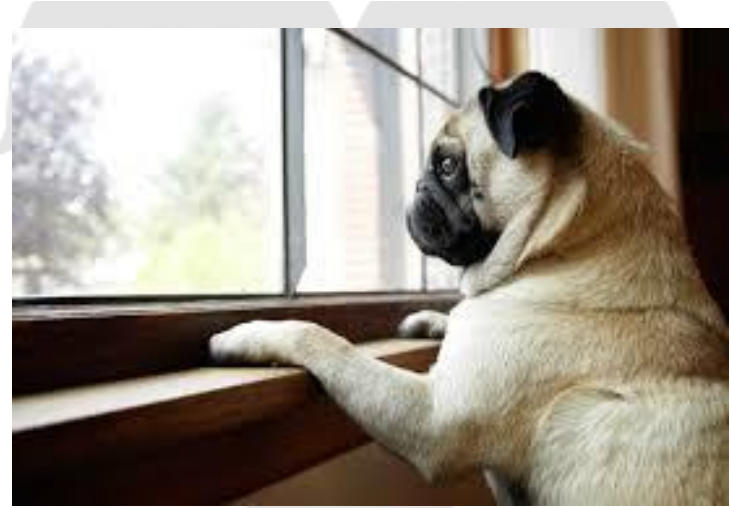

Entre 18 y 24

Entre 25 y 30

Entre 31 y 40

Entre 41 y 50

Más de 50

¿Cómo te identificas?

Hombre

Mujer

Otro:

¿En dónde trabajas? *

Elige

¿En dónde vives? *

Elige

¿Cuántos perros tienes? *

No tengo perro

1

2

3 a más

Cuéntanos un poco sobre tu perro *

hembra/pequeño/leve 


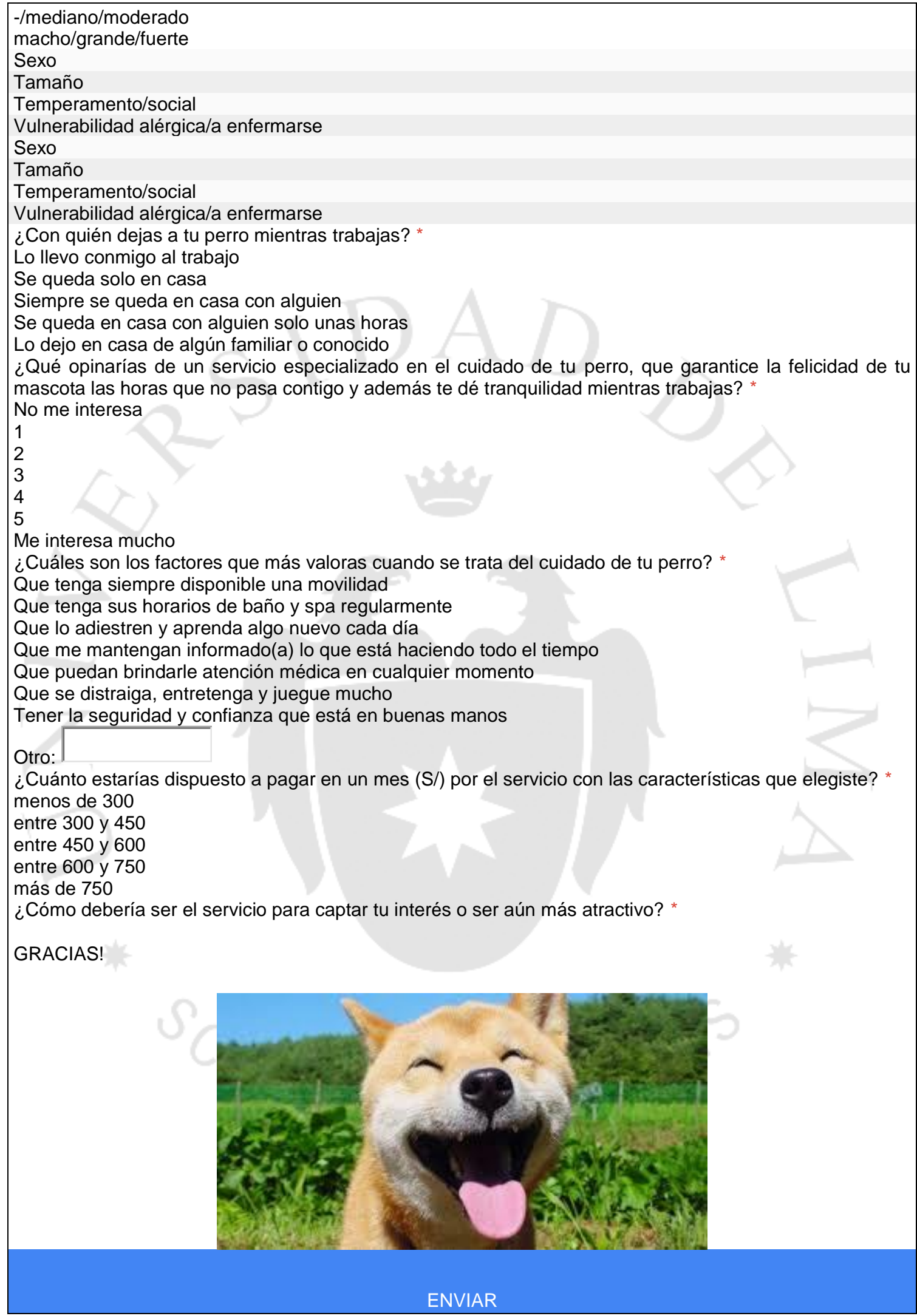




\section{Resultado de encuestas}

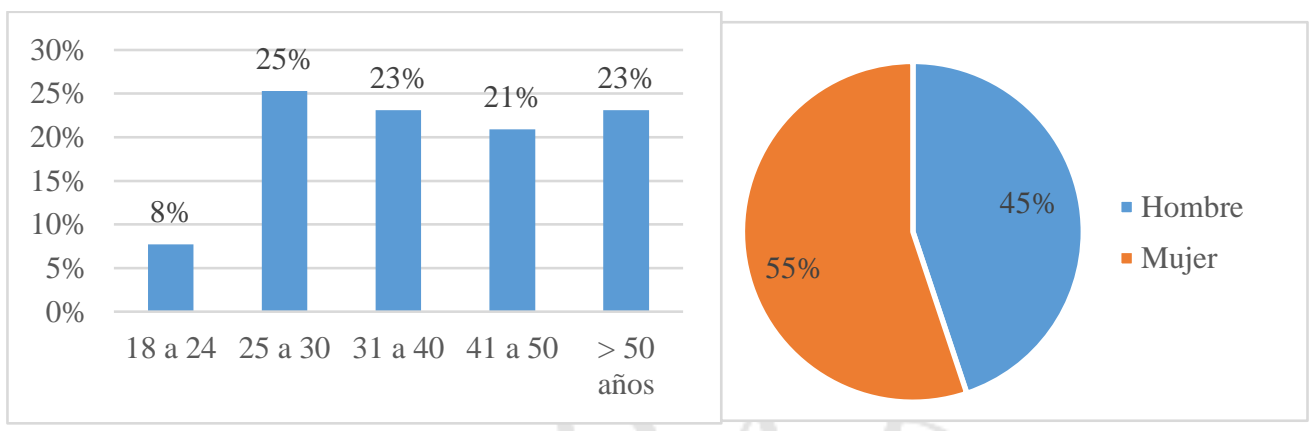

Edad de cliente.

Sexo del cliente.
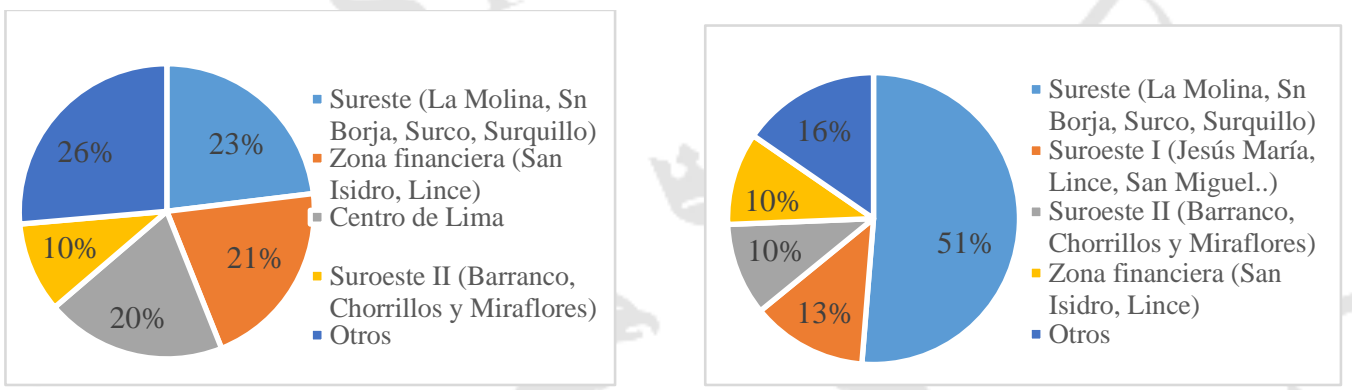

Dónde trabaja el cliente.

Dónde vive el cliente.

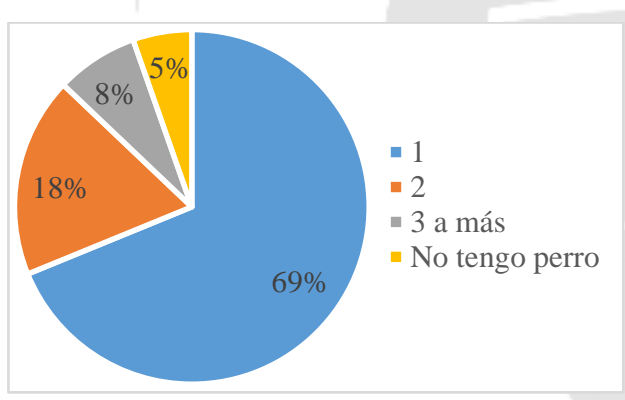

Número de perros del cliente.

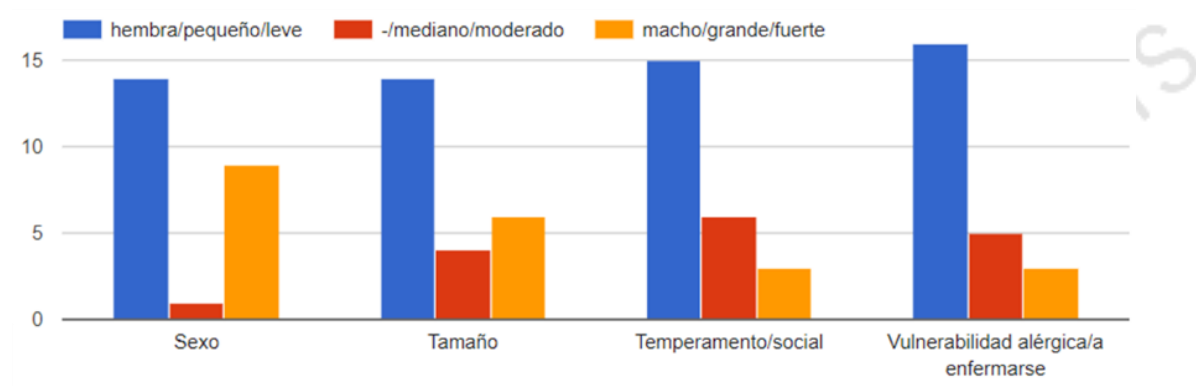

Información sobre la mascota. 


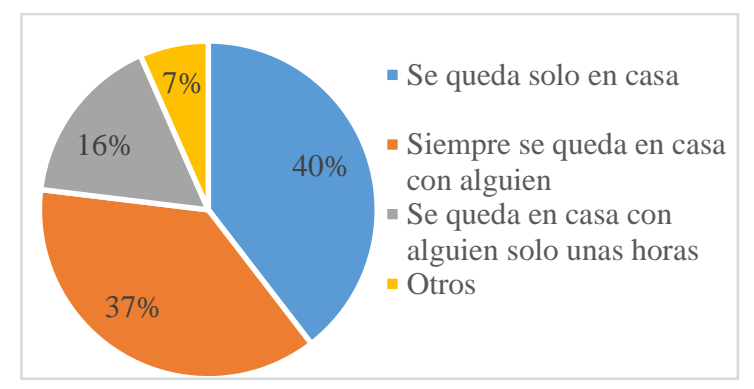

Qué hace el perro mientras el dueño trabaja.

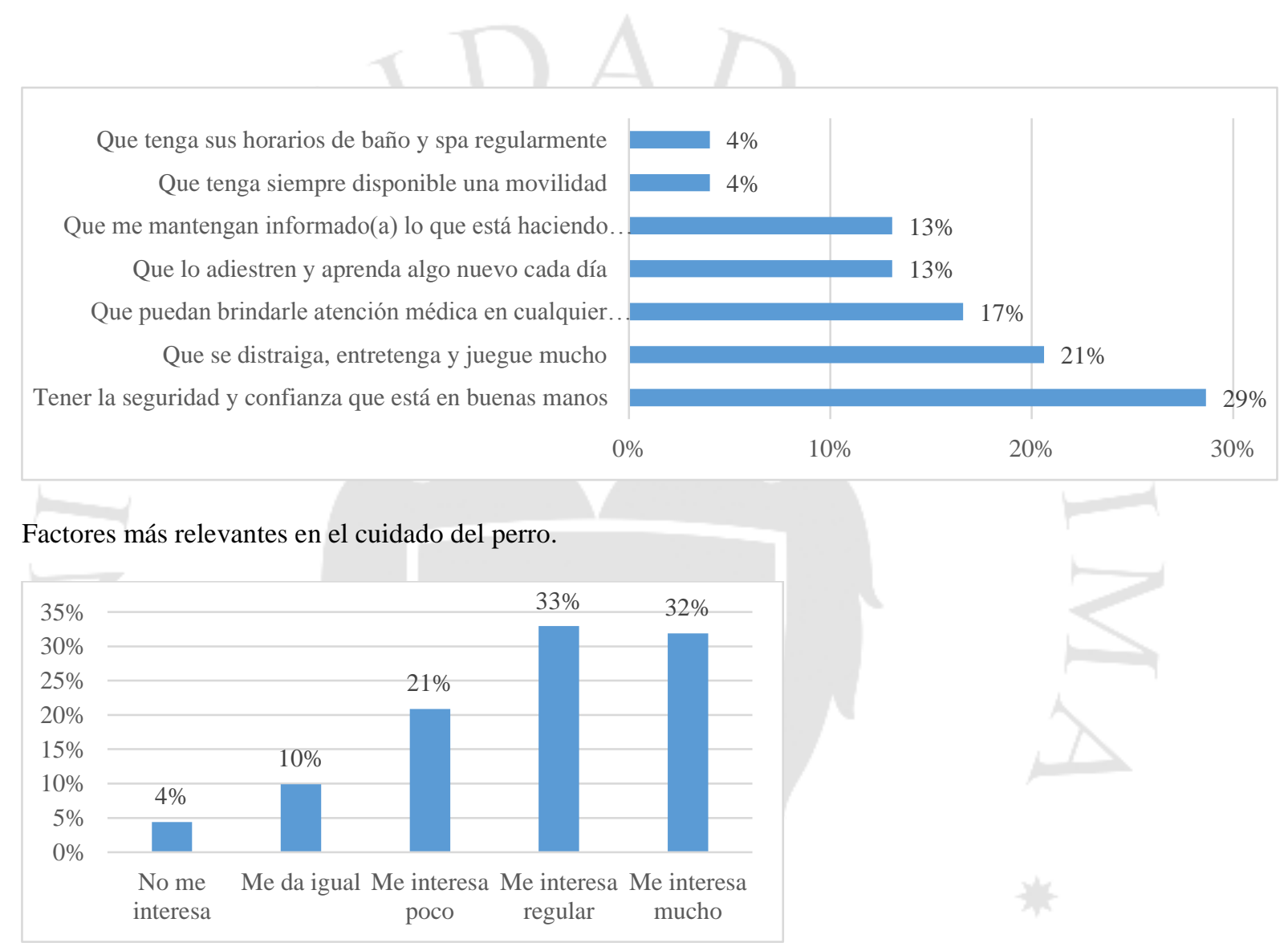

Interés del cliente en contratar el servicio.

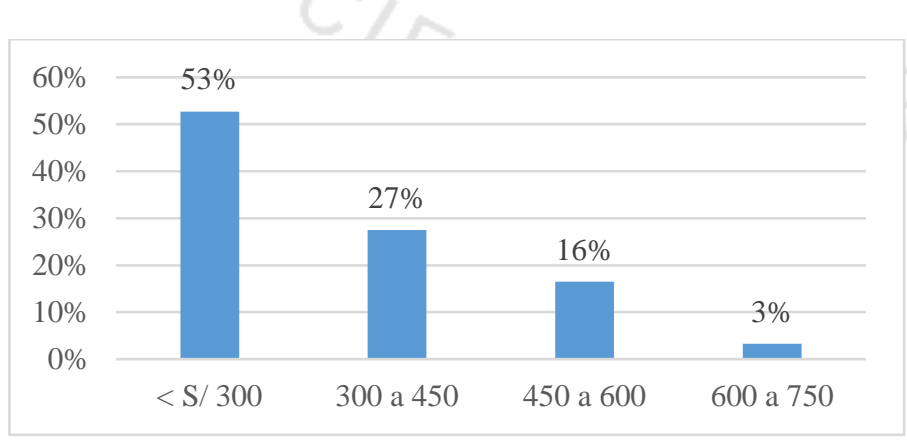

Cuánto está dispuesto a pagar el cliente. 


\section{Anexo 3: Relación de procesos}

Relación de procesos por nivel

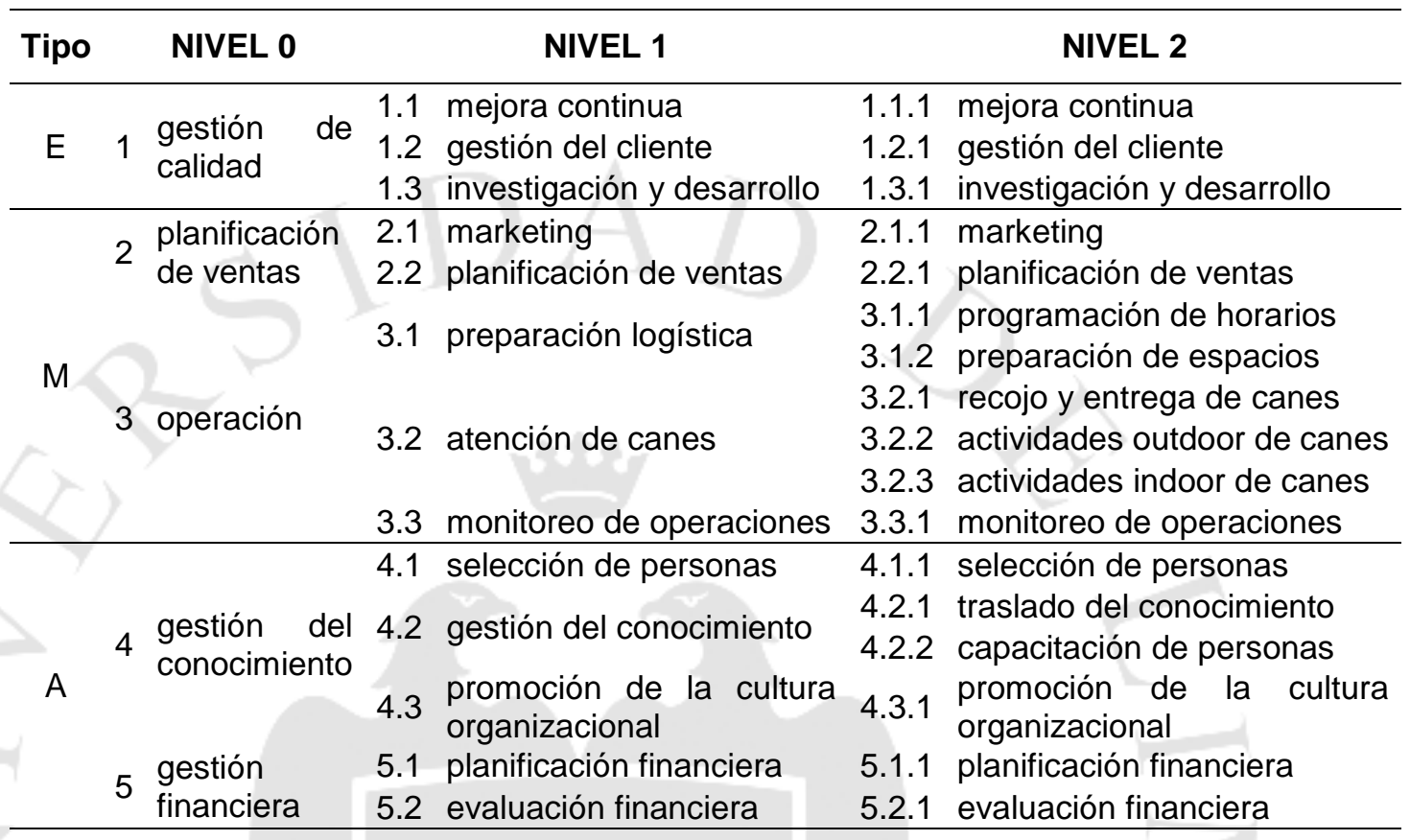

Tercerización de procesos

\begin{tabular}{|c|c|c|c|c|}
\hline Proceso & $\begin{array}{l}\text { no define la } \\
\text { misión o } \\
\text { políticas de } \\
\text { la empresa? }\end{array}$ & $\begin{array}{|lr|}\text { no } & \text { está } \\
\text { integrado } \\
\text { al } & \text { core } \\
\text { bussines? }\end{array}$ & $\begin{array}{l}\text { es más } \\
\text { barato que } \\
\text { lo haga } \\
\text { otro? }\end{array}$ & tercerizar? \\
\hline mejora continua & \multicolumn{4}{|l|}{ NO } \\
\hline gestión del cliente & \multicolumn{4}{|l|}{ NO } \\
\hline \begin{tabular}{|lll}
$\begin{array}{l}\text { promoción de la cultura } \\
\text { organizacional }\end{array}$ & \\
\end{tabular} & \multicolumn{4}{|l|}{ NO } \\
\hline marketing & SI & NO & SI & SI \\
\hline marketing & $\mathrm{SI}$ & NO & SI & SI \\
\hline programación de horarios & $\mathrm{SI}$ & \multicolumn{3}{|l|}{ NO } \\
\hline preparación de espacios & $\mathrm{SI}$ & \multicolumn{3}{|l|}{ NO } \\
\hline recojo y entrega de canes & $\mathrm{SI}$ & \multicolumn{3}{|l|}{ NO } \\
\hline actividades outdoor de canes & \multicolumn{4}{|l|}{ NO } \\
\hline actividades indoor de canes & \multicolumn{4}{|l|}{ NO } \\
\hline monitoreo de operaciones & \multicolumn{4}{|l|}{ NO } \\
\hline selección de personas & $\mathrm{SI}$ & SI & $\mathrm{SI}$ & SI \\
\hline traslado del conocimiento & $\mathrm{SI}$ & $\mathrm{SI}$ & $\mathrm{SI}$ & SI \\
\hline capacitación de personas & SI & $\mathrm{SI}$ & $\mathrm{SI}$ & SI \\
\hline planificacion financiera & $\mathrm{SI}$ & $\mathrm{SI}$ & $\mathrm{SI}$ & SI \\
\hline evaluación financiera & $\mathrm{SI}$ & $\mathrm{SI}$ & $\mathrm{SI}$ & SI \\
\hline
\end{tabular}




\section{Anexo 4: Flujos de procesos}

Promoción de la cultura organizacional

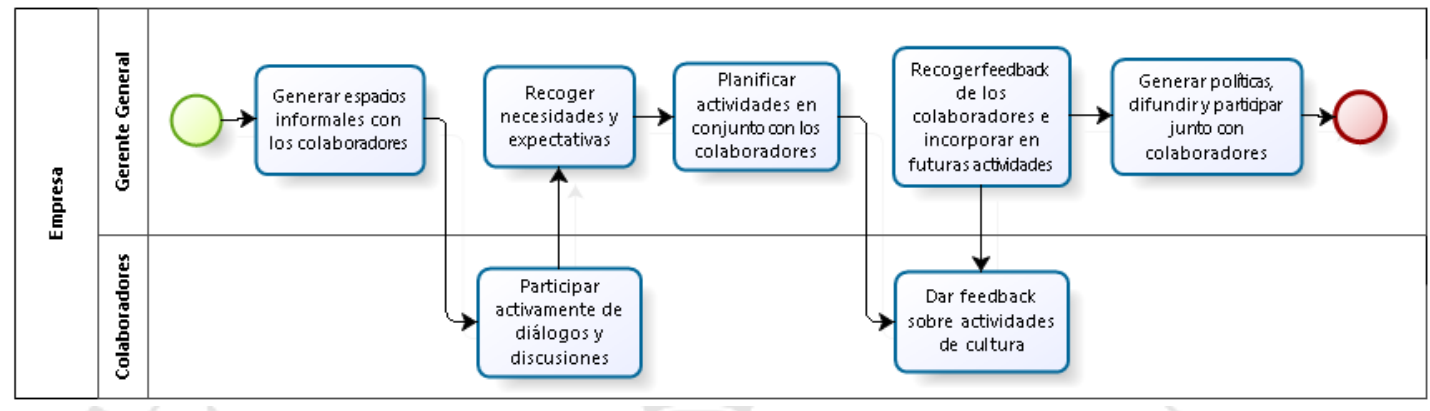

Mejora continua y gestión de calidad

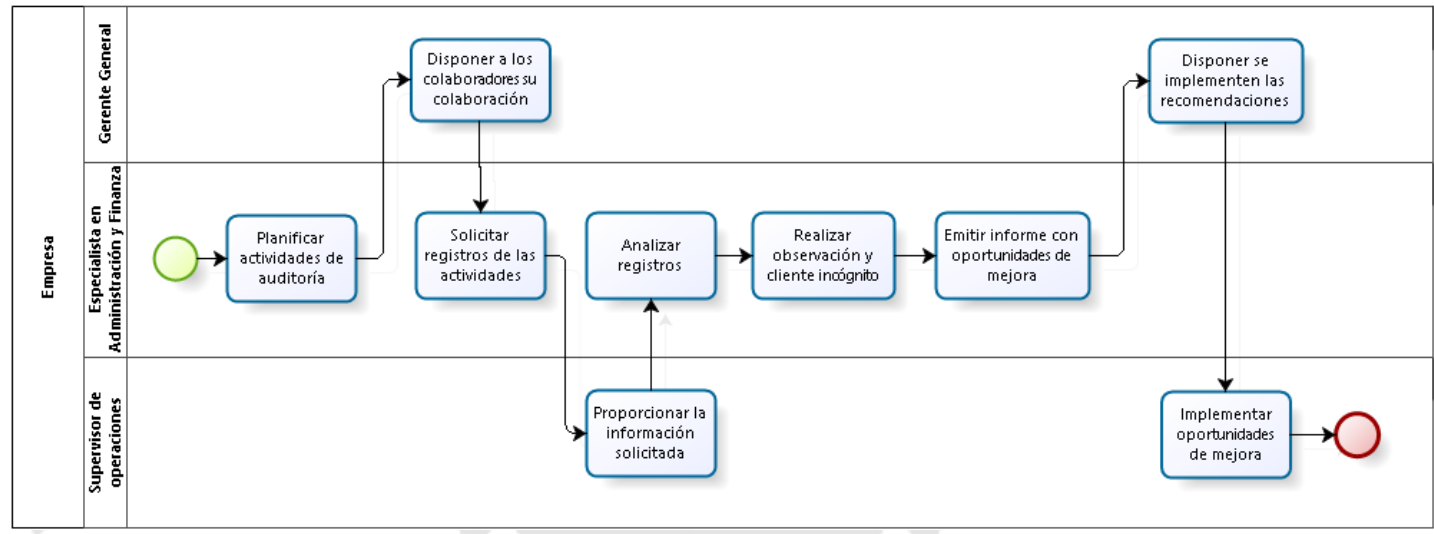

Planificación de ventas

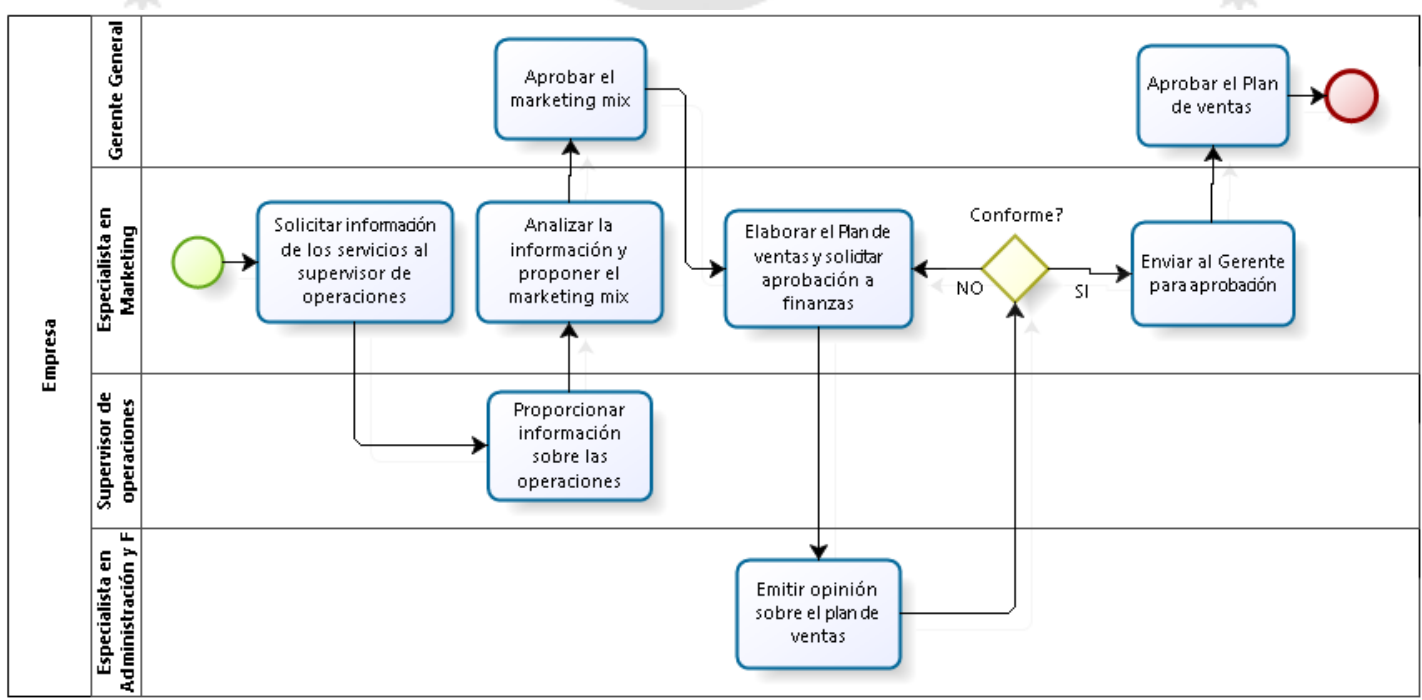


Selección y contratación de personas

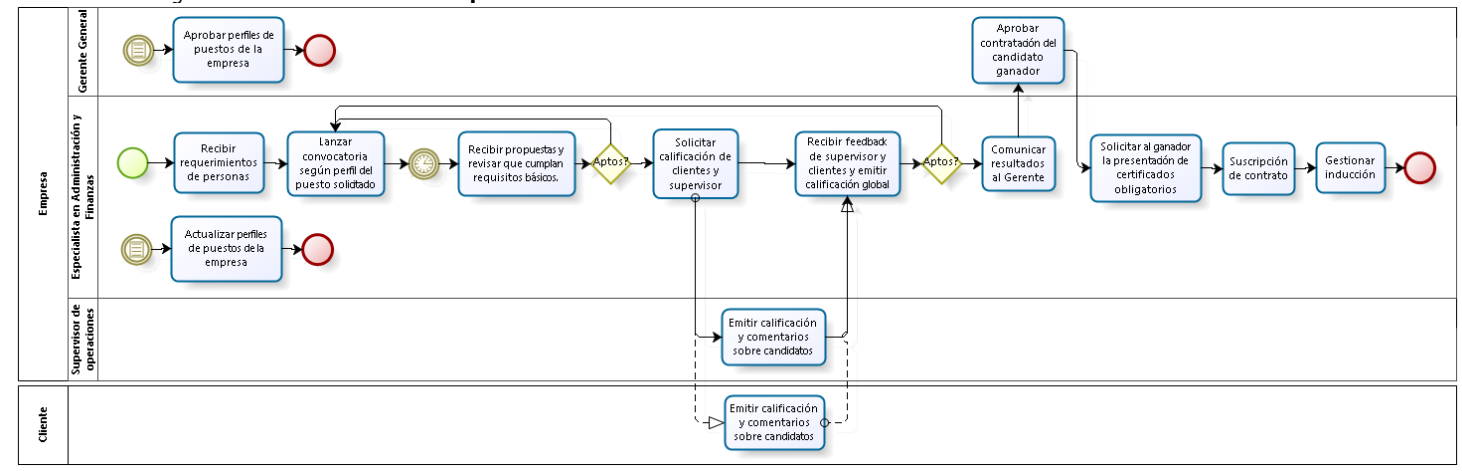

Transferencia de conocimiento

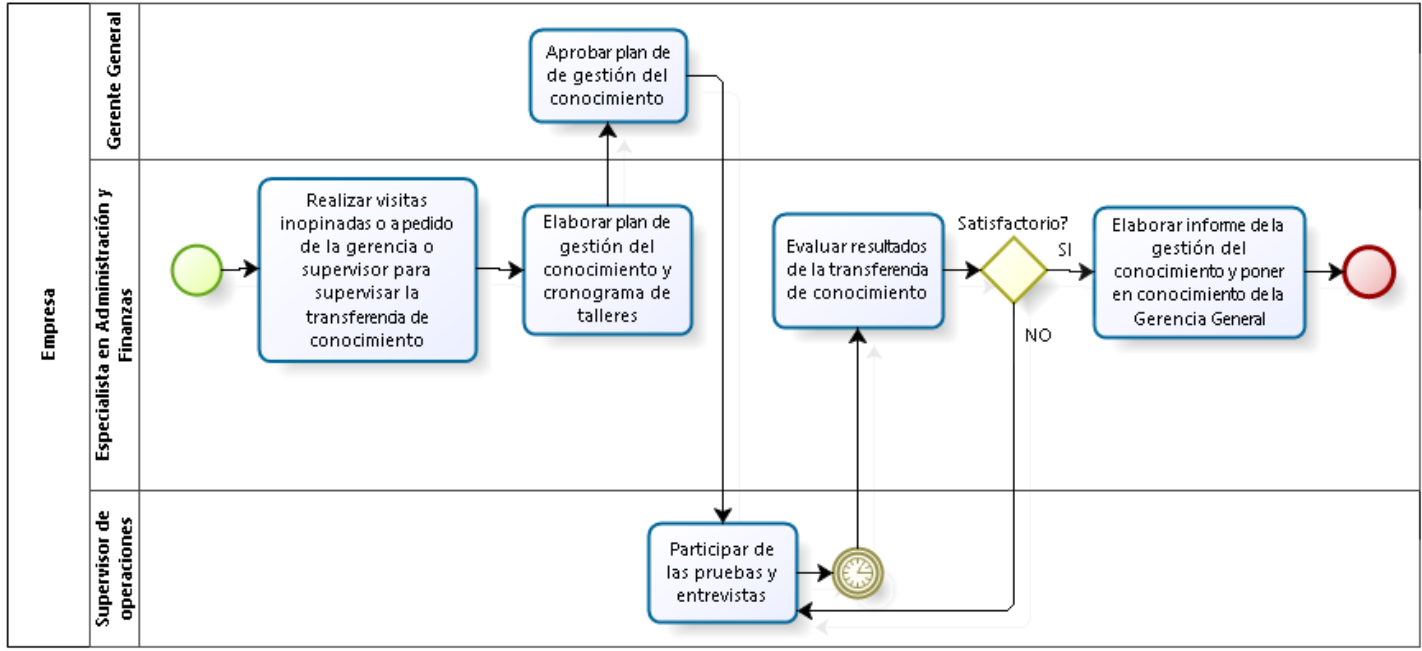

Capacitación de personas

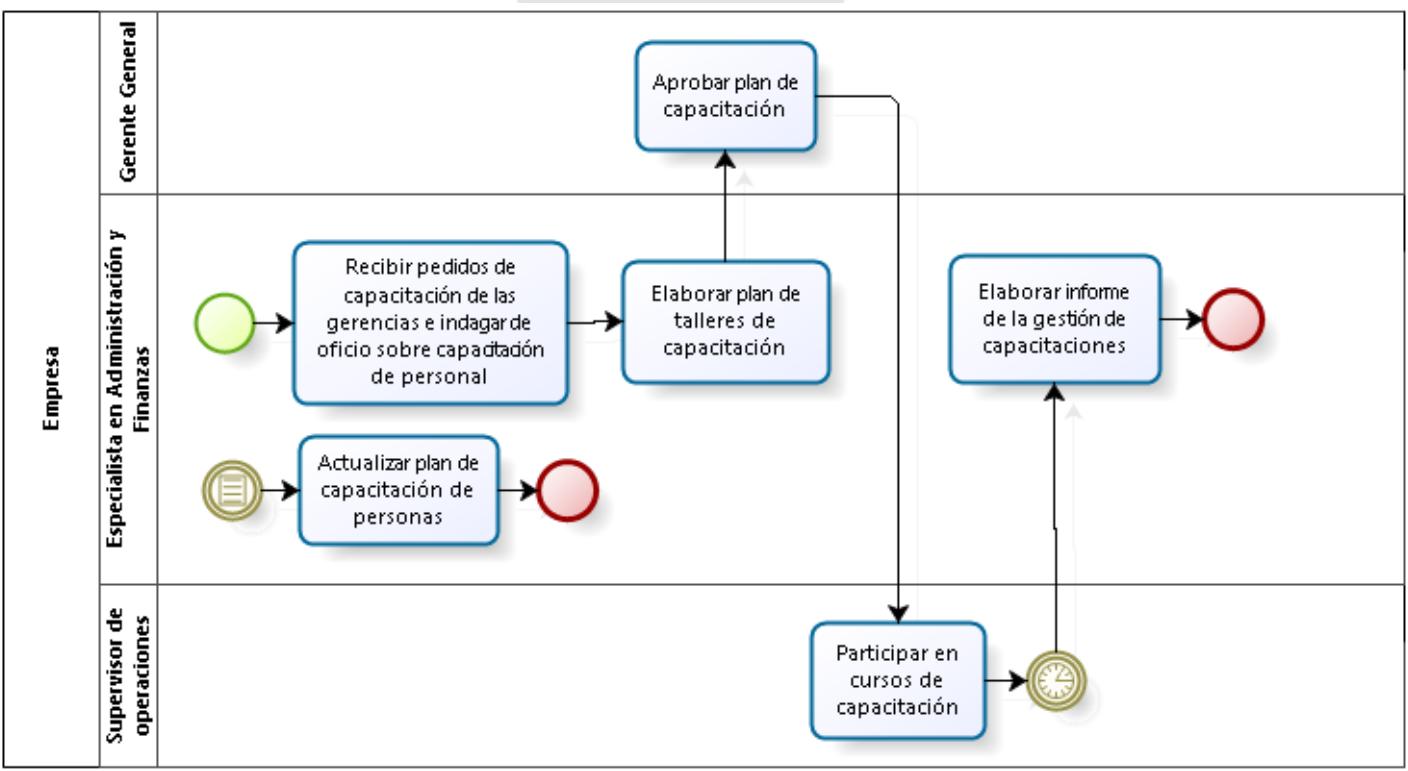


Gestión financiera

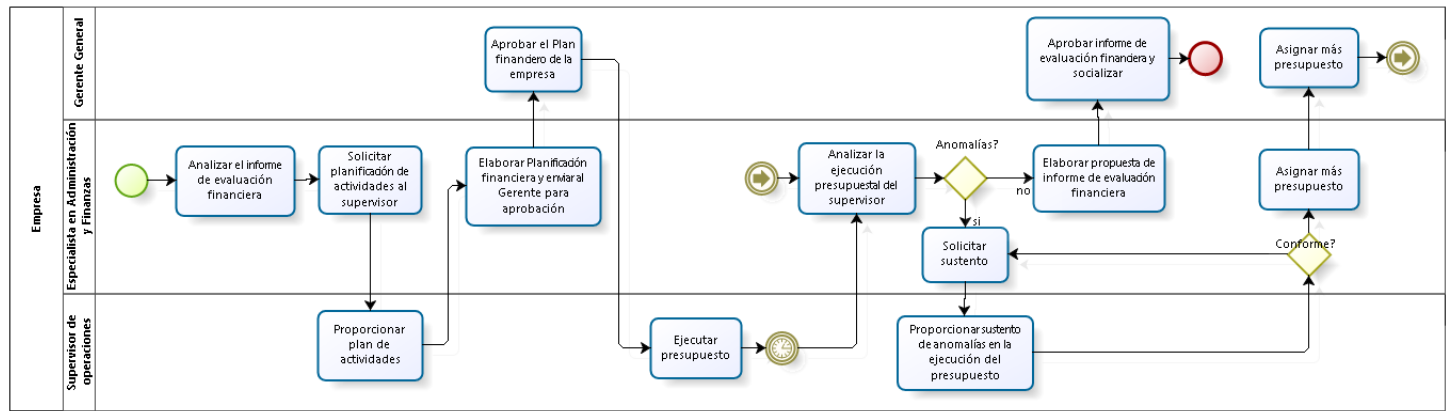

\section{Anexo 5: Bienes y servicios}

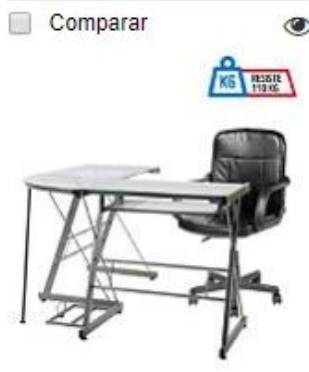

(0)

Combo Escritorio en L Asenti

+ Silla escritorio.

SKU:2262231C-2

$\mathrm{S} / 279.90 \mathrm{C} / \mathrm{U}$

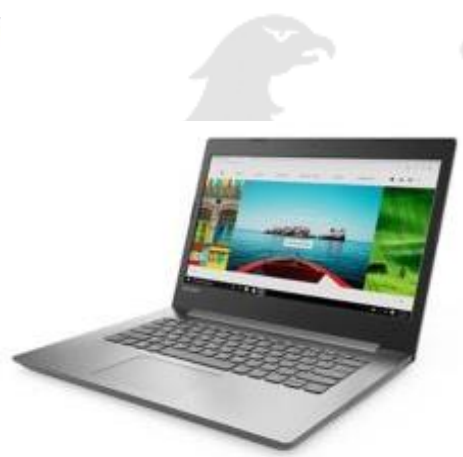

$29 \%$

LENOVO

Lenovo Ideapad 320 Celero...

S/ 999 (Internet)

S/ 1,399 (Normal)

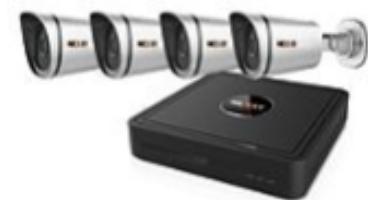

(0)

Nexxt Conectividad

Sistema de Vigilancia 8

Canales y 4 Cámaras de ...

SKU:288382-1

EXCLUSNOWEB

CIERRA PUERTAS

$\mathrm{S} / 999 \mathrm{C} / \mathrm{U}$

Alquiler

US\$ 1,300

$\mathrm{S} / 4,381$

(C) CALLE MONTE CIPRES CDR 3 
Batería De Caniles Para 12 Animales Uso Veterinario Mascotas

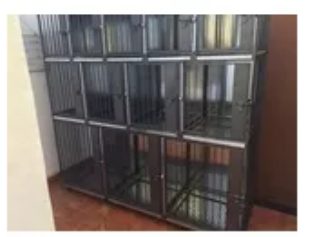

S/ 3.350

- $12 \times \mathrm{S} / 27917$

Callao

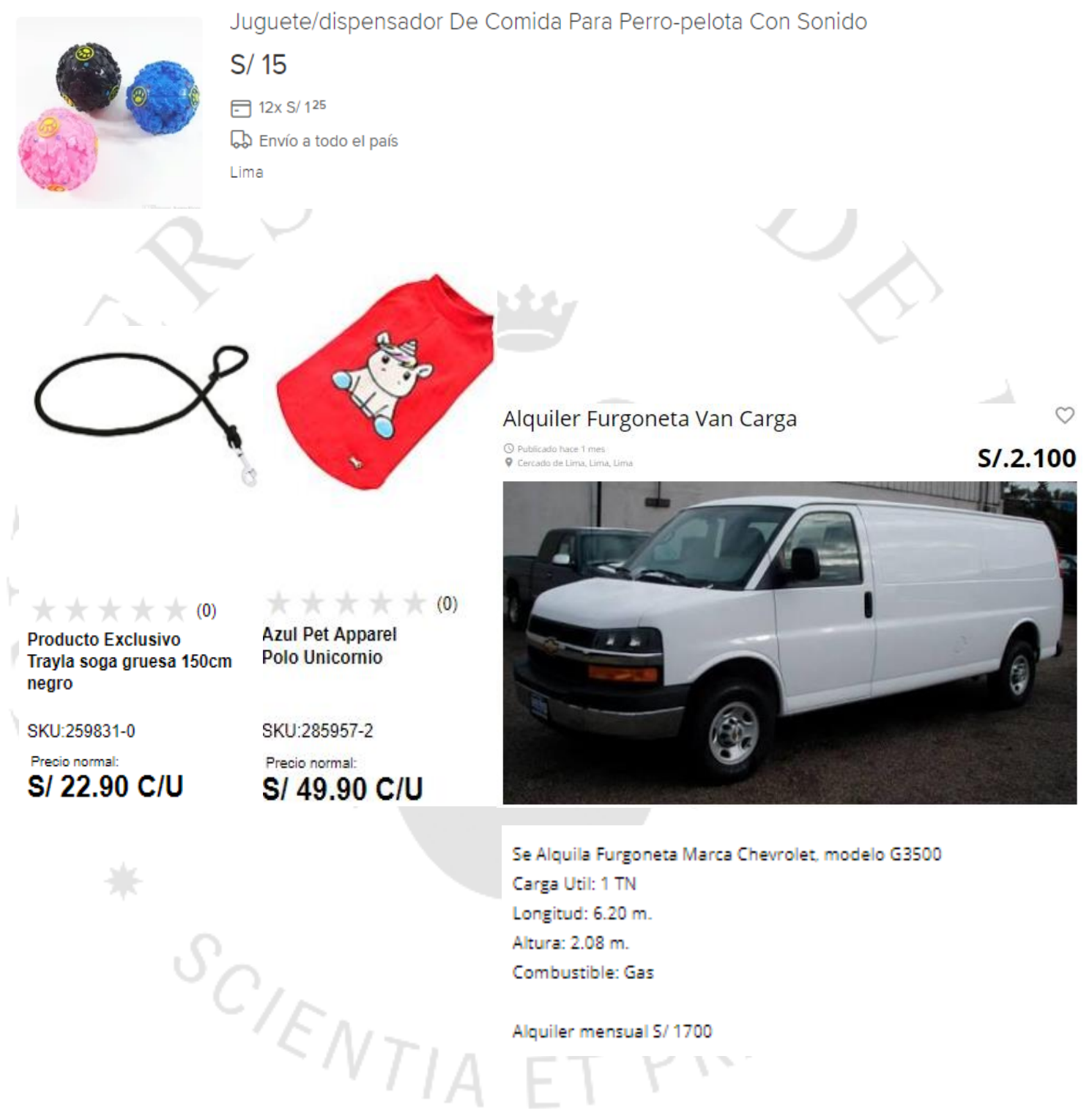

Marcas

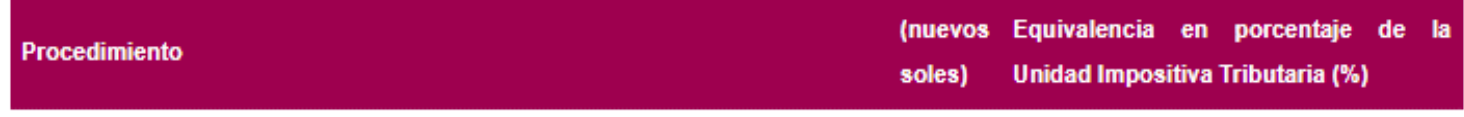

Registro de marca y otros signos

(Marcas de Producto, Servicio, Colectiva y de Certificación, Nombre Comercial y 534.99

14,46

Lema Comercial) 


\section{COTIZACIÓN APP}

Entiendo, bueno practicamente dar el servicio por completo desde la app, tanto brindar info, reserva y/o agendar cita programada de la misma y recojo del animal.

Ahora,sobre monitorear a tiempo real es mas complicado y caro ya que necesitaras diseñar un collar o algún un gps de rastreo en el auto que lo transporta que se pueda visualizar y incorporar a la app, pero creo que seria mas facil simplemente tengo camaras de seguridad inalambricas dentro del vehiculo que funcionan con ip que se pueden adherir a la app, se le asigna a la reserva y/o cita una cámara y que transmita cuando entre en ejecución

Con respecto a lo del chat y mapa pueden ser parte de las funciones principales que tiene app.

Por otra parte, como administrador de la app, que seria el dashboard o panel de control de la app, tendrias que ver si quieres mediante web y/o dentro de la misma app un usuario empleado, que responderían todo desde la misma app o desde de la pagina web que supongo que tendra tu app.

luego de eso dominio y host(servidor) para almacenar toda los archivos de la app.

El método de pago si se puede hacer desde la app, para eso ya deberás tener tu ruc, ya que necesitaras una cuenta en una pasarela de pagos que hay varias empresas que hacen eso para recibir pagos vía tarjeta u otras pagos, ejem (culqi, payU, visanet, etc.) es mas fácil, seguro y aceptan mas métodos de pago que hacer una pasarela de pagos propia ya que seria mas caro.

Por ultimo subirla a los playstore tanto de android y apple, normalmente la gente que programa lo sube pero desde su cuenta a estos sitios pero eso quiere decir que no sera legalmente tuya la app para android o apple, tienes que crearte tu propia cuenta y subir la app desde tu cuenta en android cuesta(25\$) y para el store de apple (100\$) y por ultima la app tiene que estar programada para que sea responsiva en ambas plataformas, tanto para IOS (iphone) y android (el resto de teléfonos).

Calculo estará en un rango de $\$ 1800$ a $\$ 3000$

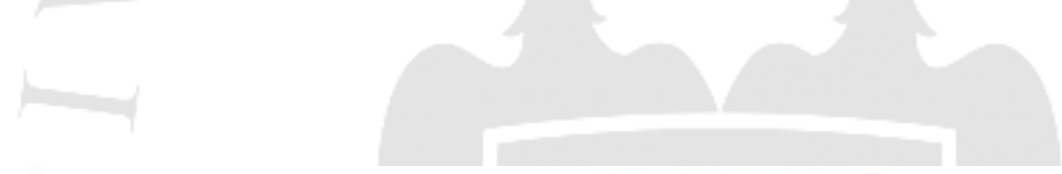

FICHA RESUMEN DE COSTOS

DENOMINACION DEL AREA OPERATIVA

SUBGERENCIA DE DESARROLLO ECONÓMICO

DENOMINACION DEL SERVICIO ADMINISTRATIVO

08.02 LICENCIA DE FUNCIONAMIENTO PARA LA APERTURA DE ESTABLECIMIENTOS COMEACIAL, INDUSTAIAL Y SERVICIOS (De 101 a 500 metros)

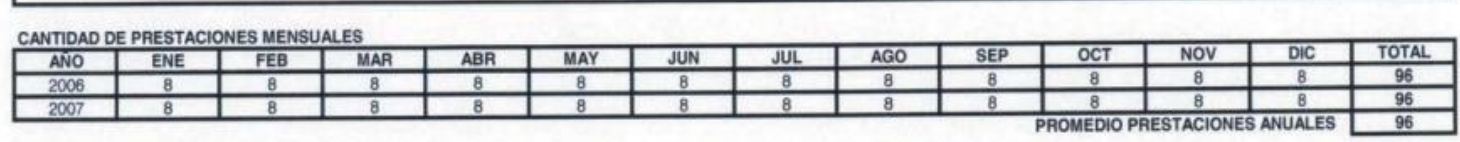

MATERIALES NO FUNGIBLES Y OTROS GASTOS Y CONSUMOS VARIABLES

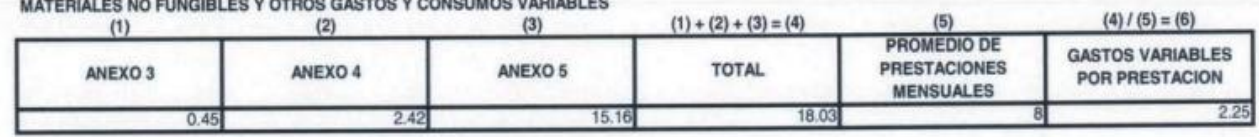

COSTO VARIABLE DE UNA PRESTACION DEL SERVICIO ADMINISTRATIVO
(7)
\begin{tabular}{|c|c|c|c|}
\hline ANEXO 1 & ANEXO 2 & $\begin{array}{c}\text { GASTOS VARIABLES } \\
\text { POR PRESTACION }\end{array}$ & TOTAL \\
\hline 283.81 & & 2.25 & 287.34 \\
\hline
\end{tabular}

MARGEN DE CONTRIBUCION PARA UNA PRESTACION DEL SERVICIO ADMINISTRATIVO

\begin{tabular}{|c|c|c|c|c|}
\hline (10) & (11) & $(10) \cdot(11)=(12)$ & (13) & $(12) /(13)=14)$ \\
\hline $\begin{array}{l}\text { COSTO FNO DE LA } \\
\text { UNIDAD ORGANICA }\end{array}$ & $\begin{array}{l}\text { \% ASIGNADO AL } \\
\text { SERVICIO }\end{array}$ & COSTO FIO ASIGNADO & $\begin{array}{l}\text { PROMEDIO DE } \\
\text { PRESTACIONES } \\
\text { ANUALES }\end{array}$ & $\begin{array}{l}\text { MARGEN DE } \\
\text { CONTRIBUCION }\end{array}$ \\
\hline 2129224 & 26 & 559.69 & & 5.83 \\
\hline
\end{tabular}

COSTO DE UNA PRESTACION DEL SERVICIO ADMINISTRATIVO

\begin{tabular}{|c|c|c|}
\hline (9) & (14) & $(9)^{*}(14)=(15)$ \\
\hline COSTO VARIABLE & $\begin{array}{l}\text { MARGEN DE } \\
\text { CONTRIBUCION }\end{array}$ & $\begin{array}{l}\text { COSTO DE UNA } \\
\text { PAESTACION }\end{array}$ \\
\hline
\end{tabular}

\begin{tabular}{|r|r|}
\hline VALOR A COBRAR & \%UIT \\
\hline 293.00 & $8.2535 \%$ \\
\hline
\end{tabular}




\begin{tabular}{|c|c|c|c|c|}
\hline \multicolumn{5}{|c|}{$\begin{array}{l}\text { EMPRESA DE DISTRIBUCION ELECTRICA LUZ DEL SUR S.A.A. } \\
\text { PRECIOS PARA LA VENTA DE ENERGIA ELECTRICA (incluye IGV) }\end{array}$} \\
\hline \multirow{2}{*}{\multicolumn{2}{|c|}{ PLIEGO TARIFARIO : 04 AGOSTO $2018(/ 1)$}} & & & LD52018-08 \\
\hline & & \multicolumn{3}{|c|}{ Sistema Lima Sur } \\
\hline MEDICION DOBLE DE ENERGIA Y CONTRATACION O MEDICION DE DOS POTENCIAS (2E2P) & Unidad & & MT2 & BT2 \\
\hline Cargo Fijo mensual & S/./Usuario & & 4,85 & 4,85 \\
\hline Cargo por Energia en punta & cent $5 / / . / \mathrm{W} . \mathrm{h}$ & & 28,19 & 30,50 \\
\hline Cargo por Energia fuera de punta & $\operatorname{cent} 5 / / / \mathrm{kW} \cdot \mathrm{h}$ & & 23,67 & 25,61 \\
\hline Cargo por potencia activa de generación en horas punta & 5//RW-mes & & 62,23 & 65,55 \\
\hline Cargo por potencia activa por uso redes de distribudión en horas punta & $5 / /$ kow-mes & & 11,51 & 53,60 \\
\hline Cargo por exceso de potencla por uso redes distribución en horas fuera de punta & $5 / /$ kW-mes & & 12,61 & 43,29 \\
\hline Cargo por energia reactiva que exceda del 30\% del tobal de la energla activa & cent 5/./Nvarh & & 5.05 & 5,05 \\
\hline MEDICION DOBLE DE ENERGIA Y UNA POTENCIA CONTRATADA (2E1P) & Unidad & & MT3 & BT3 \\
\hline Cargo Fijo mensual & S/./Usuario & & 3,85 & 3,85 \\
\hline Cargo por Energia en punta & $\operatorname{cent} 5 / / \mathrm{hW} \cdot \mathrm{h}$ & & 28,19 & 30,50 \\
\hline Cargo por Energia fuera de punta & cent $5 / / / \mathrm{kW} \cdot \mathrm{h}$ & & 23,67 & 25,61 \\
\hline Cargo por potencia activa de generación para callificación "Presentes punta" & $5 / /$ kw-mes & & 55,58 & 60,63 \\
\hline Cargo por potencia activa de generación para calficación "Fuera punta" & $5 / /$ kow-mes & & 37,88 & 41,52 \\
\hline Cargo por potencla activa por uso redes de distribudión para calificación "Presentes punta" & $5 / /$ kW:mes & & 12,65 & 56,24 \\
\hline Cargo por potencia activa por uso redes de distribudión para calificación "Fuera punta" & $5 / /$ kW-mes & & 12,65 & 51,54 \\
\hline Cargo por energia reactiva que exceda del $30 \%$ del total de la energla activa & cent $5 / . /$ kvarth & & 5,05 & 5,05 \\
\hline SIMPLE MEDICION DE EN ERGIA Y UNA POTENCIA CONTRATADA (1E1P) & Unidad & & MT4 & BT4 \\
\hline Cargo Fijo mensual & 5/./Usuario & & 3,85 & 3,85 \\
\hline Cargo por Energia & $\operatorname{cent} 5 / / \mathrm{kW} \cdot \mathrm{h}$ & & 24,69 & 26,72 \\
\hline Cargo por potencla activa de generación para calificación "Presentes punta" & $5 / /$ how-mes & & 55,58 & 60,63 \\
\hline Cargo por potencia activa de generación para calificación "Fuera punta" & $5 / /$ kw-mes & & 37,88 & 41,52 \\
\hline Cargo por potencia activa por uso redes de distribudidn para calificacidon "Presentes punta" & $5 / /$ kW-mes & & 12,66 & 56,24 \\
\hline Cargo por potencia activa por uso redes de distribudid́n para calificación "Fuera punta" & $5 / /$ kw-mes & & 12,65 & 51,54 \\
\hline Cargo por Energia Reactiva que exceda el $30 \%$ del total de la Energia Activa & cent $5 / . /$ kvarh & & 5,05 & 5,05 \\
\hline DOBLE MEDICION DE ENERGIA (2E) & Unidad & & & BTSA \\
\hline Cargo Fijo mensual & 5/./Usuario & & & 3,85 \\
\hline Cargo por Energia en punta para demandas hasta $20 \mathrm{~kW}$ en horas punta y fuera punta & $\operatorname{cent} 5 / / \mathrm{kW} \cdot \mathrm{h}$ & & & 154,60 \\
\hline Cargo por Energia en punta para demandas hasta $20 \mathrm{~kW}$ en hor.punta y $50 \mathrm{~kW}$ en fra.punta & $\operatorname{cent} 5 / . / \mathrm{hW} \cdot \mathrm{h}$ & & & 173,99 \\
\hline Cargo por Energía fuera de punta & $\operatorname{cent} 5 / / / \mathrm{hW} \cdot \mathrm{h}$ & & & 25,61 \\
\hline Cargo por exceso de potencla en horas fuera de punta & $5 / /$ kw-mes & & & 47,96 \\
\hline Cargo por eaceso de potencia en horas de punta & S/low.mes & & & 47,95 \\
\hline 5IMPLE MEDICION DE ENERGIA (1E) & Unidad & & & BTSC-AP \\
\hline Cargo Fijo mensual & S/./Usuario & & & 4,33 \\
\hline Cargo por Energia & cent $5 / / 2 \mathrm{~kW} \cdot \mathrm{h}$ & & & 62,00 \\
\hline CLIENTES A PENSION FUAA & Unidad & & & BT6 \\
\hline Cargo Fijo mensual & S/./Usuario & & & 3,08 \\
\hline Cargo mensual por Potencla & cent $5 / . /$ Watt & & & 25,16 \\
\hline SERVICO PREPAGO & Unidad & & & BT7 \\
\hline \multicolumn{5}{|l|}{ BT7 No Residencial } \\
\hline Cargo Fijo mensual - Codligos o Tarjetas & \$/./Usuario & & & 2,74 \\
\hline Cargo por Energla & $\operatorname{cent} \mathrm{S} / \mathrm{hWW} \cdot \mathrm{h}$ & & & 58,13 \\
\hline \multicolumn{5}{|l|}{$\begin{array}{l}\text { BT7 Residencial: clientes con consumos menores o iguales a } 100 \mathrm{~kW} . \mathrm{h} \text { por mes } \\
0 \text { - } 30 \mathrm{~kW} . \mathrm{h}\end{array}$} \\
\hline 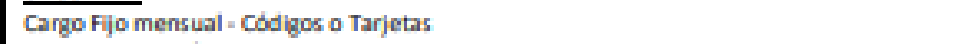 & \$/./Usuario & & & 2,61 \\
\hline Cargo por Energla Activa & $\operatorname{cent} 5 / / \mathrm{kW} \cdot \mathrm{h}$ & & & 41,60 \\
\hline $31-100 \mathrm{kWh}$ & & & & \\
\hline Cargo Fijo mensual = Codlgos o Tarjetas & 5/./Usuario & & & 2,61 \\
\hline Cargo por Energla Activa - Primeros 30 kW.h & 5/./Usuario & & & 12,43 \\
\hline Cargo por Energla Activa - Exceso de $30 \mathrm{~kW} / \mathrm{h}$ & $\operatorname{cent} 5 / / / \mathrm{kW} \cdot \mathrm{h}$ & & & 55,46 \\
\hline \multicolumn{5}{|l|}{ BT7 Residencial: clientes con consumos mayores a 100 kW.h por mes } \\
\hline Cargo Fijo mensual - Codigos o Tarjetas & 5/./Usuario & & & 2,74 \\
\hline Cargo por Energla Activa & cent $5 / / / \mathrm{kW} \cdot \mathrm{h}$ & & & 58,13 \\
\hline SIMPLE MEDICION DE ENERGIA (IE) - NO RESIDENCIAL & Unidad & BT5B & BTSD & BTSE \\
\hline Cargo Fijo mensual & 5/./Usuario & 3,08 & 3,08 & 2,77 \\
\hline Cargo por Energia & cent $5 / . / \mathrm{hW} . \mathrm{h}$ & 59,05 & 47,96 & 59,01 \\
\hline SIMPLE MEDICION DE ENERGIA (IE) - RESIDENCIAL & Unidad & BTSB & BTSD & BTSE \\
\hline \multicolumn{5}{|l|}{$\begin{array}{l}\text { 2) Usuarios con consumos menores o iguales a } 100 \mathrm{~kW} . \mathrm{h} \text { por mes } \\
\text { p- } 30 \mathrm{~kW} \cdot \mathrm{h}\end{array}$} \\
\hline Cargo Fijo Mensual & S/./Usuario & 2,94 & 2,94 & 2,64 \\
\hline Cargo por Energia Activa & $\operatorname{cent} 5 / / \mathrm{kW} \cdot \mathrm{h}$ & 42,26 & 34,33 & 42,23 \\
\hline \multicolumn{5}{|l|}{$31-100 \mathrm{kWh}$} \\
\hline Cargo Fijo Mensual & S/./Usuario & 2,94 & 2,94 & 2,64 \\
\hline Cargo por Energia Activa - Primeros $30 \mathrm{kWh}$ & S/./Usuario & 12,67 & 10,30 & 12,67 \\
\hline Cargo por Energia Activa - Exceso de 30 kW.h & $\operatorname{cent} 5 / / \mathrm{kW} \cdot \mathrm{h}$ & 56,35 & 45,76 & 56,31 \\
\hline \multicolumn{5}{|l|}{ b) Usuarios con consumos mayores a $100 \mathrm{~kW} \cdot \mathrm{h}$ por mes } \\
\hline Cargo Fijo Mensual. & 5/./Usuario & 3,08 & 3,08 & 2,77 \\
\hline Carso por Energia Activa & cent S/./LW.h & 59.05 & 47.95 & 59.01 \\
\hline
\end{tabular}




\section{Anexo 6: Tipos de empresas}

\begin{tabular}{|c|c|c|c|c|}
\hline Tipo de empresa & $\begin{array}{l}\text { Número mínimo y máximo de } \\
\text { socios/accionistas }\end{array}$ & Órganos societarios & $\begin{array}{r}\text { Capital (forma en que s } \\
\text { se divide }\end{array}$ & como \\
\hline \multirow{3}{*}{ Sociedad Anónima } & \multirow{3}{*}{ Minimo 2 y máximo 750} & " Junta General de Accionistas & \multirow{3}{*}{$\begin{array}{l}\text { Aporte en efectivo } 0 \text { en bienes. } \\
\text { Se divide en acciones. }\end{array}$} & \multirow{3}{*}{$\rightarrow$} \\
\hline & & * Gerencia & & \\
\hline & & $\begin{array}{l}\text { * Sub Gerencia } \\
\text { * Directorio }\end{array}$ & & \\
\hline \multirow{3}{*}{ Sociedad Anónima Cerrada (con directorio) } & \multirow{3}{*}{ Mínimo 2 y máximo 20} & * Junta General de Accionistas & & \multirow{3}{*}{ 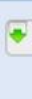 } \\
\hline & & " Gerencia & Aporte en efectivo $o$ en bienes. & \\
\hline & & $\begin{array}{l}\text { "Sub Gerencia } \\
\text { " Directorio }\end{array}$ & Se divide en acciones. & \\
\hline \multirow[t]{3}{*}{ Sociedad Anónima Cerrada (sin directorio) } & \multirow[t]{3}{*}{ Mínimo 2 y máximo 20} & * Junta General de Accionistas & Aporte en efectivo o en bienes. & \multirow{3}{*}{ 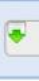 } \\
\hline & & * Gerencia & Se divide en acciones & \\
\hline & & * Sub Gerencia & & \\
\hline \multirow[t]{3}{*}{$\begin{array}{l}\text { Sociedad Comercial de Responsabilidad } \\
\text { Limitada }\end{array}$} & \multirow[t]{3}{*}{ Mínimo 2 y máximo 20} & * Junta General de Socios & Aporte en efectivo o en bienes. & \multirow{3}{*}{5} \\
\hline & & * Gerencia & Se divide en aportaciones. & \\
\hline & & * Sub Gerencia & & \\
\hline \multirow{3}{*}{$\begin{array}{l}\text { Empresa Individual de Responsabilidad } \\
\text { Limitada }\end{array}$} & \multirow{3}{*}{ Máximo 1} & & & \\
\hline & & " Titular & Aporte en efectivo 0 en bienes. & \multirow[t]{2}{*}{-} \\
\hline & & * Gerencia & & \\
\hline
\end{tabular}

\section{Anexo 7: Perfiles de puestos}

\begin{tabular}{|ll|}
\hline Nombre del puesto & Gerente General \\
\hline Nivel & 1 \\
\hline Dependencia funcional & - \\
\hline Misión del puesto & Establecer las estrategias de la empresa y gerenciar su \\
& funcionamiento. \\
\hline & - Establecer lineamientos y políticas que aseguren el \\
& cumplimiento de la visión de la empresa. \\
\hline Funciones & - Asegurar la gestión de calidad de la empresa a través de la \\
& mejora continua y promoción de la cultura organizacional. \\
& - Cumplir con los indicadores de gestión y financieros que \\
& aseguren la rentabilidad y sostenibilidad de la empresa. \\
\hline Nivel de coordinación & - Asegurar la armonía de los stakeholders de la empresa. \\
\hline Formación académica & Con todos los stakeholders de la empresa. \\
\hline & Universitaria \\
\hline Conocimientos & - En el cuidado de perros. \\
& - En innovación y tecnología \\
\hline Experiencia general & - En gestión de calidad y mejora continua. \\
\hline Experiencia específica & - En administración de negocios. \\
\hline & 5 años \\
\hline Competencias & 1 año \\
\hline & - Liderazgo \\
& - Trabajo en equipo. \\
& - Vocación por el servicio. \\
& - Innovación \\
\hline
\end{tabular}




\begin{tabular}{|ll|}
\hline Nombre del puesto & Supervisor de operaciones \\
\hline Nivel & 2 \\
\hline Dependencia funcional & Gerente General \\
\hline Misión del puesto & $\begin{array}{l}\text { Gestionar la operación de la empresa de acuerdo a su visión y } \\
\text { objetivos estratégicos. }\end{array}$ \\
\hline & - Supervisar el cuidado de los perros dentro y fuera del local. \\
& - Establecer el horario y organización de los cuidadores de \\
& perros para optimizar el nivel de servicio y calidad de la \\
atención continuamente. & \\
Funciones & - Mantener una constante comunicación con el cliente y generar \\
& estrategias para elevar su nivel de satisfacción. \\
& - Comunicar el cumplimiento de las metas operativas al gerente \\
& general. \\
& - Otras funciones que indique el gerente general. \\
\hline Nivel de coordinación & Con usuarios, clientes y personal de la empresa. \\
\hline Formación académica & Universitaria \\
\hline Conocimientos & - En el cuidado de perros. \\
\hline Experiencia general & - En innovación y tecnología \\
\hline Experiencia específica & - En gestión de calidad y mejora continua. \\
\hline & 2 años \\
\hline Competencias & - Liderazgo \\
\hline
\end{tabular}

\begin{tabular}{|ll|}
\hline Nombre del puesto & Cuidador de perros \\
\hline Nivel & 3 \\
\hline Dependencia funcional & Supervisor de operaciones \\
\hline Misión del puesto & $\begin{array}{l}\text { Atender a los perros inscritos de acuerdo a los procedimientos } \\
\text { establecidos y exigencias solicitadas por el dueño. }\end{array}$ \\
\hline & - Movilizar a los perros desde y hacia su domicilio, velando ante \\
& todo por su seguridad y comodidad. \\
Funciones & - Registrar a los perros, anotando los datos y características \\
& relevantes para su cuidado. \\
& - Alimentar, adiestrar y entretener al perro de acuerdo a los \\
& estándares, personalización y exigencias solicitadas.
\end{tabular}




\begin{tabular}{|c|c|}
\hline & $\begin{array}{l}\text { - Comunicar constantemente el cuidado del perro a su dueño } \\
\text { como al supervisor de operaciones. } \\
\text { - Otras funciones que indique el supervisor de operaciones. }\end{array}$ \\
\hline Nivel de coordinación & Con usuarios, clientes, personal de la empresa y proveedores \\
\hline Formación académica & Secundaria completa \\
\hline Conocimientos & $\begin{array}{l}\text { - En el cuidado de perros. } \\
\text { - En atención de primeros auxilios para mascotas. } \\
\text { - En gestión de calidad y servicio al cliente. }\end{array}$ \\
\hline Experiencia general & 1 año \\
\hline Experiencia específica & 1 año \\
\hline Competencias & $\begin{array}{l}\text { - Sentido de urgencia. } \\
\text { - Trabajo en equipo. } \\
\text { - Vocación por el servicio. } \\
\text { - Orientación al logro. }\end{array}$ \\
\hline
\end{tabular}

\begin{tabular}{|ll|}
\hline Nombre del puesto & Asistente de operaciones \\
\hline Nivel & 3 \\
\hline Dependencia funcional & Supervisor de operaciones \\
\hline Misión del puesto & $\begin{array}{l}\text { Apoyar en la atención a los perros, así como en la logística y } \\
\text { apoyo para la correcta operación de la empresa. }\end{array}$ \\
\hline & - Recibir materiales de proveedores y llevar inventario de los \\
& mismos. \\
& - Venta y entrega de accesorios de perros. \\
& - Actualizar el registro de perros y generar los reportes \\
& necesarios. \\
& - Alimentar y apoyar en el adiestramiento y entretenimiento de \\
Funciones & los perros. \\
& - Coordinar temas administrativos con los servicios de \\
& marketing, administración y cuidadores de perros. \\
\hline Nivel de coordinación & Con usuarios, clientes, personal de la empresa y proveedores \\
\hline Formación académica & Primaria completa \\
\hline Conocimientos & Del rubro mascotas \\
\hline Experiencia general & - \\
\hline Experiencia específica & - \\
\hline Competencias & - Vocación por el servicio. \\
\hline
\end{tabular}




\begin{tabular}{|ll|}
\hline Nombre del puesto & Especialista en marketing \\
\hline Nivel & 2 \\
\hline Dependencia funcional & Gerente General \\
\hline Misión del puesto & Proponer y ejecutar las estrategias de marketing de la empresa \\
\hline & $\begin{array}{l}\text { - Proponer estrategias y mix de marketing a través de metas } \\
\text { cuantificadas para la aprobación del gerente general. } \\
\text { - Ejecutar las estrategias de marketing a fin de conseguir nuevos } \\
\text { clientes y afianzar vínculos con los actuales. } \\
\text { Funciones }\end{array}$ \\
$\begin{array}{l}\text { - Elaborar y presentar al Gerente General el Plan de Ventas de } \\
\text { la empresa. }\end{array}$ \\
\hline Nivel de coordinación & Con usuarios, clientes y personal de la empresa. \\
\hline Formación académica & Universitaria o técnico \\
\hline Conocimientos & - En marketing digital \\
\hline Experiencia general & - En innovación y tecnología \\
\hline Experiencia específica & 2 años \\
\hline Competencias & 1 año \\
\hline
\end{tabular}

\begin{tabular}{|ll|}
\hline Nombre del puesto & Especialista en Administración y Finanzas \\
\hline Nivel & 2 \\
\hline Dependencia funcional & Gerente General \\
\hline Misión del puesto & Gestionar la administración y finanzas de la empresa \\
\hline & - Administrar el presupuesto y obligaciones tributarias de \\
& acuerdo a las políticas de la empresa. \\
& - Elaborar el plan financiero de la empresa, así como informar \\
de su evaluación periódicamente al Gerente General. \\
Funciones & - Seleccionar, evaluar y contratar al personal de la empresa. \\
& - Gestionar el traslado de conocimiento y capacitación constante \\
& del personal de la empresa. \\
& - Otras funciones que indique el gerente general. \\
\hline Nivel de coordinación & Con personal de la empresa, postulantes y proveedores. \\
\hline Formación académica & Universitaria o técnico \\
\hline Conocimientos & - En administración y finanzas \\
\hline Experiencia general & - En el rubro de servicios \\
\hline Experiencia específica & 2 años \\
\hline Competencias & 1 año \\
\hline
\end{tabular}




\section{Anexo 8: Rango salarial y planilla}

Rangos salariales de la empresa

\begin{tabular}{cccc}
\hline Proceso & Nivel & \multicolumn{2}{c}{ Rango salarial } \\
\hline \multirow{4}{*}{ Estratégico } & 1 & 2000 & 5000 \\
& 2 & 1100 & 2200 \\
& 3 & 1000 & 1200 \\
Misional & 1 & 1600 & 2600 \\
& 2 & 1000 & 1800 \\
& 3 & 930 & 1050 \\
Soporte & 2 & 1400 & 2400 \\
& 3 & 980 & 1500 \\
\hline
\end{tabular}

Planilla de la empresa

\begin{tabular}{|c|c|c|c|c|c|}
\hline Puesto & Proc & Nivel & $\begin{array}{c}\text { mensual } \\
\text { bruto }\end{array}$ & $\begin{array}{l}\text { Carga } \\
\text { social }\end{array}$ & $\begin{array}{c}\text { anual } \\
\text { total }\end{array}$ \\
\hline Supervisor de operaciones & $\mathrm{M}$ & 2 & 1250 & 320,8 & 18850,00 \\
\hline Cuidadores de perros & M & 2 & 1000 & 256,7 & 15080,00 \\
\hline Asistente de operaciones & M & 3 & 930 & 238,7 & 14024,40 \\
\hline Gerente General & $\mathrm{E}$ & 1 & 3000 & 770,0 & 45240,00 \\
\hline Especialista en marketing & M & & 600 & - & 7200,00 \\
\hline $\begin{array}{lr}\text { Especialista } & \text { en } \\
\text { Administración } & \text { y } \\
\text { (tercerizado) } & \text { Finanzas }\end{array}$ & $\mathrm{S}$ & & 350 & - & 4200,00 \\
\hline Total & & & & & 104594,40 \\
\hline
\end{tabular}

Fuente: Ley MYPE 


\section{Anexo 9: Presupuestos}

Presupuesto de ventas mensual del año 1

\begin{tabular}{|c|c|c|c|c|c|c|c|c|c|c|c|c|}
\hline & Mes 1 & Mes 2 & Mes 3 & Mes 4 & Mes 5 & Mes 6 & Mes 7 & Mes 8 & Mes 9 & Mes 10 & Mes 11 & Mes 12 \\
\hline Cuidadores & 4 & 4 & 4 & 4 & 4 & 4 & 5 & 5 & 5 & 7 & 7 & 7 \\
\hline Perro suscritos & 32 & 32 & 32 & 39 & 39 & 39 & 47 & 47 & 47 & 64 & 64 & 64 \\
\hline Precio suscripción & 525 & 525 & 525 & 525 & 525 & 525 & 525 & 525 & 525 & 525 & 525 & 525 \\
\hline Ventas por suscripción & 16,800 & 16,800 & 16,800 & 20,475 & 20,475 & 20,475 & 24,675 & 24,675 & 24,675 & 33,600 & 33,600 & 33,600 \\
\hline Perro paseados & 0 & 0 & 0 & 1 & 1 & 1 & 3 & 3 & 3 & 6 & 6 & 6 \\
\hline Precio de paseo & 300 & 300 & 300 & 300 & 300 & 300 & 300 & 300 & 300 & 300 & 300 & 300 \\
\hline Ventas por paseo & - & - & - & 300 & 300 & 300 & 900 & 900 & 900 & 1,800 & 1,800 & $\mathbf{1 , 8 0 0}$ \\
\hline cantidad accesorios & - & - & 32 & - & - & 40 & - & - & 50 & - & - & 70 \\
\hline precio jueguete & 23 & 23 & 23 & 23 & 23 & 23 & 23 & 23 & 23 & 23 & 23 & 23 \\
\hline venta juguetes & - & - & 720 & - & - & 900 & - & - & 1,125 & - & - & 1,575 \\
\hline precio ropa & 75 & 75 & 75 & 75 & 75 & 75 & 75 & 75 & 75 & 75 & 75 & 75 \\
\hline venta ropa & - & - & 2,400 & - & - & 3,000 & - & - & 3,750 & - & - & 5,250 \\
\hline Ventas por accesorios & - & - & 3,120 & - & - & 3,900 & - & - & 4,875 & - & - & 6,825 \\
\hline Ventas & 16,800 & 16,800 & 19,920 & 20,775 & 20,775 & 24,675 & 25,575 & 25,575 & 30,450 & 35,400 & 35,400 & 42,225 \\
\hline
\end{tabular}


Presupuesto de ventas anual

\begin{tabular}{lrrrrr}
\hline & Año 1 & \multicolumn{1}{c}{ Año 2 } & \multicolumn{1}{c}{ Año 3 } & \multicolumn{1}{c}{ Año 4 } & \multicolumn{1}{c}{ Año 5 } \\
\hline Ventas & $\mathbf{3 1 4 , 3 7 0}$ & $\mathbf{5 3 1 , 0 6 2}$ & $\mathbf{5 4 9 , 1 1 9}$ & $\mathbf{5 6 7 , 7 8 9}$ & $\mathbf{5 8 7 , 0 9 3}$ \\
Ventas por suscripción & 286,650 & 469,022 & 484,969 & 501,458 & 518,508 \\
Ventas por paseo & 9,000 & 29,779 & 30,792 & 31,839 & 32,921 \\
Ventas por accesorios & 18,720 & 32,261 & 33,358 & 34,492 & 35,665 \\
\hline
\end{tabular}

Presupuesto de gastos administrativos y de ventas

\begin{tabular}{lrrrrr}
\hline & \multicolumn{1}{c}{ Año 1 } & \multicolumn{1}{c}{ Año 2 } & \multicolumn{1}{c}{ Año 3 } & \multicolumn{1}{c}{ Año 4 } & \multicolumn{1}{c}{ Año 5 } \\
\hline Gastos de Ventas & $\mathbf{7 , 2 0 0 . 0}$ & $\mathbf{7 , 2 0 0 . 0}$ & $\mathbf{7 , 2 0 0 . 0}$ & $\mathbf{7 , 2 0 0 . 0}$ & $\mathbf{7 , 2 0 0 . 0}$ \\
Especialista en marketing & $7,200.0$ & $7,200.0$ & $7,200.0$ & $7,200.0$ & $7,200.0$ \\
Gastos Administrativos: & $\mathbf{4 9 , 4 4 0 . 0}$ & $\mathbf{4 9 , 4 4 0 . 0}$ & $\mathbf{4 9 , 4 4 0 . 0}$ & $\mathbf{4 9 , 4 4 0 . 0}$ & $\mathbf{4 9 , 4 4 0 . 0}$ \\
Gerente General & $45,240.0$ & $45,240.0$ & $45,240.0$ & $45,240.0$ & $45,240.0$ \\
Especialista en Adm y Finanzas & $4,200.0$ & $4,200.0$ & $4,200.0$ & $4,200.0$ & $4,200.0$ \\
Amortización de A. Intangibles & $\mathbf{1 6 6}$ & $\mathbf{1 6 6}$ & $\mathbf{1 6 6}$ & $\mathbf{1 6 6}$ & $\mathbf{1 6 6}$ \\
Permiso municipal & 58.6 & 58.6 & 58.6 & 58.6 & 58.6 \\
Patentes & 107 & 107 & 107 & 107 & 107 \\
Gastos operativos & $\mathbf{5 6 , 8 0 6}$ & $\mathbf{5 6 , 8 0 6}$ & $\mathbf{5 6 , 8 0 6}$ & $\mathbf{5 6 , 8 0 6}$ & $\mathbf{5 6 , 8 0 6}$ \\
\hline
\end{tabular}

Presupuesto de inversión

\begin{tabular}{|c|c|c|c|c|c|c|}
\hline & Año 0 & Año 1 & Año 2 & Año 3 & Año 4 & Liquidación \\
\hline Inversión Fija tangible & 102,832 & & & & & 8,762 \\
\hline Servidor & 1,000 & & & & & 0 \\
\hline Escritorio y silla & 280 & & & & & 0 \\
\hline Sistema de monitoreo & 1,000 & & & & & 0 \\
\hline App de reservas y seguimiento & 5,940 & & & & & 0 \\
\hline Caniles (para furgoneta) & 3,350 & & & & & 0 \\
\hline Garantía de alquiler & 8,762 & & & & & 8,762 \\
\hline Acondicionamiento & 82,500 & & & & & 0 \\
\hline Inversión Fija Intangible & 828 & & & & & $\mathbf{0}$ \\
\hline Permiso municipal & 293 & & & & & 0 \\
\hline Patentes & 535 & & & & & 0 \\
\hline Inversión en KW & $\mathbf{9 , 5 3 6}$ & 2,722 & -1 & $\mathbf{0}$ & $\mathbf{0}$ & 12,256 \\
\hline Caja Minima Operaciones & $7,176.0$ & $9,897.6$ & $9,896.4$ & $9,896.4$ & $9,896.4$ & \\
\hline Caja Minima Administrac & $2,360.0$ & $2,360.0$ & $2,360.0$ & $2,360.0$ & $2,360.0$ & \\
\hline Requerim en KW & $9,536.0$ & $12,257.6$ & $12,256.4$ & $12,256.4$ & $12,256.4$ & \\
\hline Inversión total & 113,196 & 2,722 & - & - & - & 21,018 \\
\hline
\end{tabular}

Presupuesto de gastos financieros

\begin{tabular}{lcccc}
\hline & Año 0 & Año 1 & Año 2 & Año 3 \\
\hline Saldo & 88,550 & 62,556 & 33,186 & - \\
Amortización & - & 25,994 & 29,370 & 33,186 \\
Intereses & - & 9,440 & 6,063 & 2,248 \\
Seguro desgr. & - & - & - & - \\
Cuota & - & 35,433 & 35,433 & 35,433 \\
Escudo tributario & - & 2,832 & 1,819 & 674 \\
\hline FC financiamiento & - & 32,602 & 33,615 & 34,759 \\
Int sin IGV & - & 8,000 & 5,138 & 1,905 \\
IGV & - & 1,440 & 925 & 343 \\
\hline
\end{tabular}




\section{Anexo 10: Financiamiento}

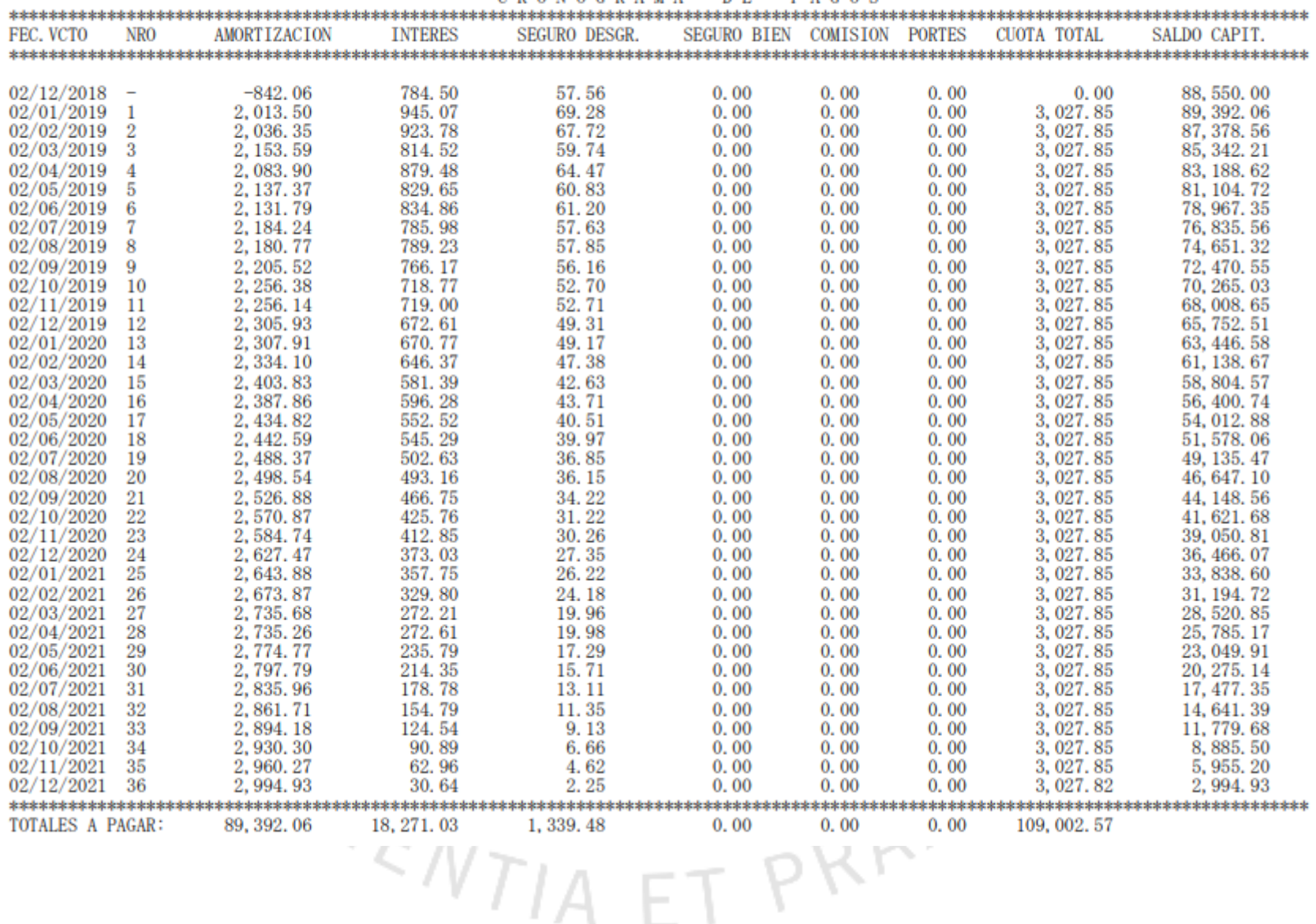


Anexo 11: Estado de Situación

Efectivo (incluido IGV)

ANALISIS HORIZONTAL

\begin{tabular}{|c|c|c|c|c|c|c|c|c|}
\hline \multicolumn{4}{|c|}{ ANALISIS HORIZONTAL } & & \multicolumn{4}{|c|}{ ANALISIS VERTICAL } \\
\hline Año 2 & Año 3 & Año 4 & Año 5 & Año 1 & Año 2 & Año 3 & Año 4 & Año 5 \\
\hline $69 \%$ & $3 \%$ & $3 \%$ & $3 \%$ & $75 \%$ & $88 \%$ & $97 \%$ & $106 \%$ & $118 \%$ \\
\hline $67 \%$ & $0 \%$ & $0 \%$ & $0 \%$ & $0 \%$ & $0 \%$ & $0 \%$ & $0 \%$ & $0 \%$ \\
\hline $69 \%$ & $3 \%$ & $3 \%$ & $3 \%$ & $75 \%$ & $88 \%$ & $97 \%$ & $106 \%$ & $118 \%$ \\
\hline$-18 \%$ & $-22 \%$ & $-29 \%$ & $-41 \%$ & $24 \%$ & $14 \%$ & $11 \%$ & $9 \%$ & $5 \%$ \\
\hline$-100 \%$ & $-100 \%$ & & & $1 \%$ & $0 \%$ & $0 \%$ & $0 \%$ & $0 \%$ \\
\hline$-25 \%$ & $-33 \%$ & $-50 \%$ & $-100 \%$ & $0 \%$ & $0 \%$ & $0 \%$ & $0 \%$ & $0 \%$ \\
\hline$-21 \%$ & $-23 \%$ & $-29 \%$ & $-41 \%$ & $25 \%$ & $14 \%$ & $11 \%$ & $9 \%$ & $5 \%$ \\
\hline $46 \%$ & $0 \%$ & $0 \%$ & $0 \%$ & $100 \%$ & $102 \%$ & $108 \%$ & $115 \%$ & $123 \%$ \\
\hline \multirow[t]{3}{*}{$-47 \%$} & $-100 \%$ & & & $18 \%$ & $7 \%$ & $0 \%$ & $0 \%$ & $0 \%$ \\
\hline & $4881 \%$ & $18 \%$ & $13 \%$ & & $0 \%$ & $8 \%$ & $10 \%$ & $12 \%$ \\
\hline & $20 \%$ & $-35 \%$ & $-76 \%$ & & $51 \%$ & $65 \%$ & $45 \%$ & $11 \%$ \\
\hline $18 \%$ & $-35 \%$ & $-60 \%$ & $-162 \%$ & $91 \%$ & $75 \%$ & $52 \%$ & $22 \%$ & $-15 \%$ \\
\hline $0 \%$ & $0 \%$ & $0 \%$ & $0 \%$ & $7 \%$ & $5 \%$ & $5 \%$ & $5 \%$ & $6 \%$ \\
\hline $1114 \%$ & $105 \%$ & $57 \%$ & $40 \%$ & $2 \%$ & $20 \%$ & $43 \%$ & $73 \%$ & $109 \%$ \\
\hline $283 \%$ & $84 \%$ & $51 \%$ & $37 \%$ & $9 \%$ & $25 \%$ & $48 \%$ & $78 \%$ & $115 \%$ \\
\hline $43 \%$ & $-6 \%$ & $-6 \%$ & $-7 \%$ & $100 \%$ & $100 \%$ & $100 \%$ & $100 \%$ & $100 \%$ \\
\hline
\end{tabular}

\begin{tabular}{|c|c|c|c|c|c|c|c|c|}
\hline \multicolumn{4}{|c|}{ ANALISIS HORIZONTAL } & & \multicolumn{4}{|c|}{ ANALISIS VERTICAL } \\
\hline Año 2 & Año 3 & Año 4 & Año 5 & Año 1 & Año 2 & Año 3 & Año 4 & Año 5 \\
\hline $69 \%$ & $3 \%$ & $3 \%$ & $3 \%$ & $75 \%$ & $88 \%$ & $97 \%$ & $106 \%$ & $118 \%$ \\
\hline $67 \%$ & $0 \%$ & $0 \%$ & $0 \%$ & $0 \%$ & $0 \%$ & $0 \%$ & $0 \%$ & $0 \%$ \\
\hline $69 \%$ & $3 \%$ & $3 \%$ & $3 \%$ & $75 \%$ & $88 \%$ & $97 \%$ & $106 \%$ & $118 \%$ \\
\hline$-18 \%$ & $-22 \%$ & $-29 \%$ & $-41 \%$ & $24 \%$ & $14 \%$ & $11 \%$ & $9 \%$ & $5 \%$ \\
\hline$-100 \%$ & $-100 \%$ & & & $1 \%$ & $0 \%$ & $0 \%$ & $0 \%$ & $0 \%$ \\
\hline$-25 \%$ & $-33 \%$ & $-50 \%$ & $-100 \%$ & $0 \%$ & $0 \%$ & $0 \%$ & $0 \%$ & $0 \%$ \\
\hline$-21 \%$ & $-23 \%$ & $-29 \%$ & $-41 \%$ & $25 \%$ & $14 \%$ & $11 \%$ & $9 \%$ & $5 \%$ \\
\hline $46 \%$ & $0 \%$ & $0 \%$ & $0 \%$ & $100 \%$ & $102 \%$ & $108 \%$ & $115 \%$ & $123 \%$ \\
\hline \multirow[t]{3}{*}{$-47 \%$} & $-100 \%$ & & & $18 \%$ & $7 \%$ & $0 \%$ & $0 \%$ & $0 \%$ \\
\hline & $4881 \%$ & $18 \%$ & $13 \%$ & & $0 \%$ & $8 \%$ & $10 \%$ & $12 \%$ \\
\hline & $20 \%$ & $-35 \%$ & $-76 \%$ & & $51 \%$ & $65 \%$ & $45 \%$ & $11 \%$ \\
\hline $18 \%$ & $-35 \%$ & $-60 \%$ & $-162 \%$ & $91 \%$ & $75 \%$ & $52 \%$ & $22 \%$ & $-15 \%$ \\
\hline $0 \%$ & $0 \%$ & $0 \%$ & $0 \%$ & $7 \%$ & $5 \%$ & $5 \%$ & $5 \%$ & $6 \%$ \\
\hline $1114 \%$ & $105 \%$ & $57 \%$ & $40 \%$ & $2 \%$ & $20 \%$ & $43 \%$ & $73 \%$ & $109 \%$ \\
\hline $283 \%$ & $84 \%$ & $51 \%$ & $37 \%$ & $9 \%$ & $25 \%$ & $48 \%$ & $78 \%$ & $115 \%$ \\
\hline $43 \%$ & $-6 \%$ & $-6 \%$ & $-7 \%$ & $100 \%$ & $100 \%$ & $100 \%$ & $100 \%$ & $100 \%$ \\
\hline
\end{tabular}

Activo corriente

Activo fijo neto tangible

Cambio de KW

Activo fijo neto intangible

Activo no corriente

TOTAL ACTIVOS

Pasivo financiero

Impuestos por Pagar

Otras cuentas por pagar

Pasivo

Capital social

Utilidades acumuladas

Patrimonio

TOTAL PASIVO + PATRIMONIO 


\section{Anexo 12: Estado de resultados}

\begin{tabular}{l}
\hline \\
\hline Ventas \\
Costo de ventas \\
Utilidad Bruta \\
Gastos Operativos \\
Utilidad Operativa \\
Depreciación \\
Amortización \\
UAII \\
Intereses \\
UAI (EBIT) \\
Impuestos \\
Utilidad Neta \\
\hline
\end{tabular}

\begin{tabular}{rrrr}
\multicolumn{5}{c}{ ANALISIS HORIZONTAL } \\
\hline Año 2 & Año 3 & Año 4 & Año 5 \\
\hline $69 \%$ & $3 \%$ & $3 \%$ & $3 \%$ \\
$38 \%$ & $0 \%$ & $0 \%$ & $0 \%$ \\
$126 \%$ & $7 \%$ & $7 \%$ & $7 \%$ \\
$0 \%$ & $0 \%$ & $0 \%$ & $0 \%$ \\
$315 \%$ & $10 \%$ & $9 \%$ & $9 \%$ \\
$0 \%$ & $0 \%$ & $0 \%$ & $0 \%$ \\
$0 \%$ & $0 \%$ & $0 \%$ & $0 \%$ \\
$552 \%$ & $11 \%$ & $10 \%$ & $10 \%$ \\
$-36 \%$ & & & \\
$1014 \%$ & $14 \%$ & $12 \%$ & $10 \%$ \\
& & $12 \%$ & $10 \%$ \\
$1014 \%$ & $14 \%$ & $12 \%$ & $10 \%$ \\
\hline
\end{tabular}

\begin{tabular}{rrrrr}
\multicolumn{5}{c}{ ANALISIS VERTICAL } \\
\hline Año 1 & Año 2 & Año 3 & Año 4 & Año 5 \\
\hline $100 \%$ & $100 \%$ & $100 \%$ & $100 \%$ & $100 \%$ \\
$65 \%$ & $53 \%$ & $51 \%$ & $49 \%$ & $48 \%$ \\
$35 \%$ & $47 \%$ & $49 \%$ & $51 \%$ & $52 \%$ \\
$21 \%$ & $13 \%$ & $12 \%$ & $12 \%$ & $11 \%$ \\
$14 \%$ & $35 \%$ & $37 \%$ & $39 \%$ & $41 \%$ \\
$6 \%$ & $4 \%$ & $3 \%$ & $3 \%$ & $3 \%$ \\
$0 \%$ & $0 \%$ & $0 \%$ & $0 \%$ & $0 \%$ \\
$8 \%$ & $31 \%$ & $33 \%$ & $36 \%$ & $38 \%$ \\
$4 \%$ & $1 \%$ & $0 \%$ & $0 \%$ & $0 \%$ \\
$5 \%$ & $30 \%$ & $33 \%$ & $36 \%$ & $38 \%$ \\
$1 \%$ & $9 \%$ & $10 \%$ & $11 \%$ & $11 \%$ \\
$3 \%$ & $21 \%$ & $23 \%$ & $25 \%$ & $26 \%$ \\
\hline
\end{tabular}

\section{Anexo 13: Análisis Dupont}

\begin{tabular}{|c|c|c|c|c|c|}
\hline & Año 1 & Año 2 & Año 3 & Año 4 & Año 5 \\
\hline Activo Total (AT) & 113,196 & 356,731 & 521,565 & 520,758 & 520,470 \\
\hline Patrimonio Neto & 24,646 & 33,048 & 126,636 & 233,626 & 353,266 \\
\hline Ventas & 266,415 & 450,053 & 465,355 & 481,177 & 497,537 \\
\hline Beneficio Neto & 8,402 & 93,588 & 106,990 & 119,639 & 131,091 \\
\hline Margen Neto & $3.15 \%$ & $20.79 \%$ & $22.99 \%$ & $24.86 \%$ & $26.35 \%$ \\
\hline Rotacion de Activos & 2.35 & 1.26 & 0.89 & 0.92 & 0.96 \\
\hline ROA & $7.42 \%$ & $26.24 \%$ & $20.51 \%$ & $22.97 \%$ & $25.19 \%$ \\
\hline Multiplo de Endeudamiento & 4.59 & 10.79 & 4.12 & 2.23 & 1.47 \\
\hline ROE & $34.09 \%$ & $283.19 \%$ & $84.49 \%$ & $51.21 \%$ & $37.11 \%$ \\
\hline $\mathrm{EVA}=(\mathrm{ROA}-\mathrm{WACC}) * \mathrm{AT}$ & $2,884.86$ & $18,410.61$ & $11,933.93$ & $14,719.35$ & $17,224.39$ \\
\hline
\end{tabular}




\section{Anexo 14: Escenarios}

Escenario Esperado

\begin{tabular}{lcccccc}
\hline & Año 0 & Año 1 & Año 2 & Año 3 & Año 4 & Año 5 \\
\hline Ingresos & 0 & 266,415 & 450,053 & 465,355 & 481,177 & 497,537 \\
Inversión & 113,196 & 0 & 0 & 0 & 0 & 0 \\
Cambio en KL & 0 & 2,722 & -1 & 0 & 0 & 0 \\
Costo de ventas & 0 & 172,224 & 237,543 & 237,514 & 237,514 & 237,514 \\
Gastos operativos & 0 & 56,640 & 56,640 & 56,640 & 56,640 & 56,640 \\
IGV por pagar & 0 & 32,145 & 65,528 & 68,869 & 72,059 & 75,004 \\
IR por pagar & 0 & 769 & 38,290 & 45,179 & 51,274 & 56,182 \\
Liquidación & 0 & 0 & 0 & 0 & 0 & 21,018 \\
FLUJO ECONOMICO & $-\mathbf{1 1 3 , 1 9 6}$ & $\mathbf{1 , 9 1 6}$ & $\mathbf{5 2 , 0 5 3}$ & $\mathbf{5 7 , 1 5 4}$ & $\mathbf{6 3 , 6 9 0}$ & $\mathbf{9 3 , 2 1 5}$ \\
\hline COK & $\mathbf{1 3 \%}$ & & & & & \\
TIRE & $\mathbf{2 7 \%}$ & & & & & \\
TIRME & $\mathbf{2 3 \%}$ & & & & &
\end{tabular}

Escenario Pesimista

\begin{tabular}{|c|c|c|c|c|c|c|c|}
\hline & & Año 0 & Año 1 & Año 2 & Año 3 & Año 4 & Año 5 \\
\hline Ingresos & & 0 & 266,415 & 450,053 & 465,355 & 481,177 & 497,537 \\
\hline Inversión & & 113,868 & 0 & 0 & 0 & 0 & 0 \\
\hline Cambio en KL & & 0 & 3,256 & -1 & 0 & 0 & 0 \\
\hline Costo de ventas & & 0 & 188,359 & 266,496 & 266,467 & 266,467 & 266,467 \\
\hline Gastos operativos & & 0 & 56,640 & 56,640 & 56,640 & 56,640 & 56,640 \\
\hline IGV por pagar & & 0 & 32,145 & 65,528 & 68,869 & 72,059 & 75,004 \\
\hline IR por pagar & & 0 & $-4,072$ & 29,604 & 36,493 & 42,588 & 47,496 \\
\hline Liquidación & & 0 & 0 & 0 & 0 & 0 & 22,225 \\
\hline FLUJO ECONOMICO & - & 113,868 & 9,913 & 31,786 & 36,886 & 43,422 & 74,154 \\
\hline COK & & $13 \%$ & & & & & \\
\hline TIRE & & $12 \%$ & & & & & \\
\hline TIRME & & $12 \%$ & & & & & \\
\hline VANE & & $-5,770.53$ & & & & & \\
\hline
\end{tabular}

Escenario Optimista

\begin{tabular}{lcccccc}
\hline & Año 0 & Año 1 & Año 2 & Año 3 & Año 4 & Año 5 \\
\hline Ingresos & 0 & 278,943 & 451,315 & 466,659 & 482,526 & 498,932 \\
Inversión & 113,196 & 0 & 0 & 0 & 0 & 0 \\
Cambio en KL & 0 & 2,722 & -1 & 0 & 0 & 0 \\
Costo de ventas & 0 & 172,224 & 237,543 & 237,514 & 237,514 & 237,514 \\
Gastos operativos & 0 & 56,640 & 56,640 & 56,640 & 56,640 & 56,640 \\
IGV por pagar & 0 & 34,400 & 65,755 & 69,103 & 72,302 & 75,255 \\
IR por pagar & 0 & 4,527 & 38,669 & 45,570 & 51,679 & 56,600 \\
Liquidación & 0 & 0 & 0 & 0 & 0 & 21,018 \\
FLUJO ECONOMICO & $-\mathbf{1 1 3 , 1 9 6}$ & $\mathbf{8 , 4 3 0}$ & $\mathbf{5 2 , 7 0 9}$ & $\mathbf{5 7 , 8 3 2}$ & $\mathbf{6 4 , 3 9 1}$ & $\mathbf{9 3 , 9 4 1}$ \\
\hline COK & $\mathbf{1 3 \%}$ & & & & & \\
TIRE & $\mathbf{3 0 \%}$ & $\mathbf{2 4 \%}$ & & & & \\
TIRME & $\mathbf{6 5 , 4 2 1 . 3 5}$ & & & & & \\
VANE & & & & & &
\end{tabular}




\section{Anexo 15: Zonas geográficas de Lima}

Distribución por zonas geográficas APEIM 2017

\begin{tabular}{|c|c|c|c|c|c|c|}
\hline \multirow{2}{*}{ Zonas } & \multirow{2}{*}{ Personas } & \multicolumn{5}{|c|}{ NSE (\%) } \\
\hline & & A & B & C & D & $\mathbf{E}$ \\
\hline Puente piedra, Comas, Carabayllo & 1213,4 & 0,5 & 10,9 & 46,6 & 29,8 & 12,2 \\
\hline $\begin{array}{l}\text { Independencia, Los Olivos, San Martin de } \\
\text { Porras }\end{array}$ & 132 & 2 & 23,7 & 52,1 & 19,8 & 2,4 \\
\hline San Juan de Lurigancho & 1121,3 & 0 & 19,1 & 44,2 & 26,7 & 10 \\
\hline Carcado, Rímac, Breña, La Victoria & 710 & 4,3 & 27,1 & 44,6 & 20,2 & 3,8 \\
\hline $\begin{array}{l}\text { Ate, Chclacayo, Chosica, Santa Anita, San } \\
\text { Luis, El Agustino }\end{array}$ & 1408 & 2,1 & 12,3 & 42,7 & 34 & 8,9 \\
\hline $\begin{array}{l}\text { Jesuús María, Lince, Pueblo Libre, Magdalena, } \\
\text { San Miguel }\end{array}$ & 404,2 & 13,7 & 58 & 22,1 & 5,4 & 0,8 \\
\hline $\begin{array}{l}\text { Miraflores, San Isidro, San Borja, Surco, La } \\
\text { Molina }\end{array}$ & 795 & 35,9 & 43,3 & 14,9 & 4,5 & 1,4 \\
\hline $\begin{array}{l}\text { Surquillo, Barranco, Chorrillos, San Juan de } \\
\text { Miraflores }\end{array}$ & 877,7 & 3,9 & 26,6 & 44,6 & 20,5 & 4,4 \\
\hline $\begin{array}{l}\text { Villa el Salvador, Villa María del Triunfo, } \\
\text { Lurín, Pachacamac }\end{array}$ & 1157 & 0 & 6,3 & 45,7 & 36,6 & 11,4 \\
\hline $\begin{array}{l}\text { Callao, Bellavista, La Perla, La Punta, Carmen } \\
\text { de la Legua, Ventanillam Mi Perú }\end{array}$ & 1038 & 1,2 & 19,7 & 44,2 & 23,8 & 11,1 \\
\hline Cieneguilla y Balnearios & 155,3 & 0 & 8,1 & 47,6 & 25,4 & 18,9 \\
\hline Total Lima Metropolitana & $10.208,60$ & 4,8 & 21,7 & 42,4 & 23,8 & 7,3 \\
\hline
\end{tabular}

Fuente: APEIM, Estructura socioeconómica 2016 


\section{Anexo 16: Indicadores estratégicos y operativos}

Indicadores de objetivos estratégicos

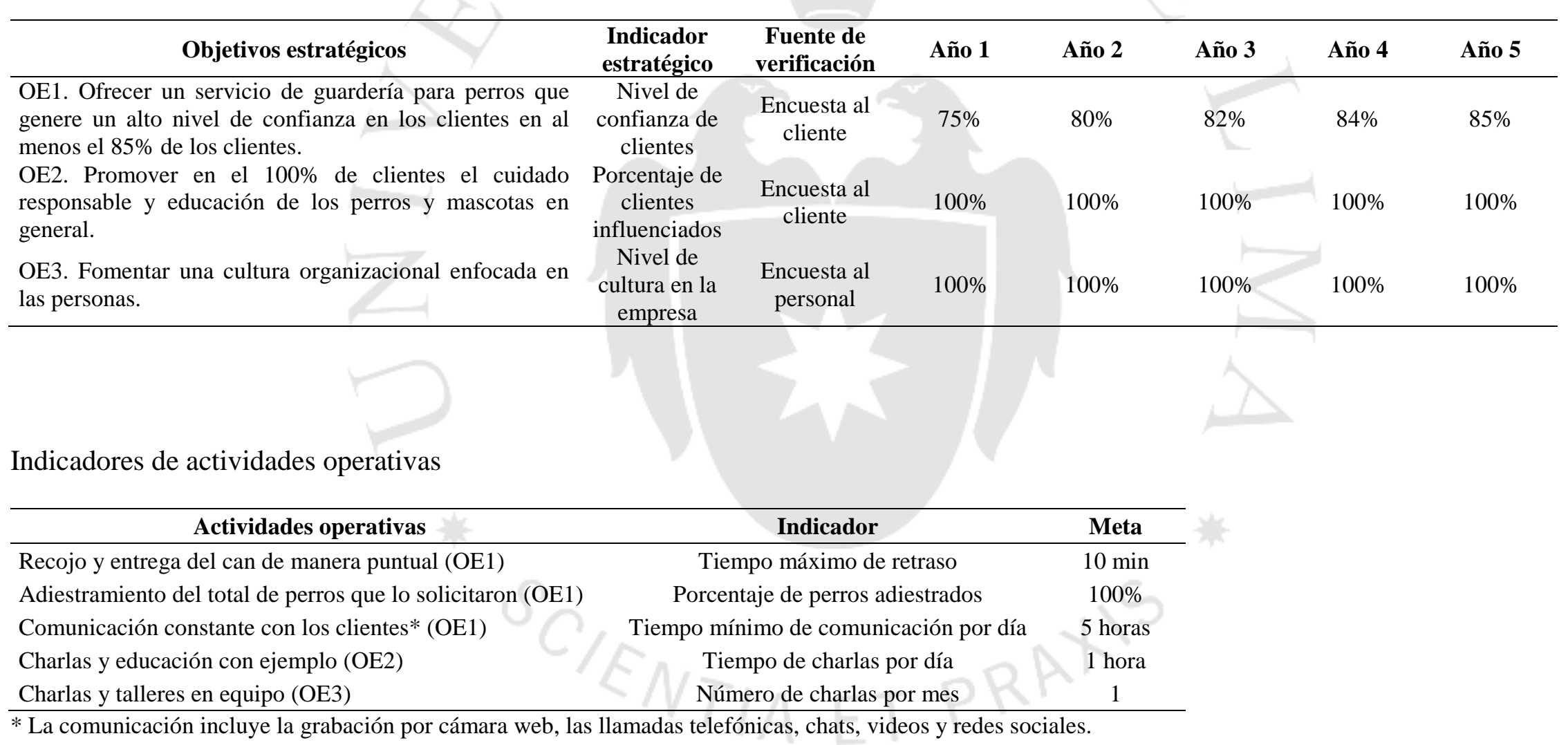

